\title{
Synthesis of Isoxazoline/Cyclic Nitrone-Featured Methylenes Using Unsaturated Ketoximes: A Dual Role of TEMPO
}

\author{
Fei Chen, Xiu-Long Yang, Zhi-Wei Wu, and Bing Han* \\ State Key Laboratory of Applied Organic Chemistry, College of Chemistry and \\ Chemical Engineering, Lanzhou University, Lanzhou, Gansu, 730000, P. R. China \\ hanb@/zu.edu.cn
}

\section{Supporting Information}

- Contents

page

- ORTEP Plot, Crystal Data and Refinement Results for Compounds 3g and 3v

- Copies of ${ }^{1} \mathrm{H}$ and ${ }^{13} \mathrm{C}$ Spectra of Substrates

- Copies of ${ }^{1} \mathrm{H}$ and ${ }^{13} \mathrm{C}$ Spectra of Products 
ORTEP plot for compounds 3g and 3v:

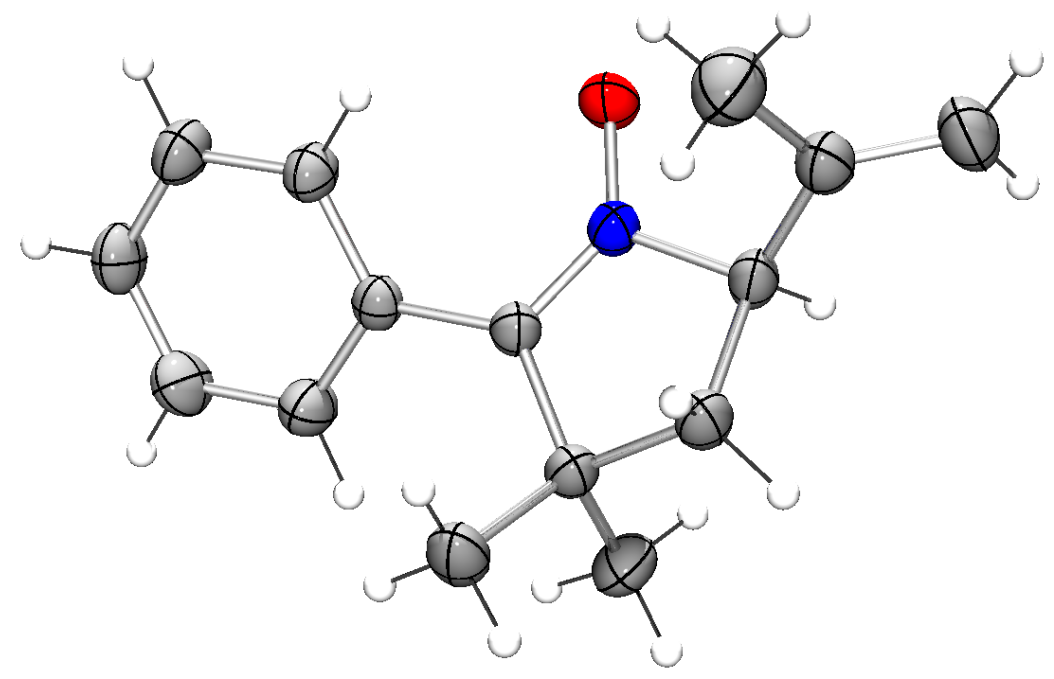

Figure S1. Compound $\mathbf{3 g}$, thermal ellipsoids are drawn at 30\% probability level.

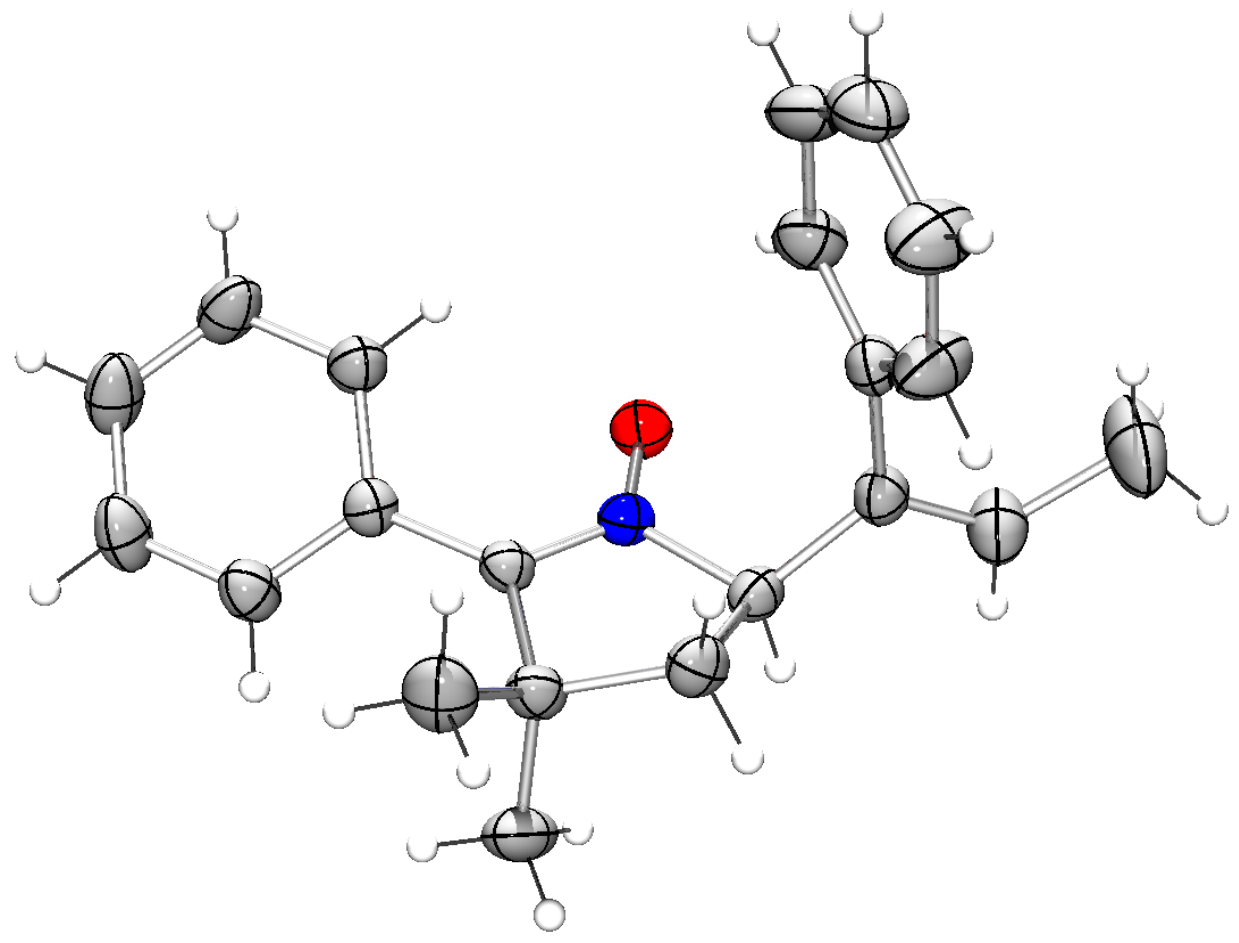

Figure S2. Compound 3v, thermal ellipsoids are drawn at 30\% probability level. 


\section{Crystallographic Studies}

The data were collected using a SuperNova (Dual) X-ray diffractometer equipped with a graphite-monochromated $\mathrm{Cu} /$ Mo K $\alpha$ radiation source $(\lambda=1.54184 / 0.71073 \AA)$. The structures were solved by direct methods using the Siemens SHELXTL PLUS program. Non-hydrogen atoms were refined with anisotropic displacement parameters during the final cycles. All hydrogen atoms were placed by geometrical considerations and were added to the structure-factor calculations. The crystal data and refinement results were summarized in Table $\mathbf{S 1}$.

Table S1. The crystal data and refinement results of compounds $\mathbf{3 g}$ and $\mathbf{3 v}$

\begin{tabular}{|c|c|c|}
\hline Compound number & $3 g$ & $3 v$ \\
\hline Formula & $\mathrm{C}_{15} \mathrm{H}_{19} \mathrm{NO}$ & $\mathrm{C}_{21} \mathrm{H}_{23} \mathrm{NO}$ \\
\hline Fw & 229.31 & 305.40 \\
\hline Temp & $293.66(10)$ & $295.4(1)$ \\
\hline Crystal system & monoclinic & triclinic \\
\hline Space group & $\mathrm{P} 21 / c$ & $\mathrm{P}-1$ \\
\hline a $\AA$ & $9.9162(10)$ & $9.6457(18)$ \\
\hline $\mathrm{b} \AA$ & $12.1827(9)$ & $10.255(2)$ \\
\hline$c \AA$ & $11.4435(12)$ & 10.4809 (19) \\
\hline$\alpha^{\circ}$ & 90.00 & $114.778(19)$ \\
\hline$\beta^{\circ}$ & $106.801(12)$ & $103.217(16)$ \\
\hline$\gamma^{\circ}$ & 90.00 & $93.707(16)$ \\
\hline$V \AA^{3}$ & $1323.5(2)$ & $901.1(3)$ \\
\hline Z & 4 & 2 \\
\hline Density (calcd) $\mathrm{g} \cdot \mathrm{cm}^{-3}$ & 1.151 & 1.126 \\
\hline Absorb.coeff. $\mathrm{mm}^{-1}$ & 0.071 & 0.068 \\
\hline$F(000)$ & 496 & 328 \\
\hline Index ranges & $\begin{array}{l}-11 \leq h \leq 12 \\
-13 \leq k \leq 15 \\
-11 \leq l \leq 14\end{array}$ & $\begin{aligned}-11 & \leq \mathrm{h} \leq 11 \\
-12 & \leq \mathrm{k} \leq 11 \\
-12 & \leq \mathrm{l} \leq 11\end{aligned}$ \\
\hline
\end{tabular}




\begin{tabular}{|c|c|c|}
\hline Data/restr./param & $2590 / 0 / 166$ & $3541 / 0 / 212$ \\
\hline GOF & 1.05 & 1.04 \\
\hline$[I>2 \sigma(I)]$ & $\begin{array}{c}R_{1}=0.049 \\
w R_{2}=0.139\end{array}$ & $\begin{array}{c}R_{1}=0.059 \\
w R_{2}=0.144\end{array}$ \\
\hline
\end{tabular}


Compound (1a)<smiles>CC(C)=CCC(=NO)c1ccccc1</smiles>

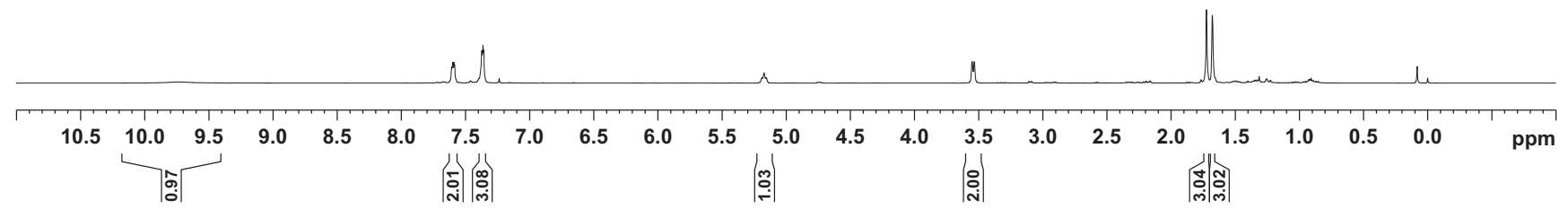<smiles>CC(C)=CCC(=NO)c1ccccc1</smiles>

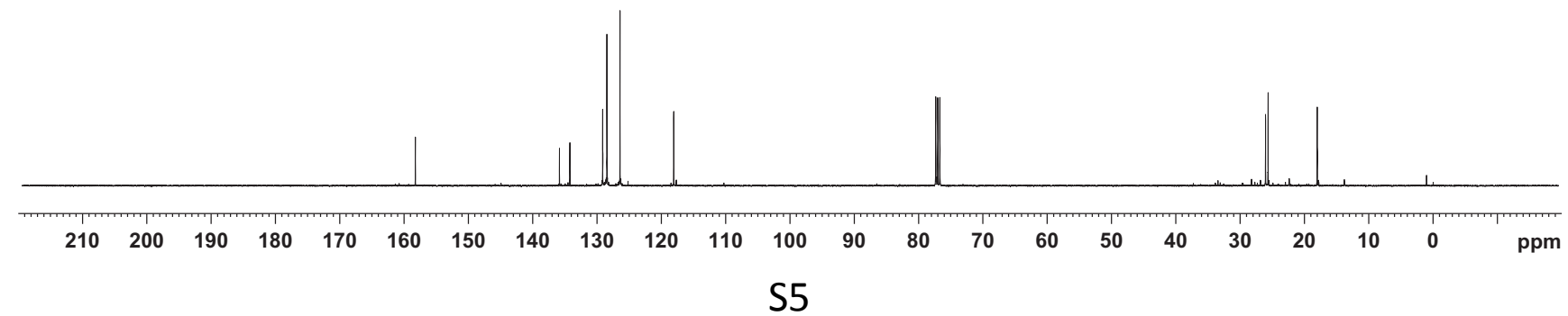




\section{compound (1b)}

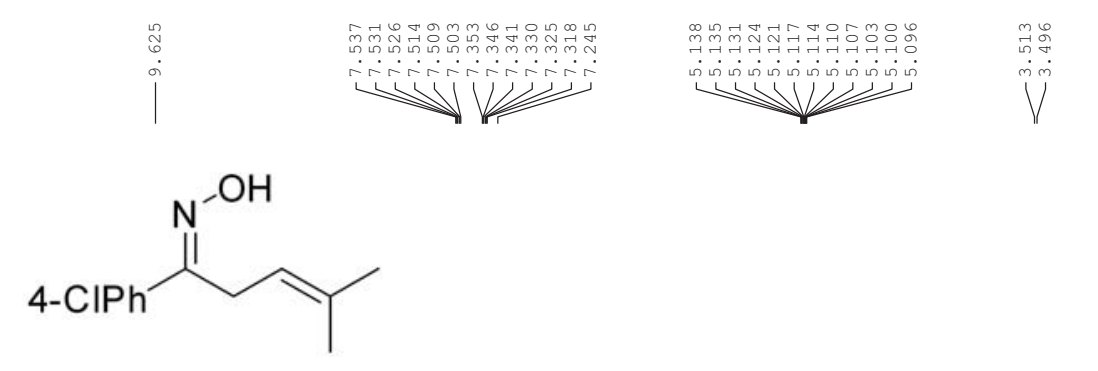

\section{骂}

\section{i}


compound (1c)
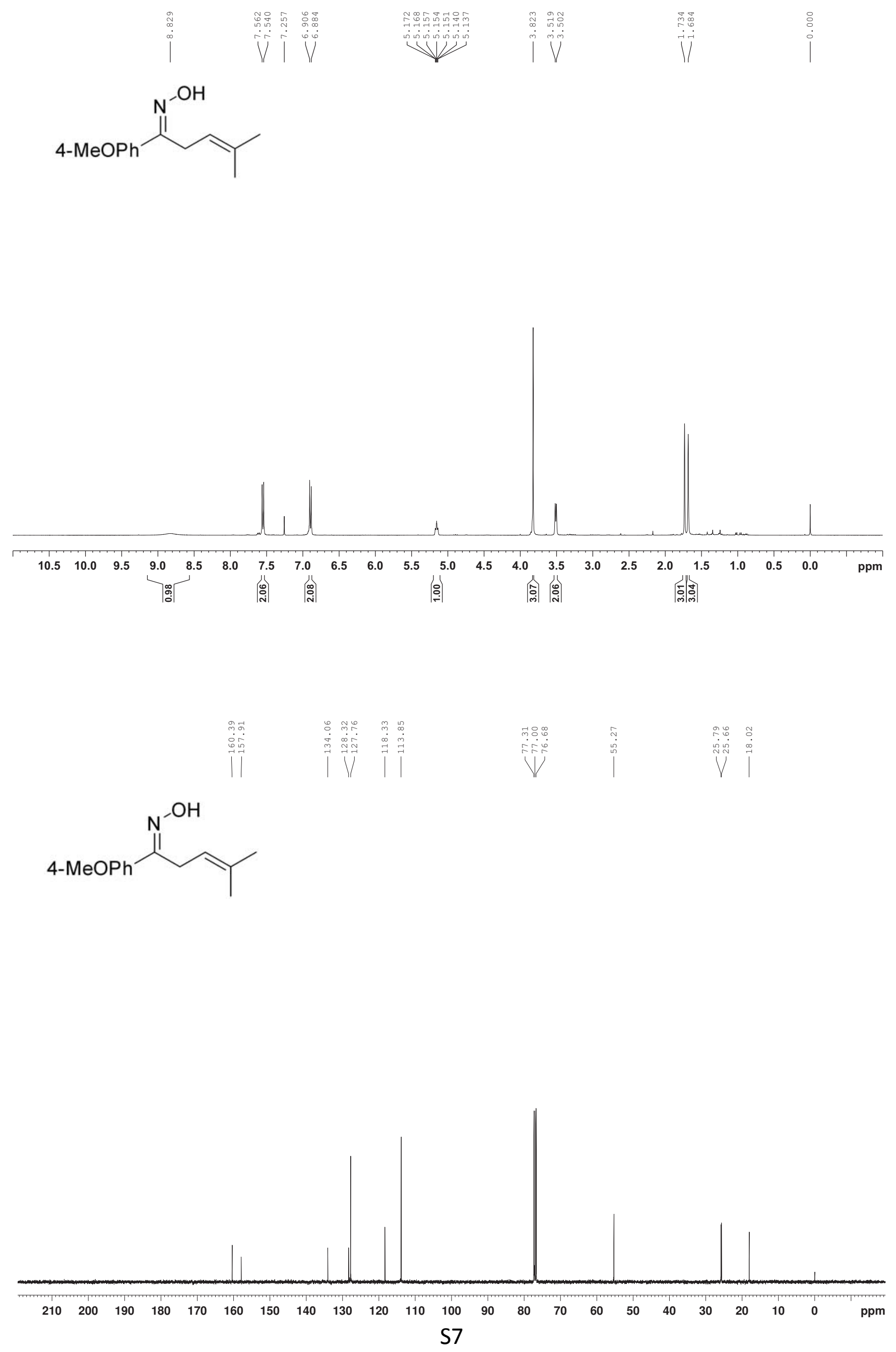
Compound (1d)

i

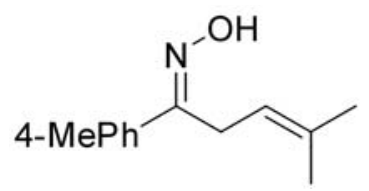
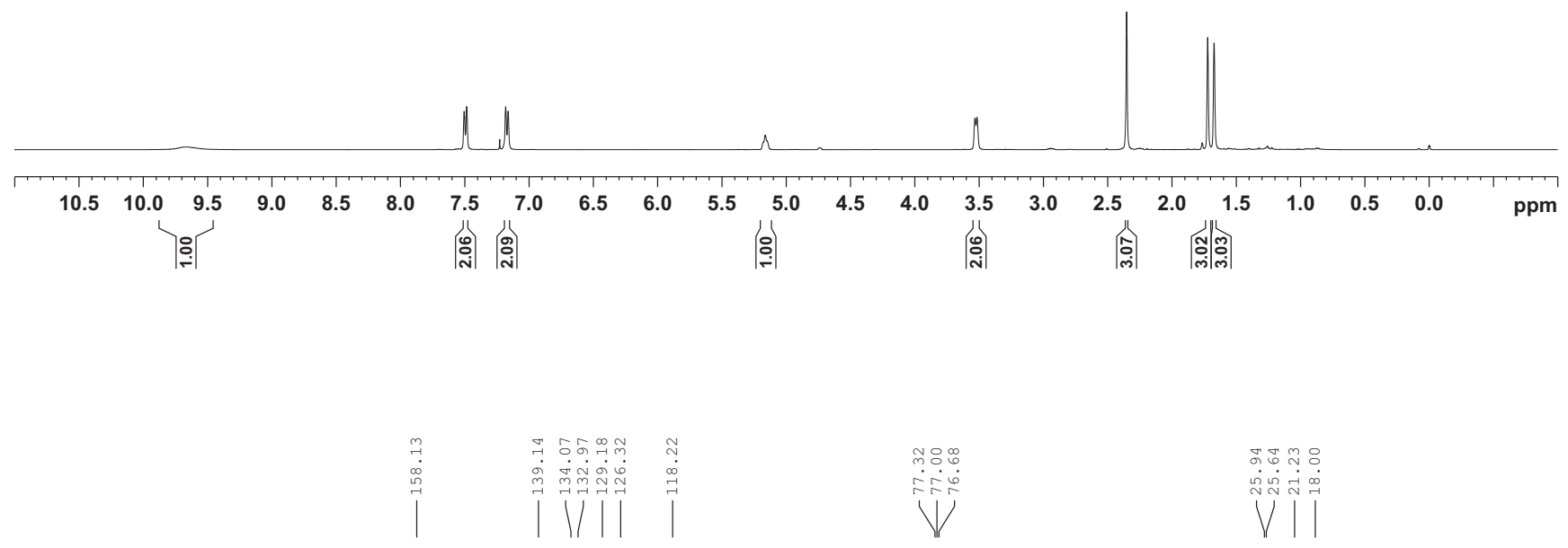

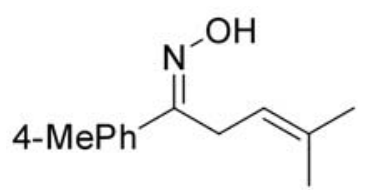

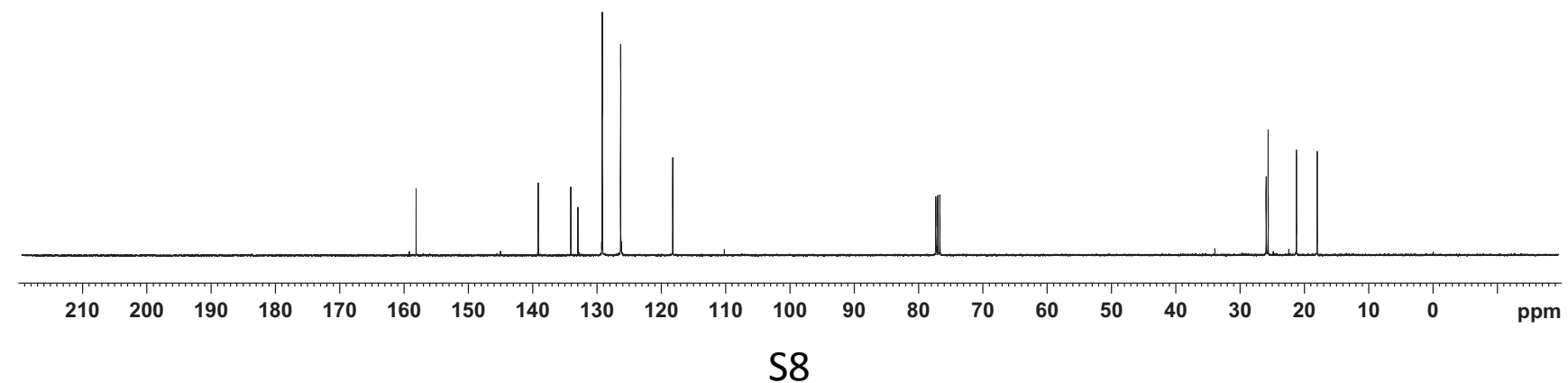


Compound (1e)
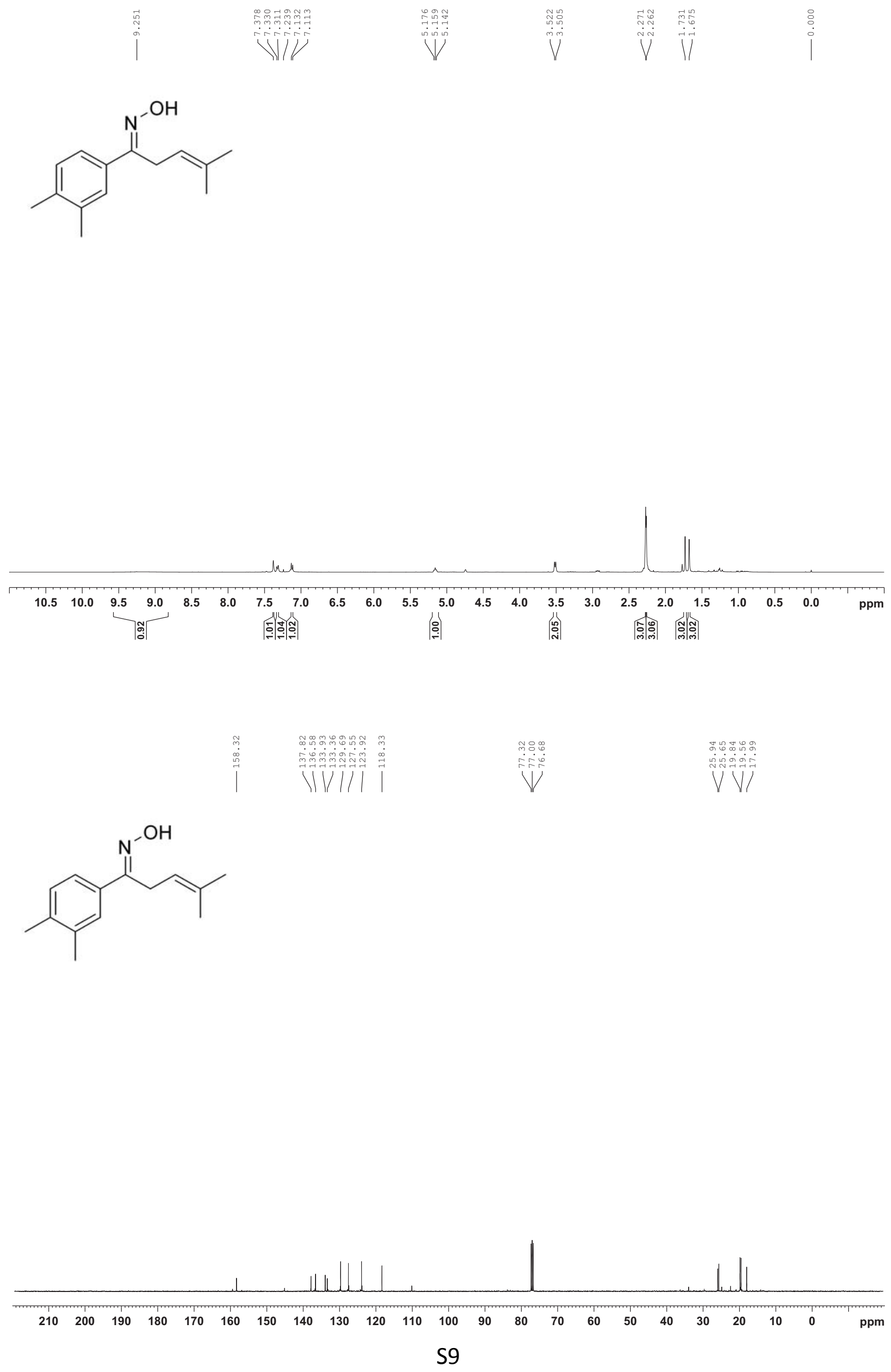
Compound (1f)
i
V|
$\mid$
$\sqrt{V}$<smiles>COc1cc(OC)cc(C(CC=C(C)C)=NO)c1</smiles>

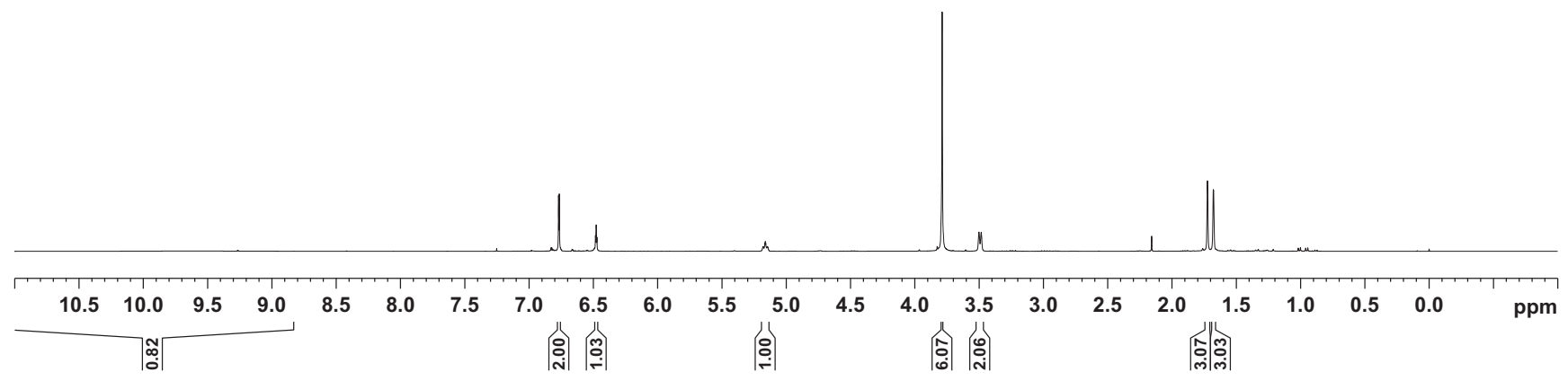

\#<smiles>COc1cc(OC)cc(C(CC=C(C)C)=NO)c1</smiles>

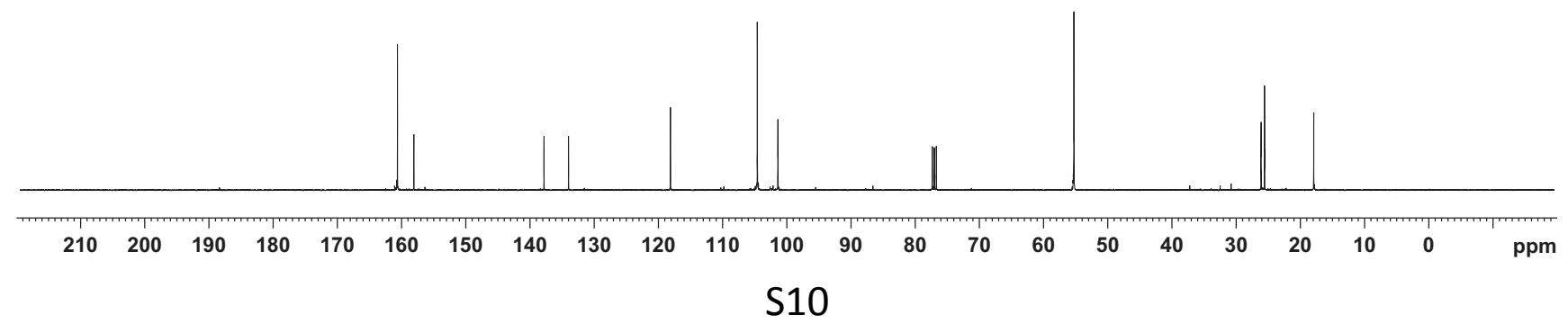


compound (1g)

|

HO<smiles>CC(C)=CCC(C)(C)C(=NO)c1ccccc1</smiles>

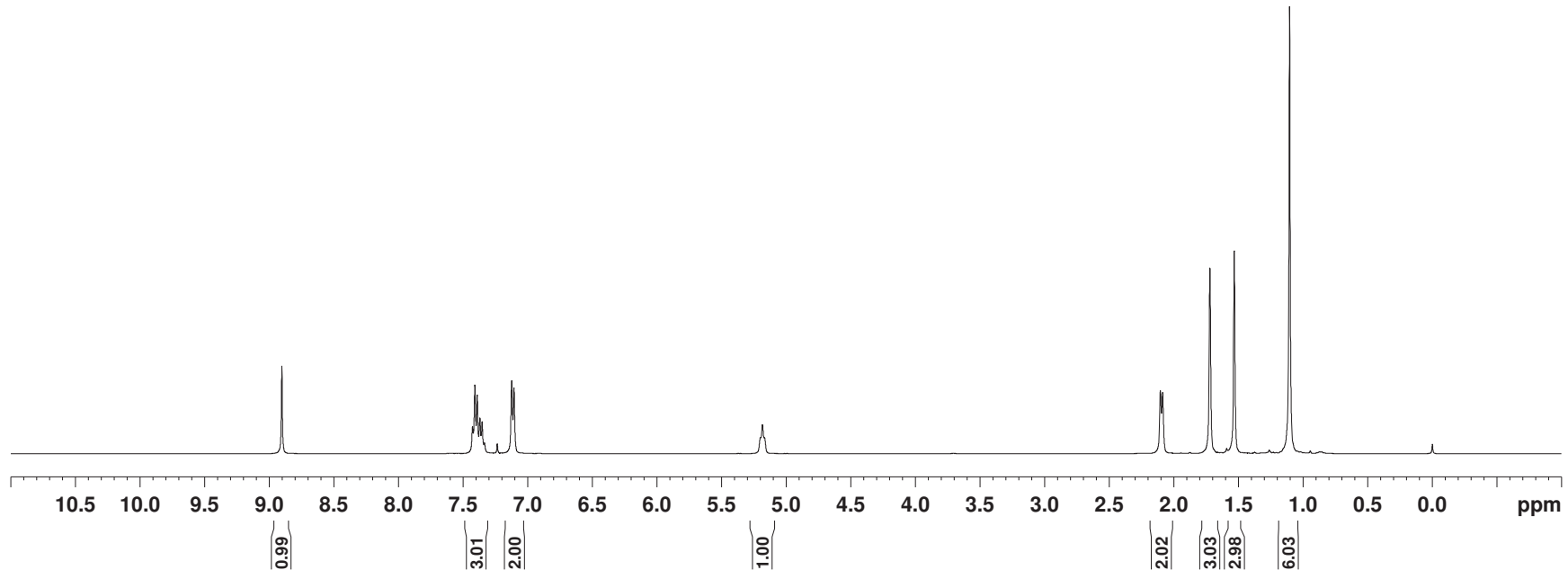

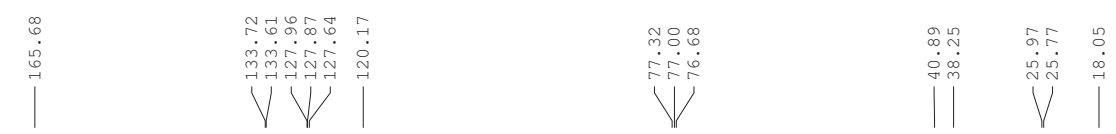

$\mathrm{HO}$ -<smiles>CN=C(c1ccccc1)C(C)(C)CC=C(C)C</smiles>

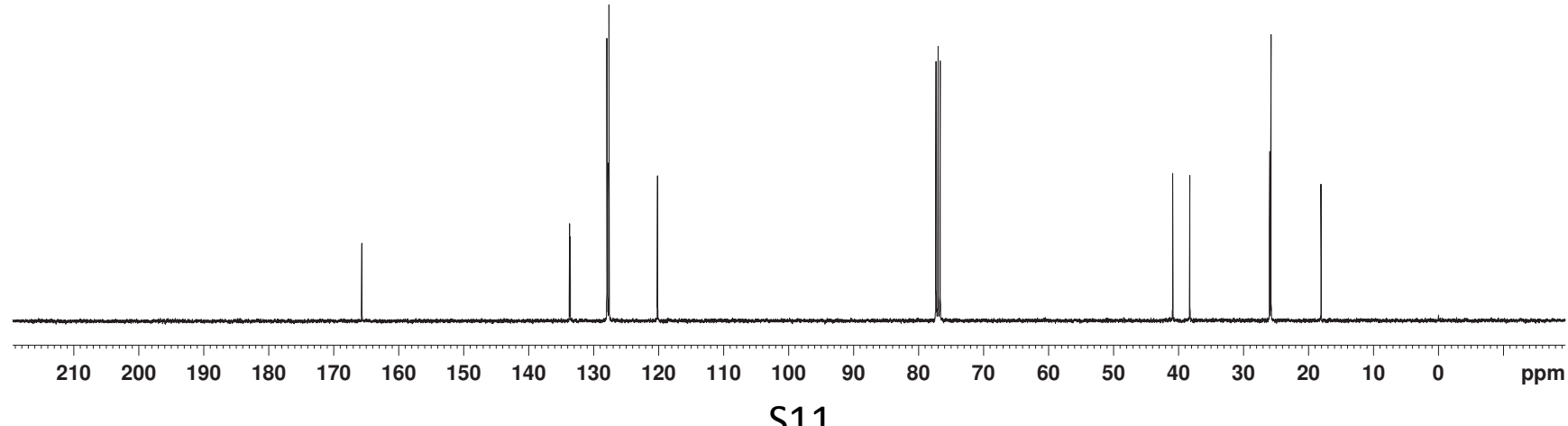


compound (1h)
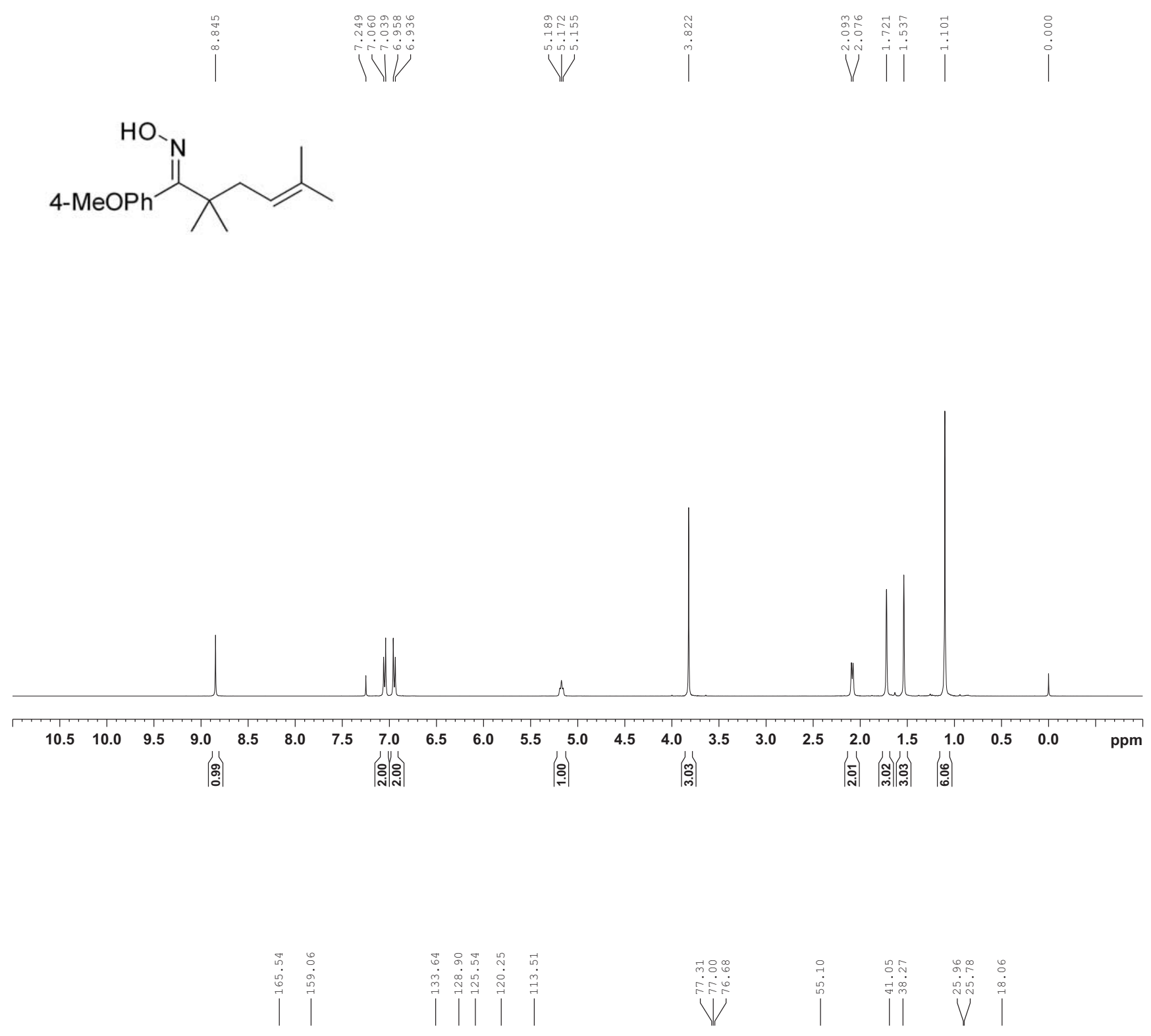<smiles>COc1ccccc1/C(=N\O)C(C)(C)CC=C(C)C</smiles>

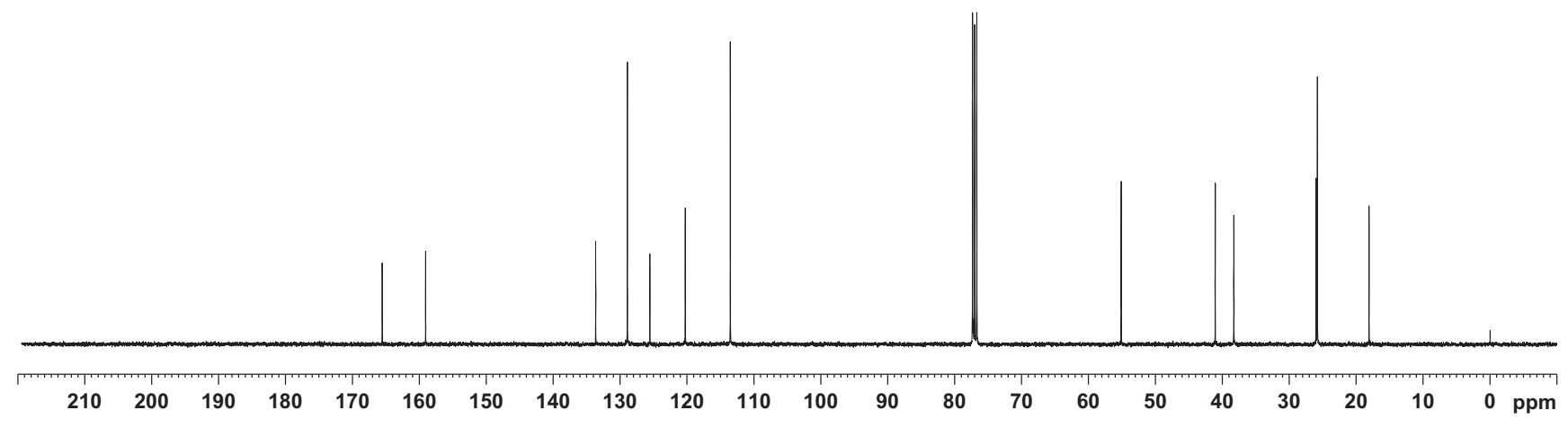


compound (1i)

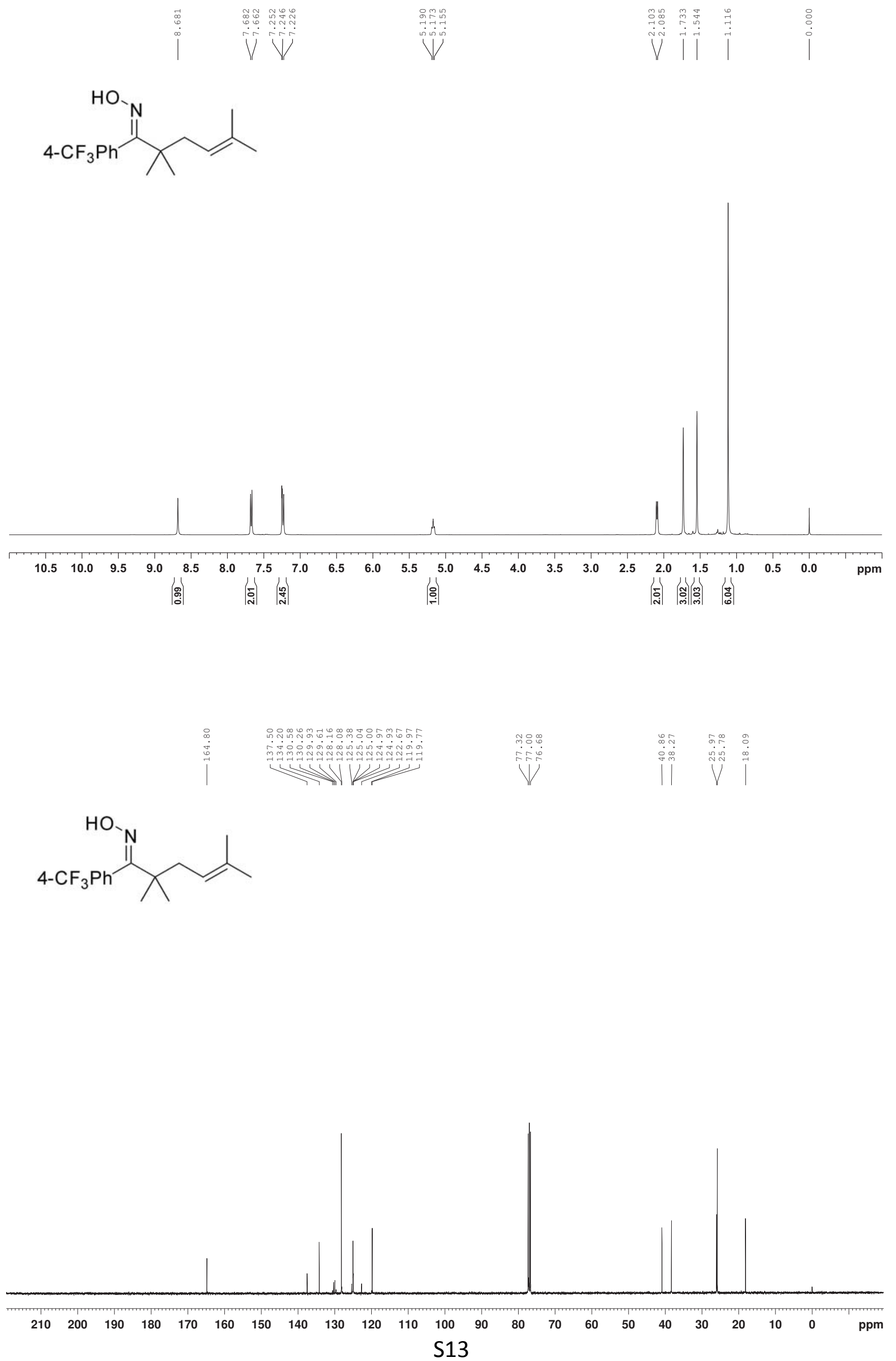


compound (1j)

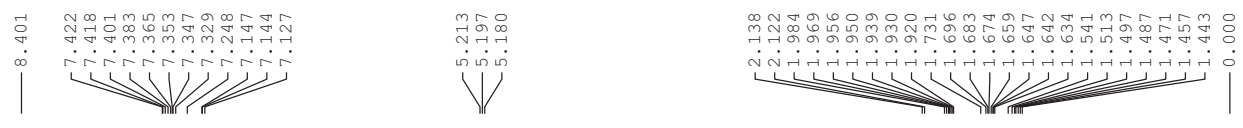<smiles>CC(C)=CCC1(/C(=N/O)c2ccccc2)CCCC1</smiles>

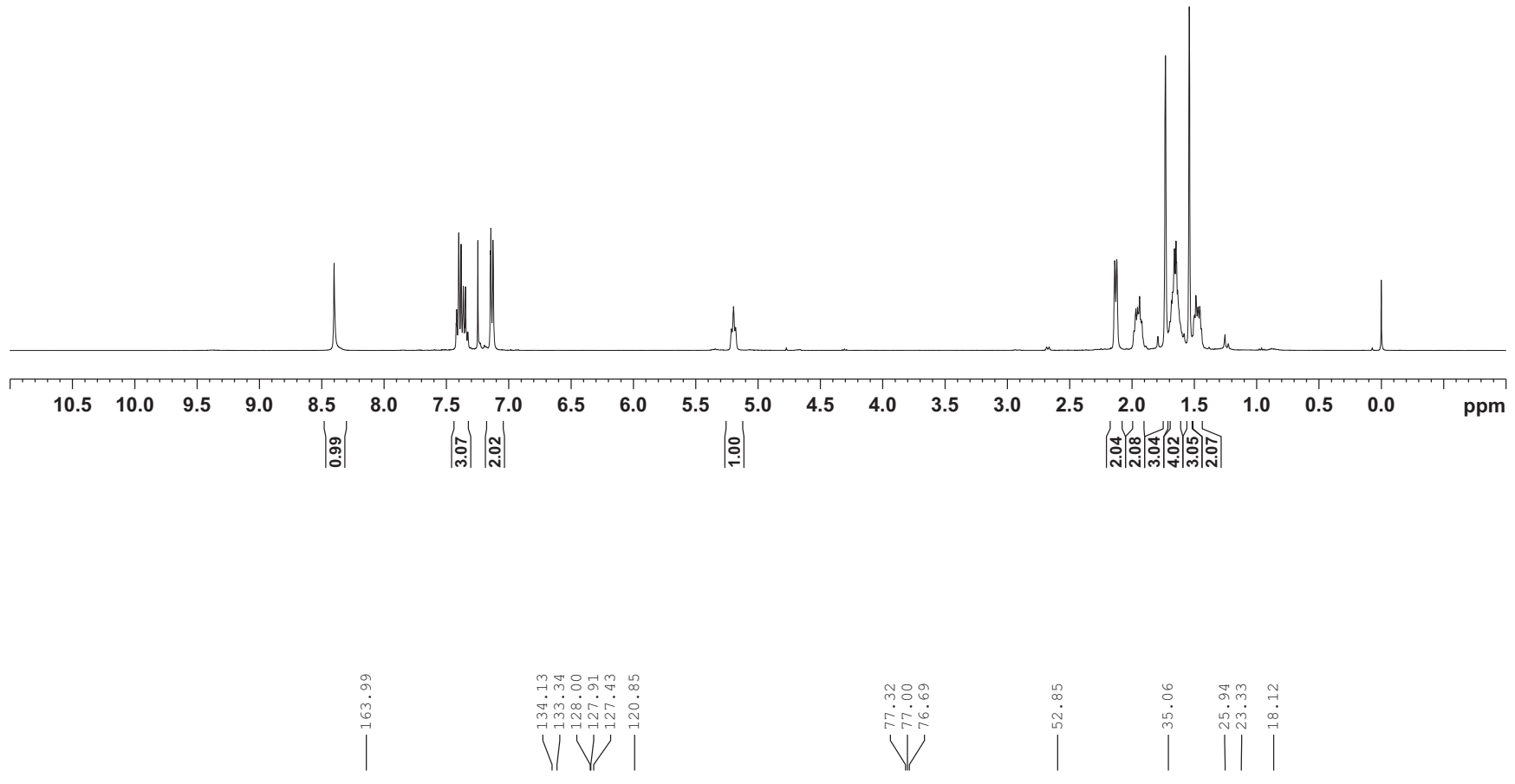<smiles>CC(C)=CCC1(/C(=N/O)c2ccccc2)CCCC1</smiles>

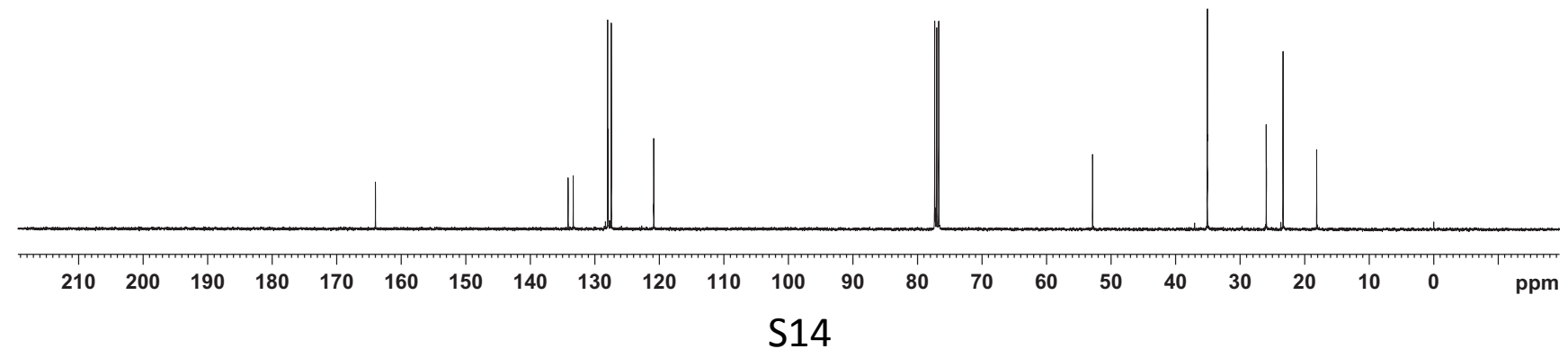


compound (1k)
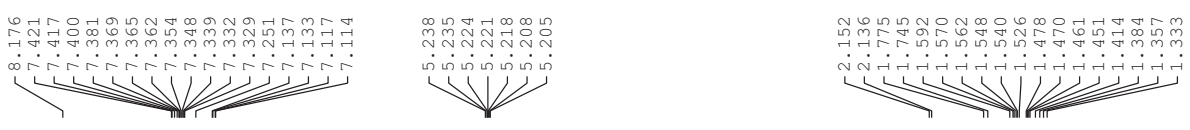

$\stackrel{\circ}{\circ}$<smiles>CC(C)=CCC1(/C(=N/O)c2ccccc2)CCCCC1</smiles>
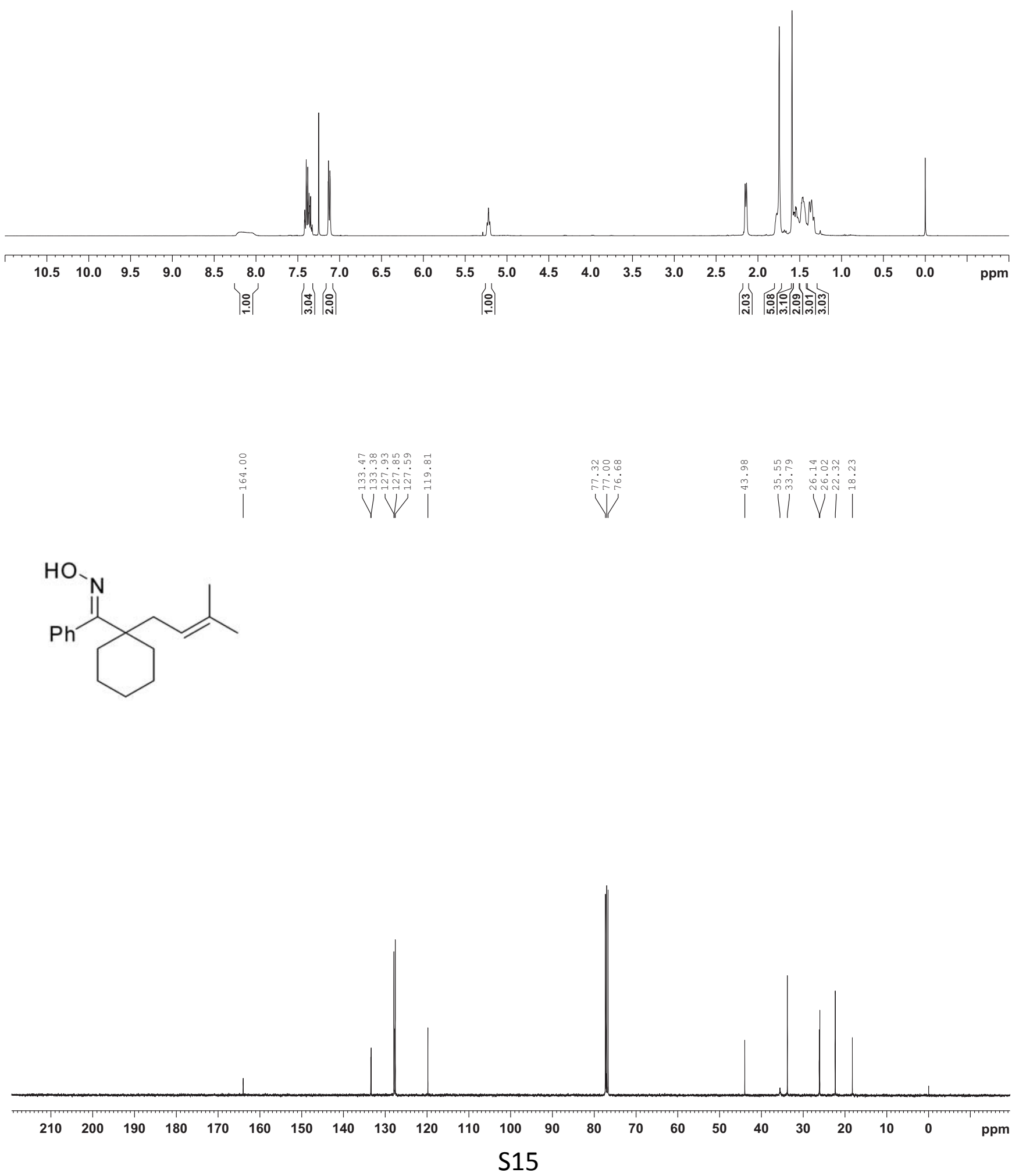
compound (1I)

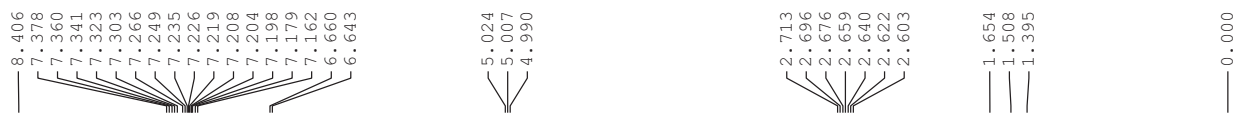<smiles>CC(C)=CCC(C)(/C(=N/O)c1ccccc1)c1ccccc1</smiles>
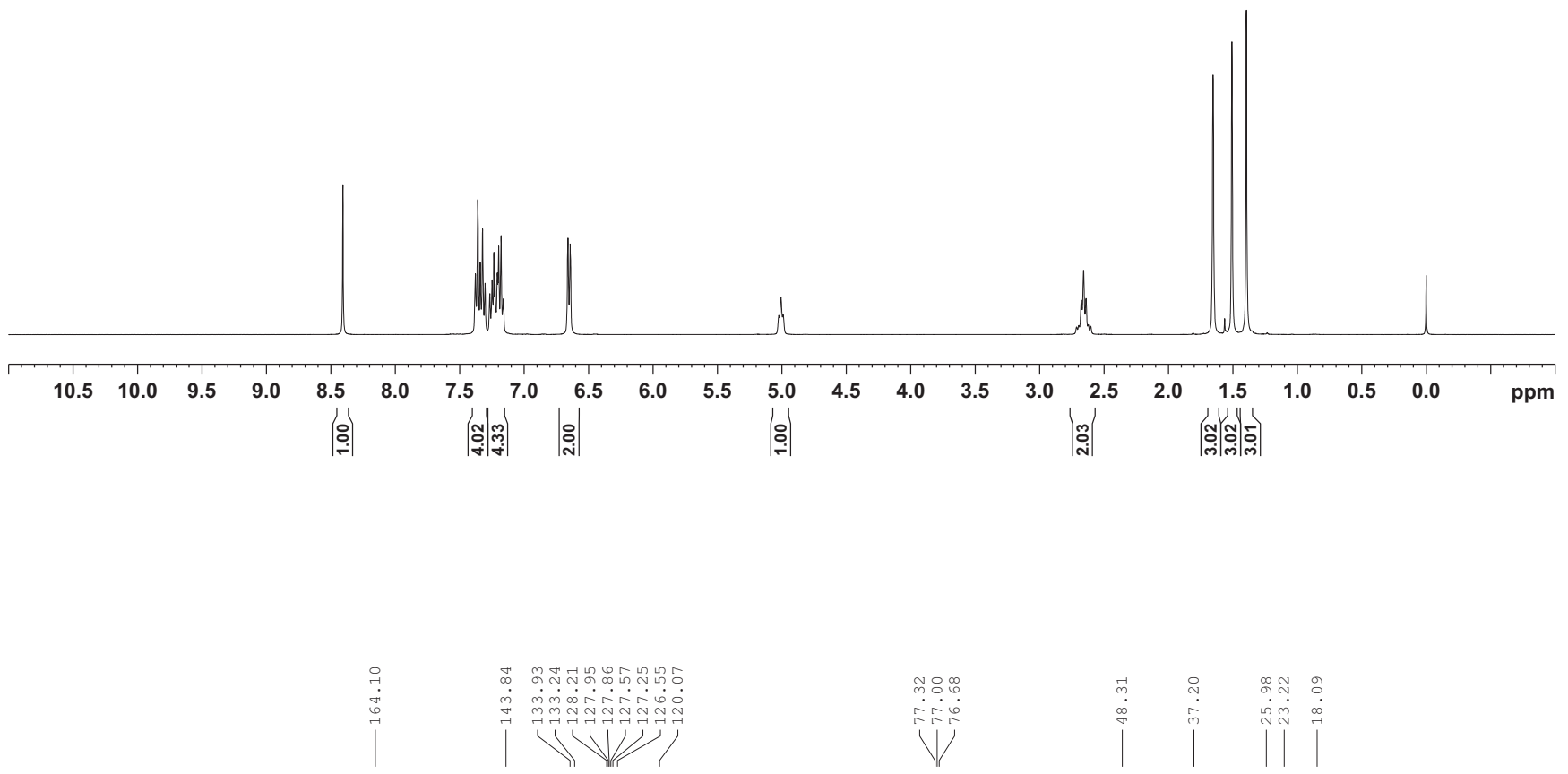

(NO

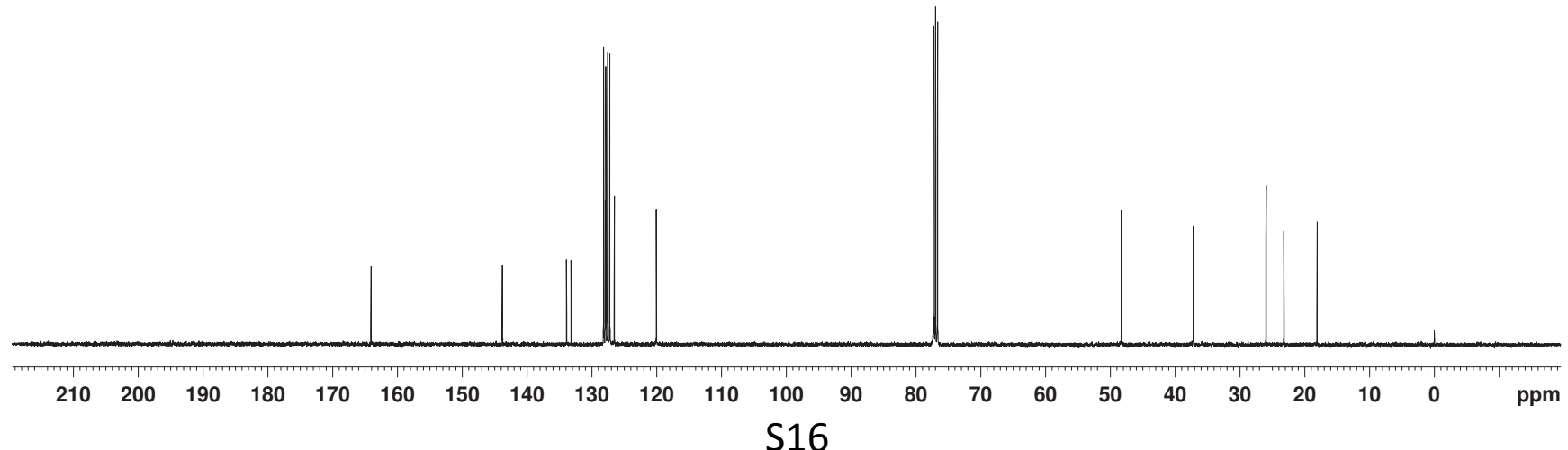


compound (1m)

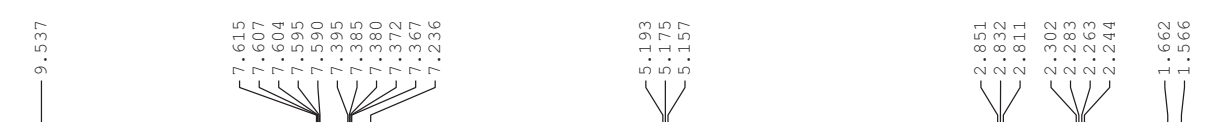<smiles>CC(C)=CCC/C(=N\O)c1ccccc1</smiles>
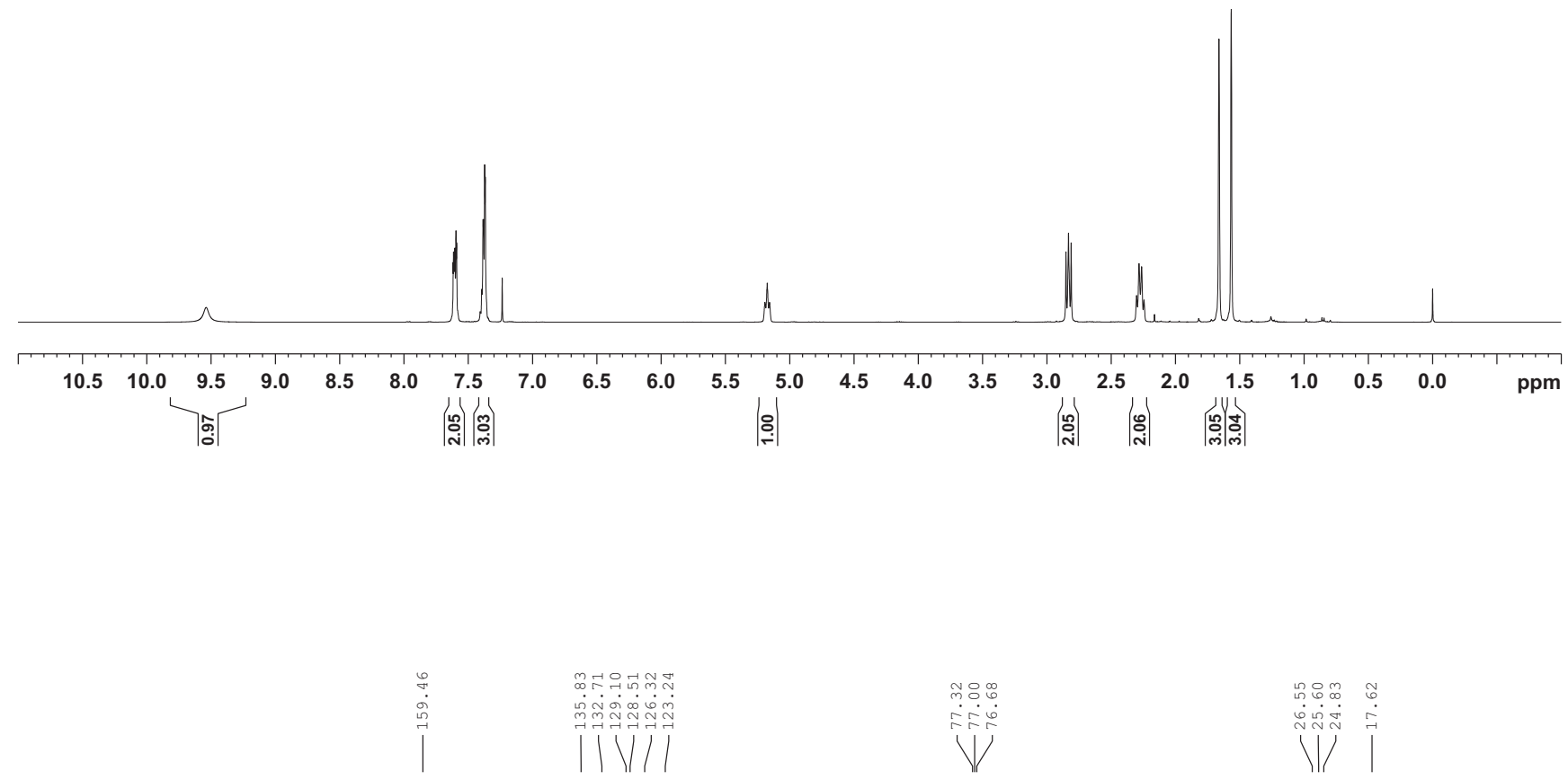<smiles>CC(C)=CCC/C(=N\O)c1ccccc1</smiles>

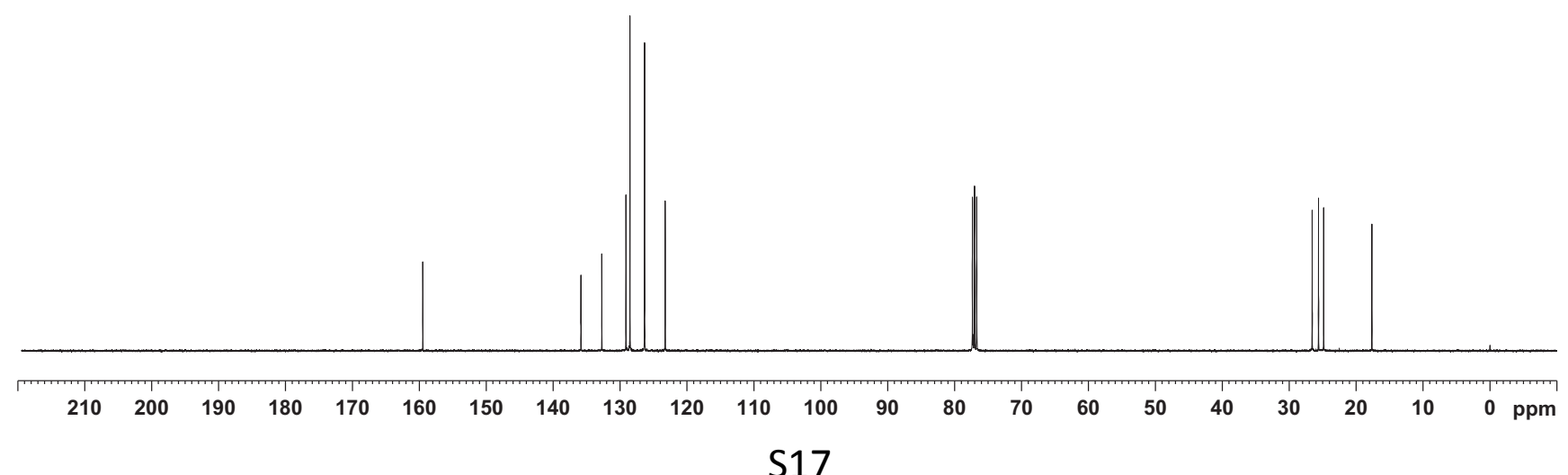


compound (1n)

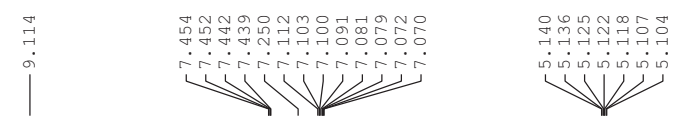<smiles>CC(C)=CCC(C)(C)/C(=N/O)c1cccs1</smiles>
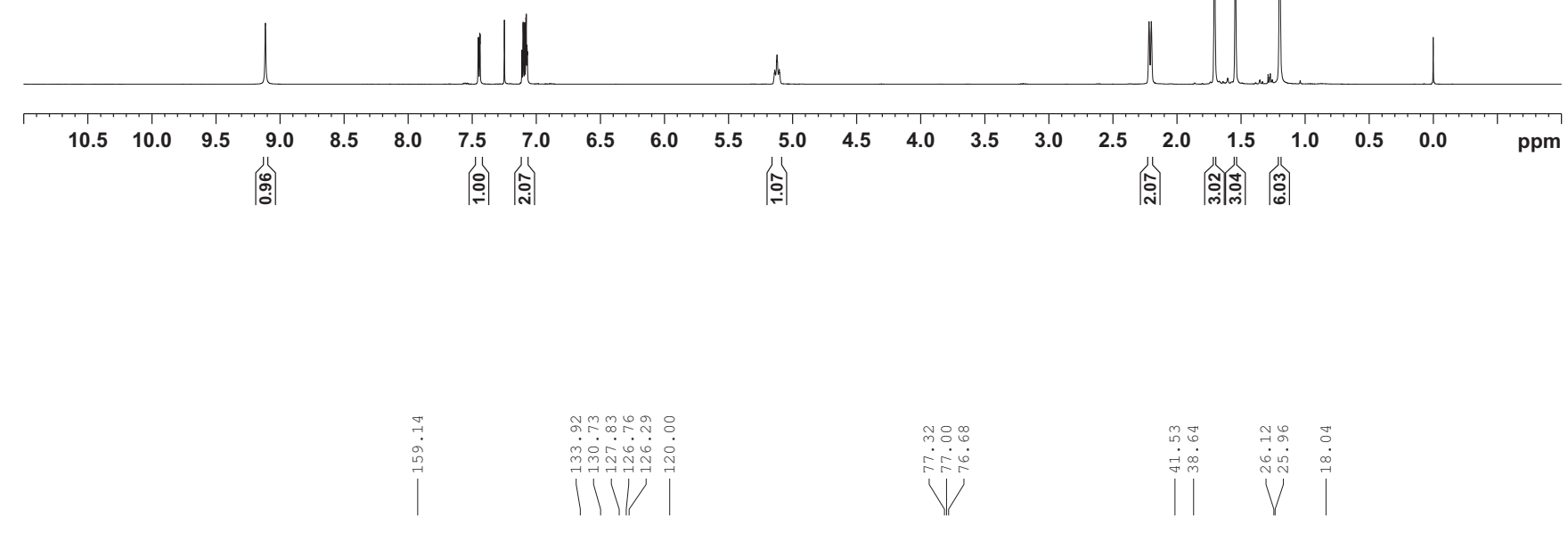<smiles>CC(C)=CCC(C)(C)/C(=N/O)c1cccs1</smiles>

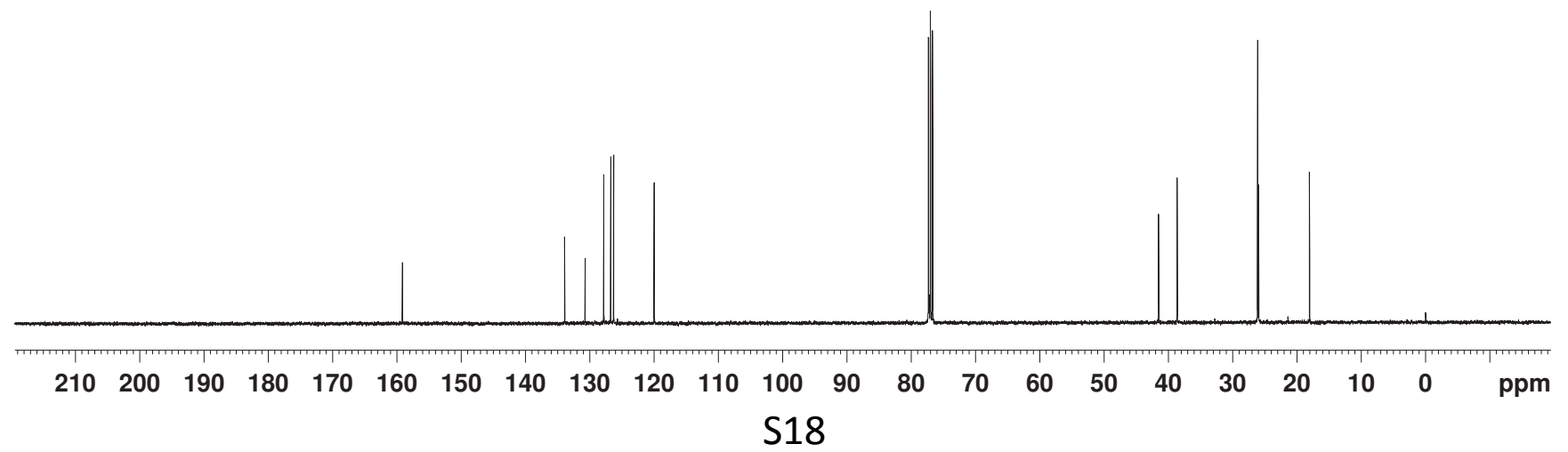


compound (10)

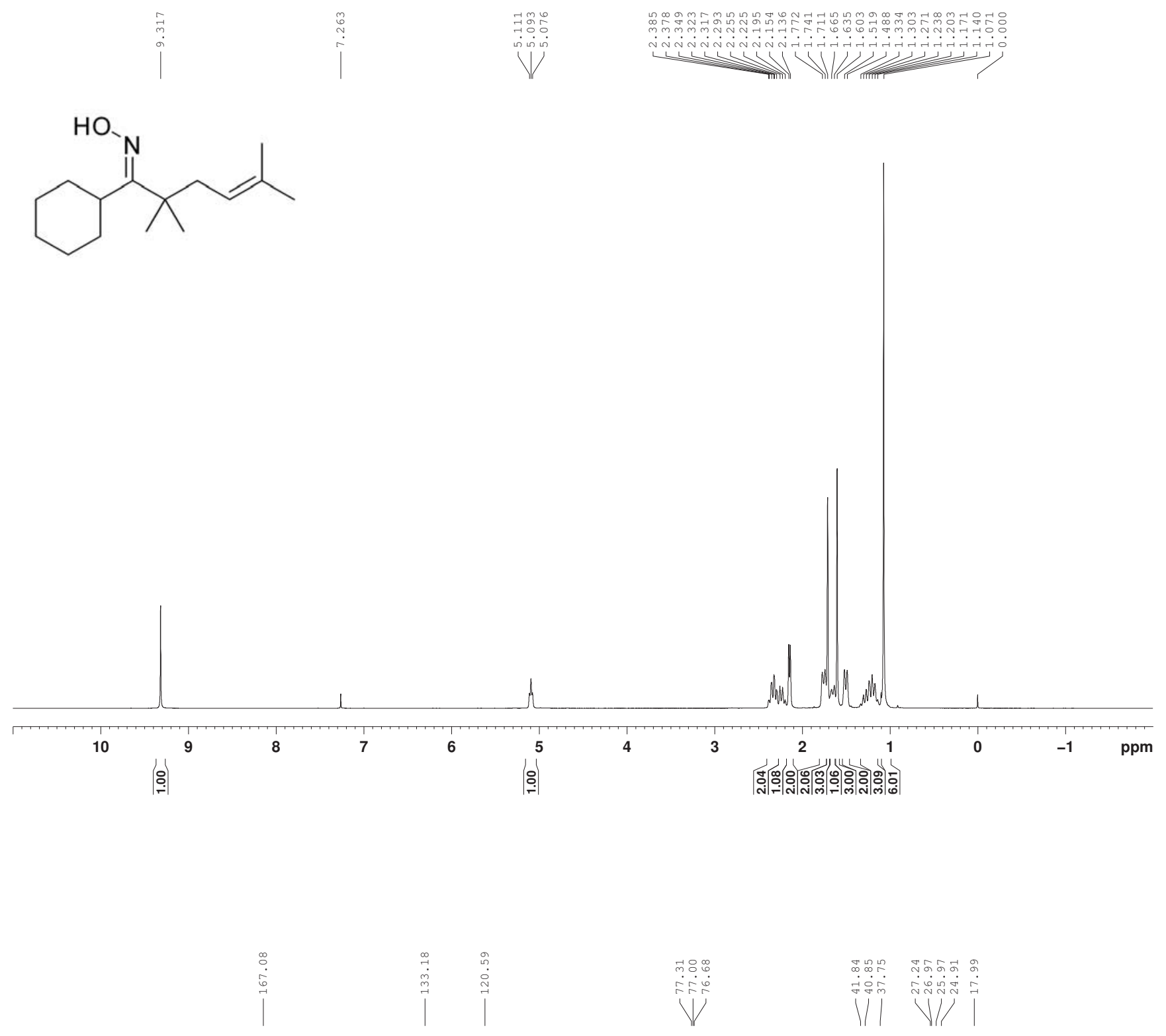<smiles>CC(C)=CCC(C)(C)C(=NO)C1CCCCC1</smiles>

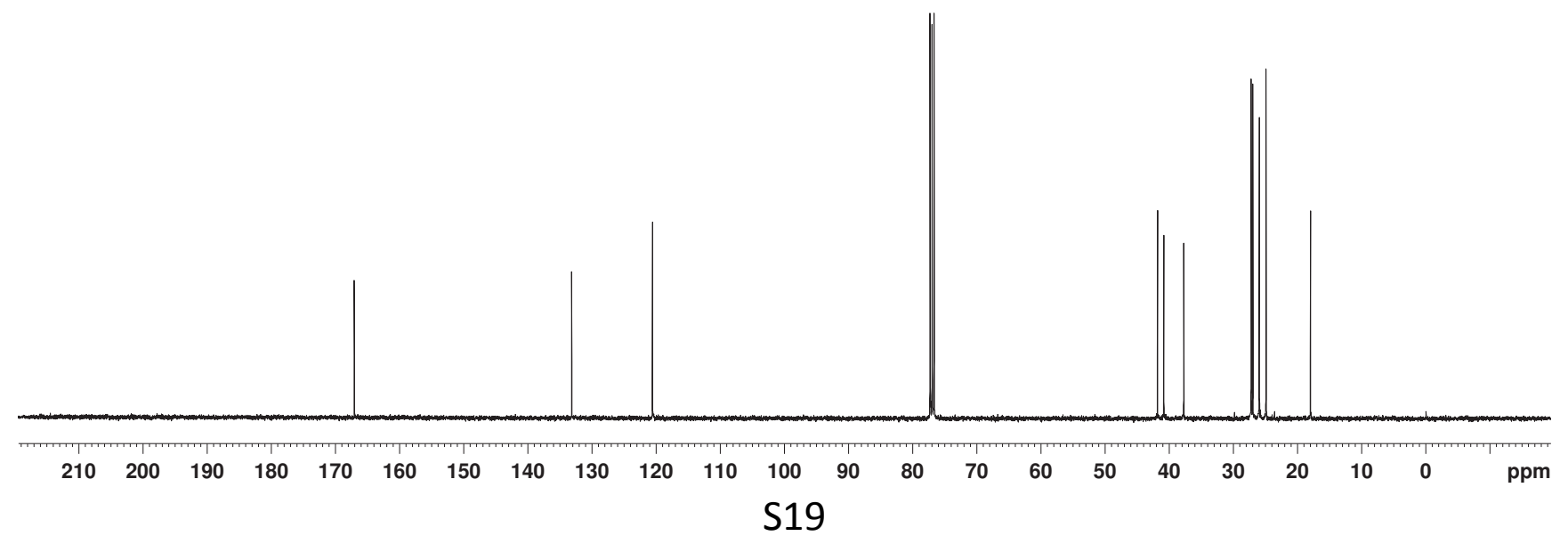


compound (1p)

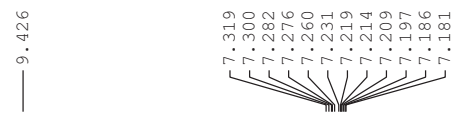

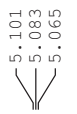

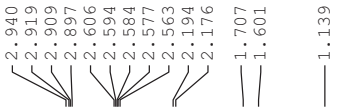<smiles>CC(C)=CCC(C)(C)/C(CCc1ccccc1)=N/O</smiles>
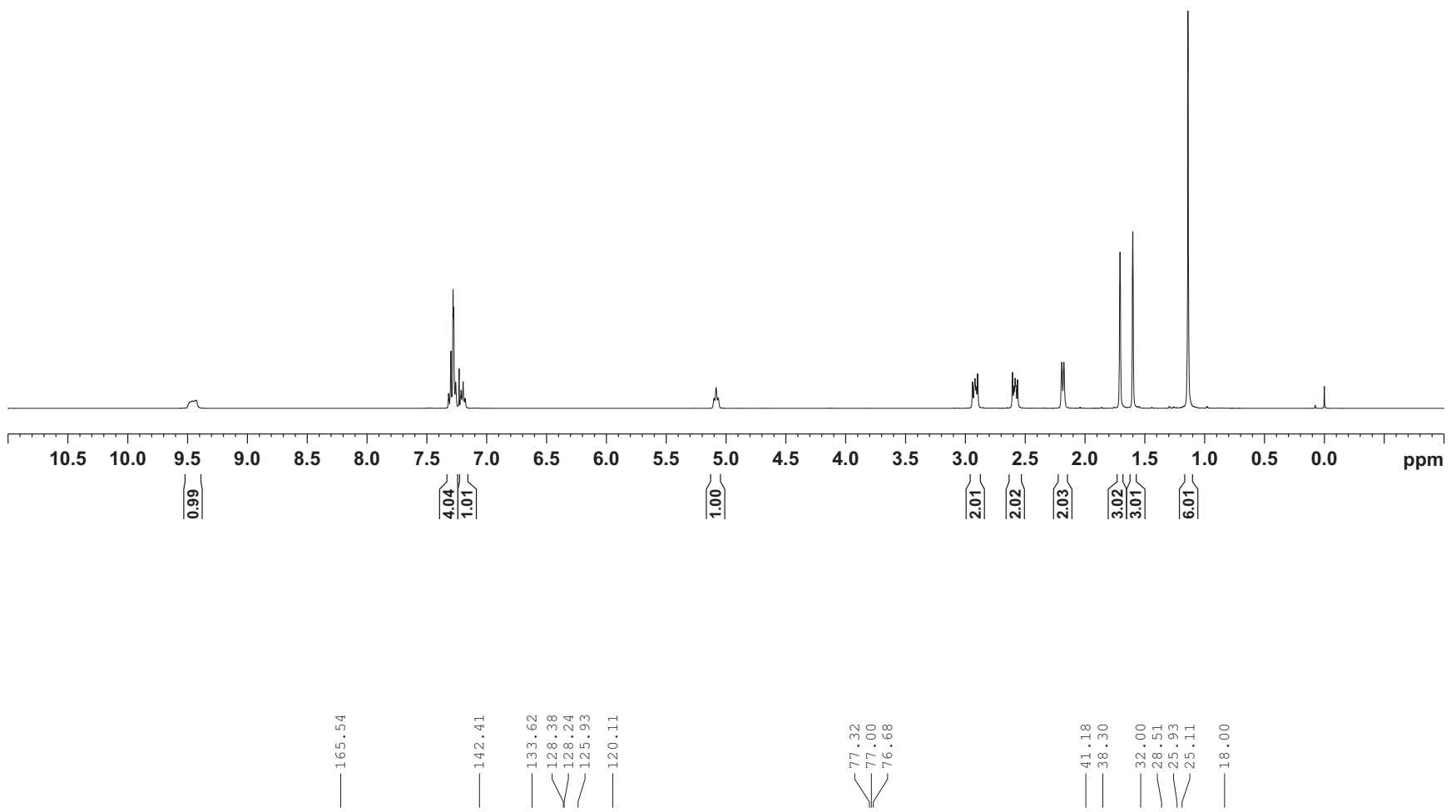<smiles>CC(C)=CCC(C)(C)/C(CCc1ccccc1)=N/O</smiles>

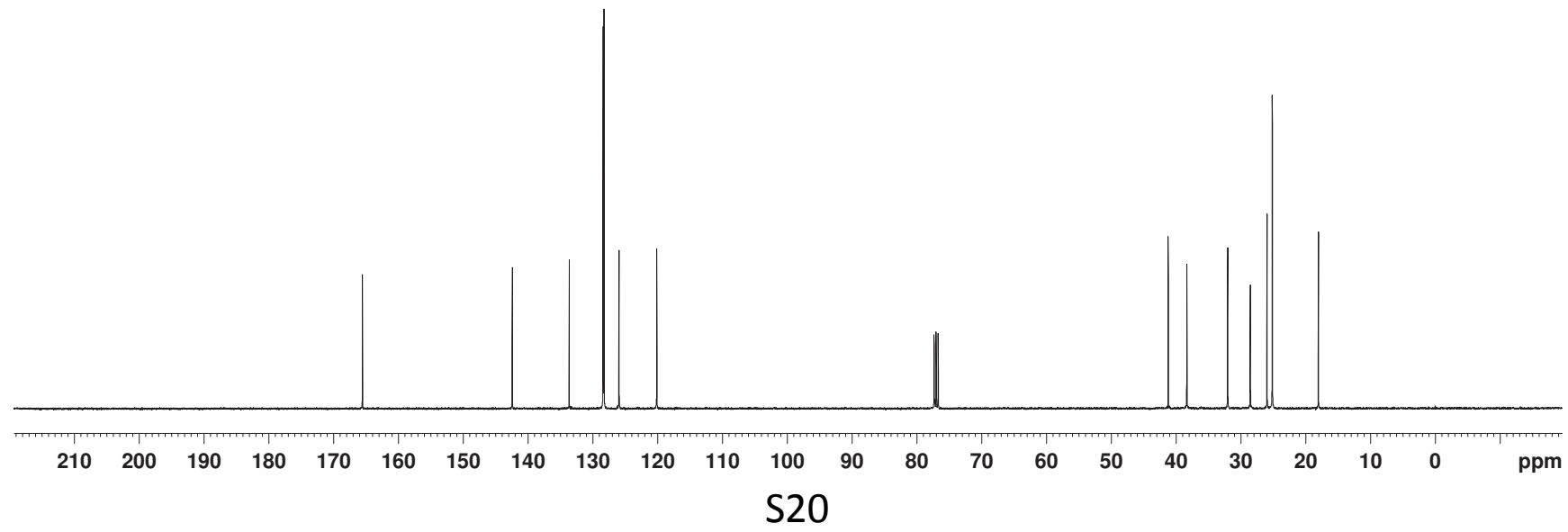


compound (1q)

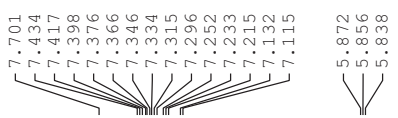

$\mathrm{HO}$<smiles>C/C(=C\CC(C)(C)/C(=N/O)c1ccccc1)c1ccccc1</smiles>
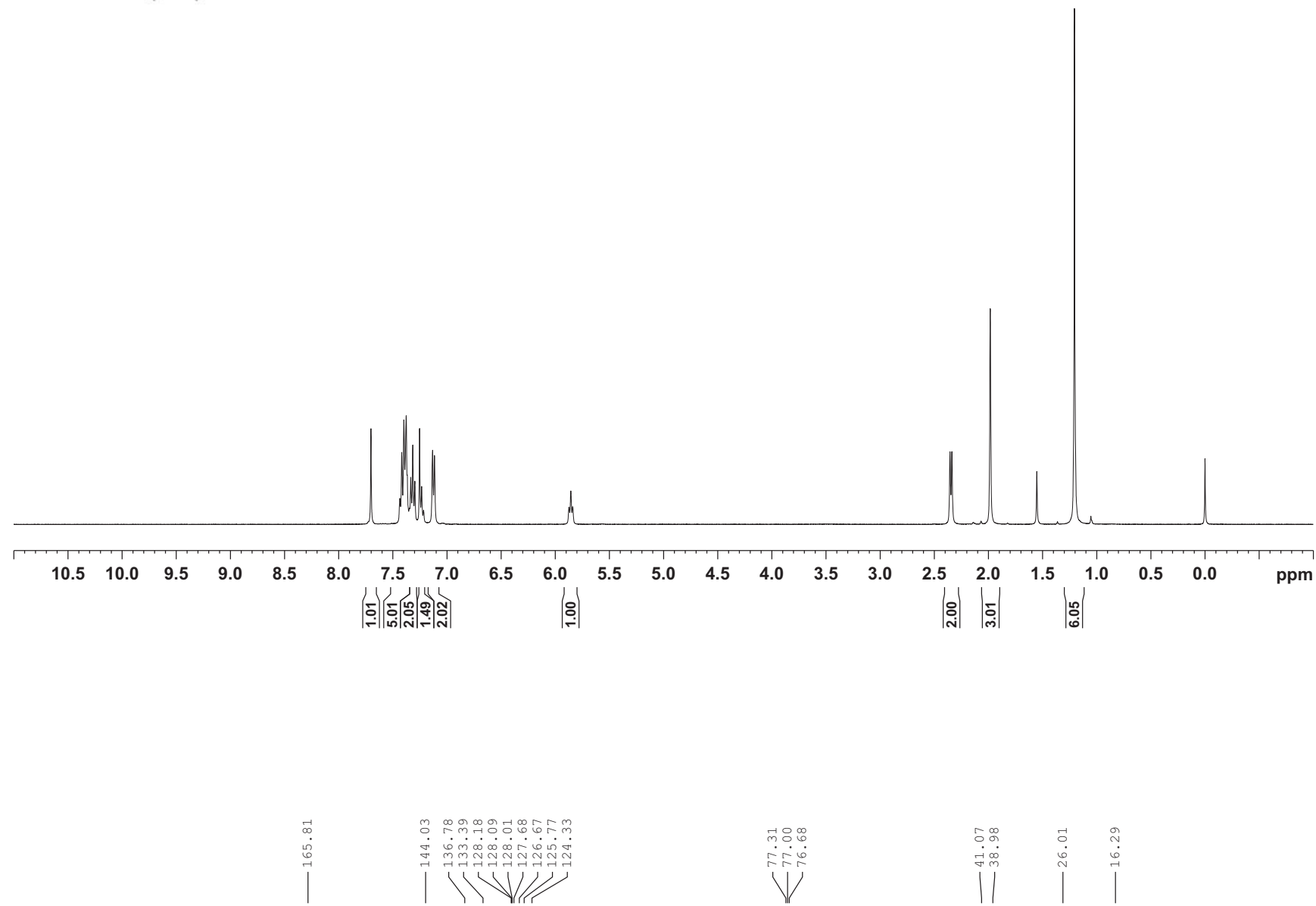

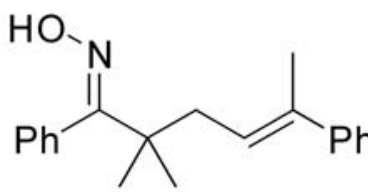


compound (1r)

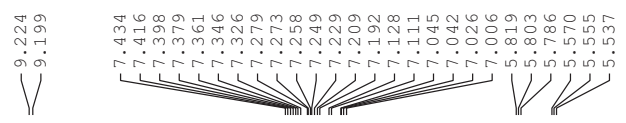

HO、<smiles>C/C(=C\CC(C)(C)/C(=N/O)c1ccccc1)P(Cl)c1ccccc1</smiles>
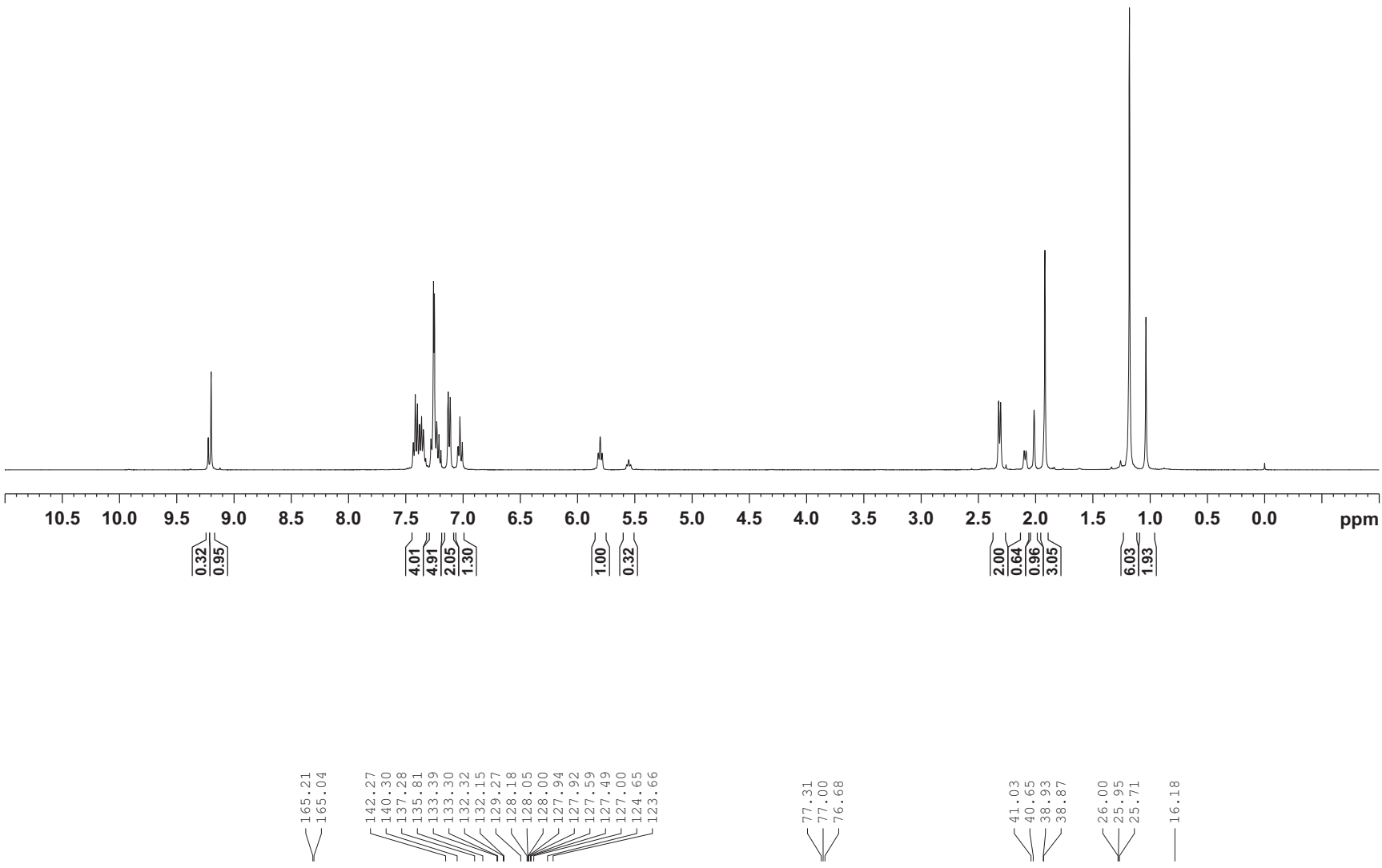



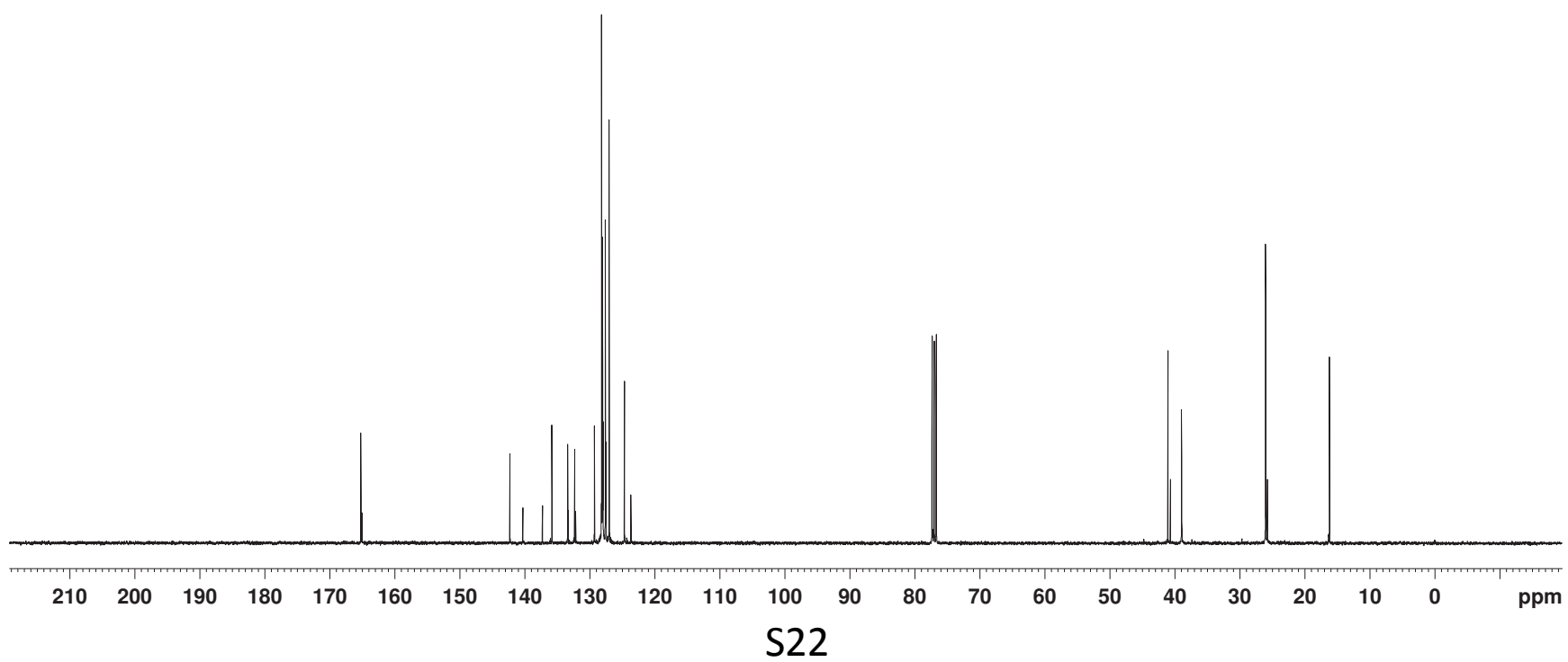


compound (1s)
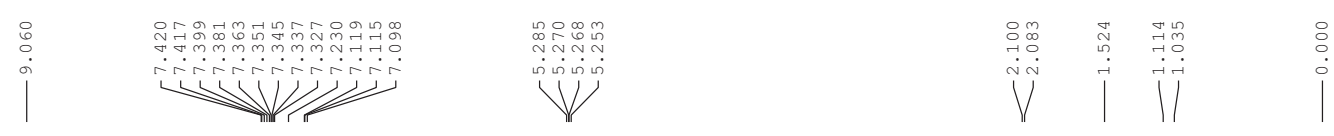<smiles>C/C(=C\CC(C)(C)/C(=N/O)c1ccccc1)C(C)(C)C</smiles>
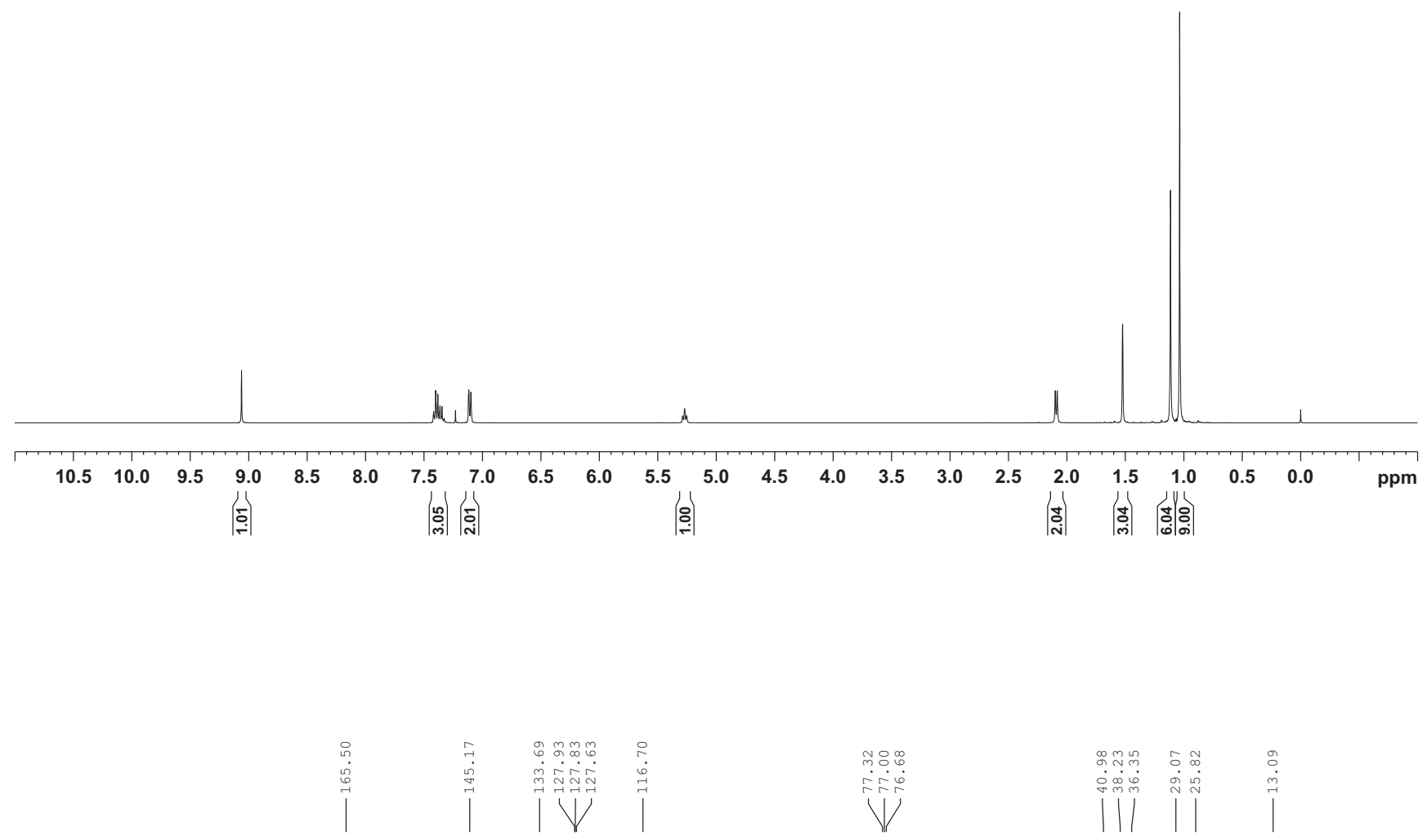

$\mathrm{HO}$<smiles>C/C(=C\CC(C)(C)C(=NO)c1ccccc1)C(C)(C)C</smiles>

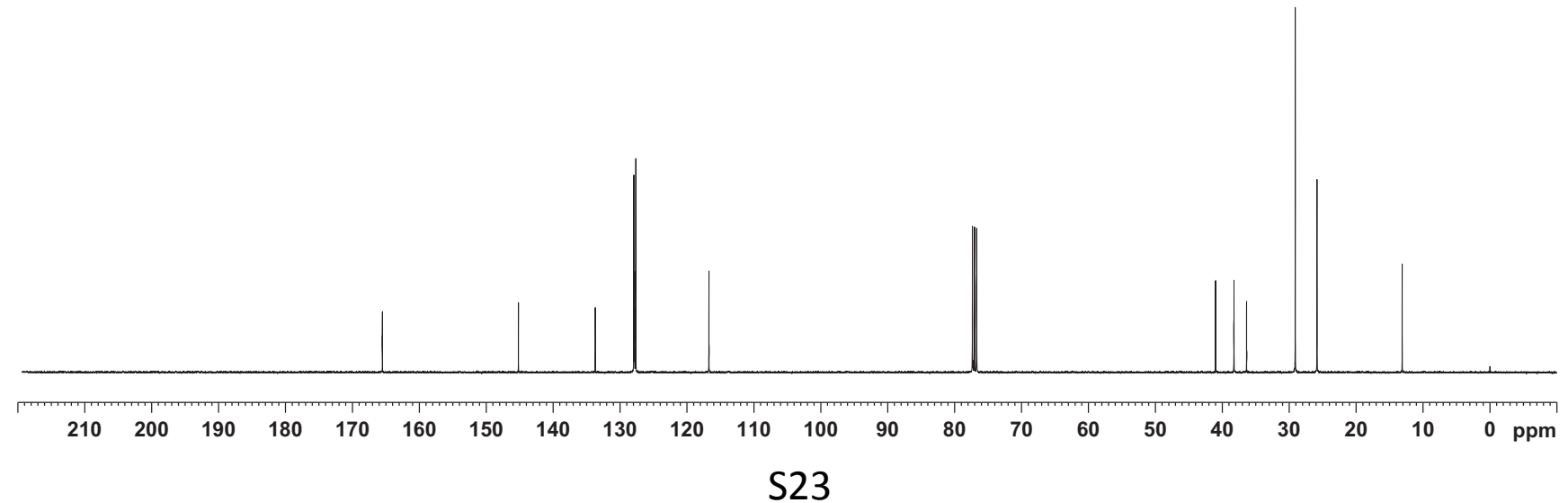


compound (1t)

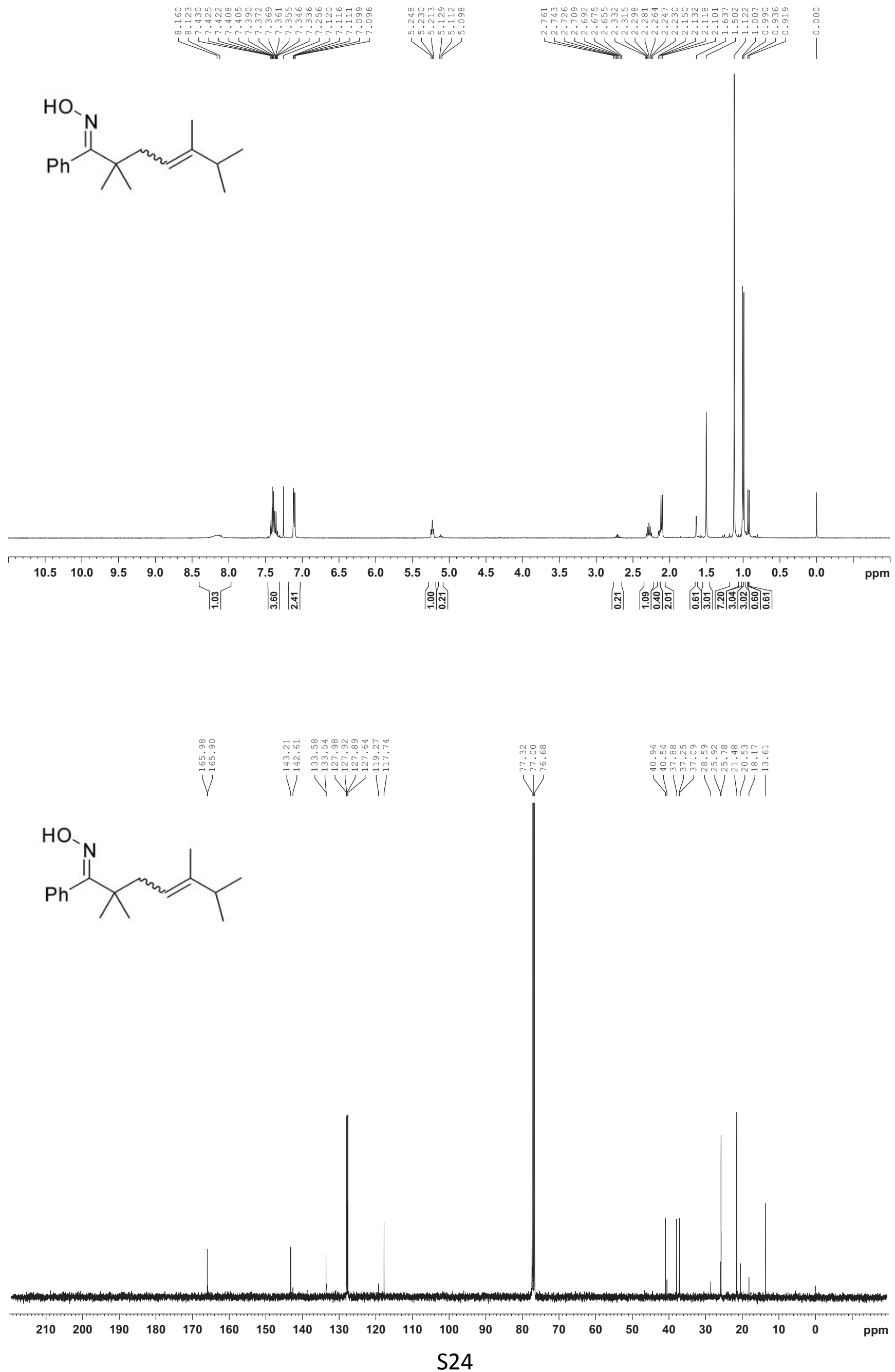


compound (1u)
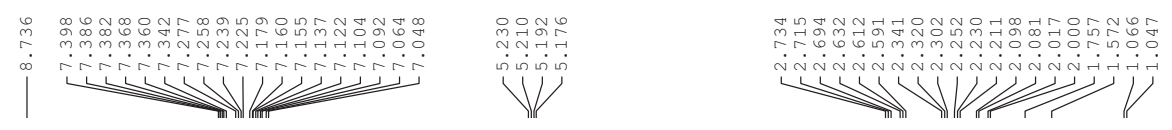

Po
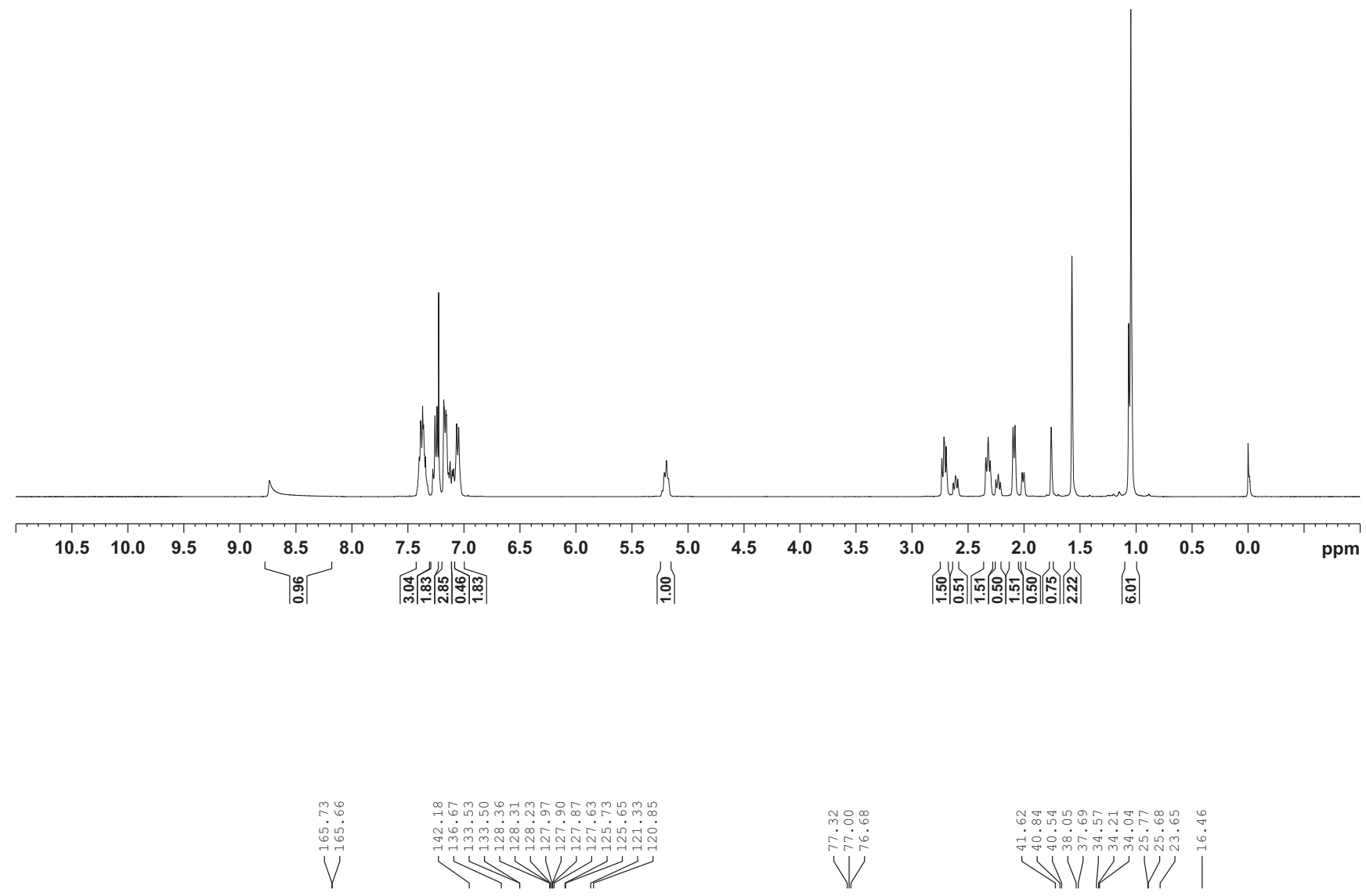



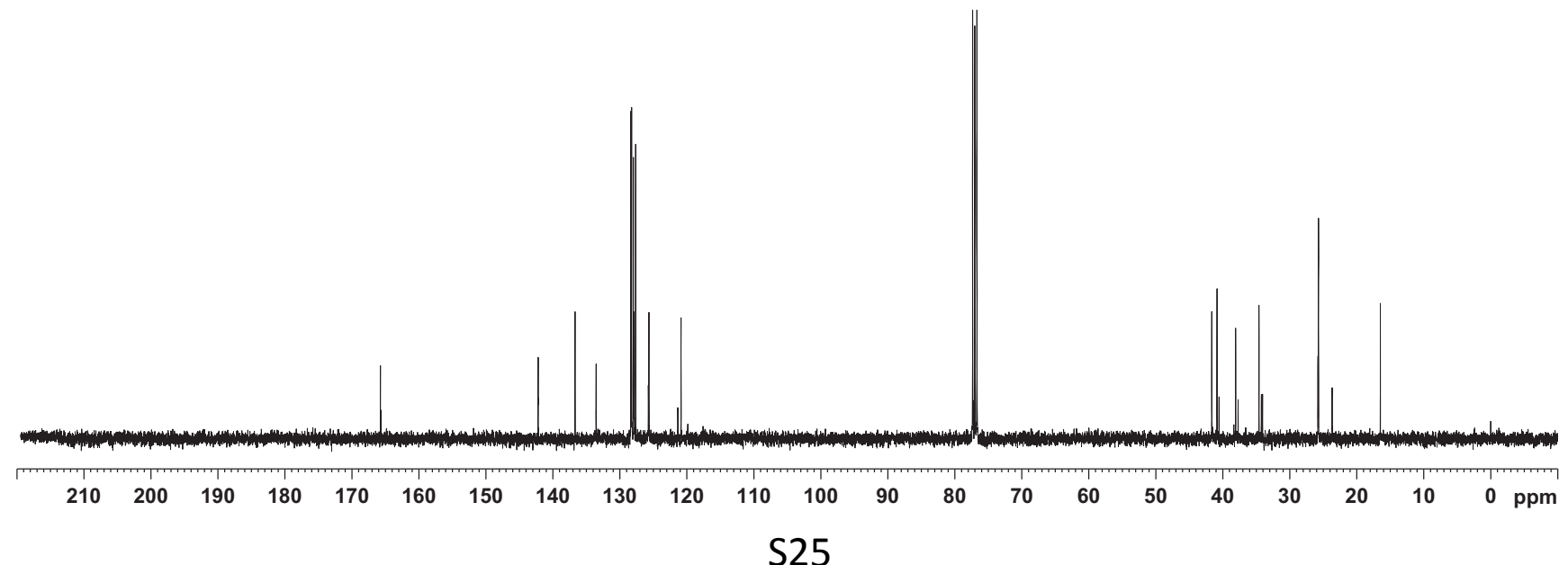



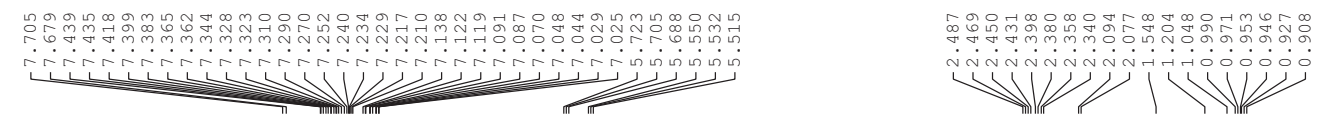



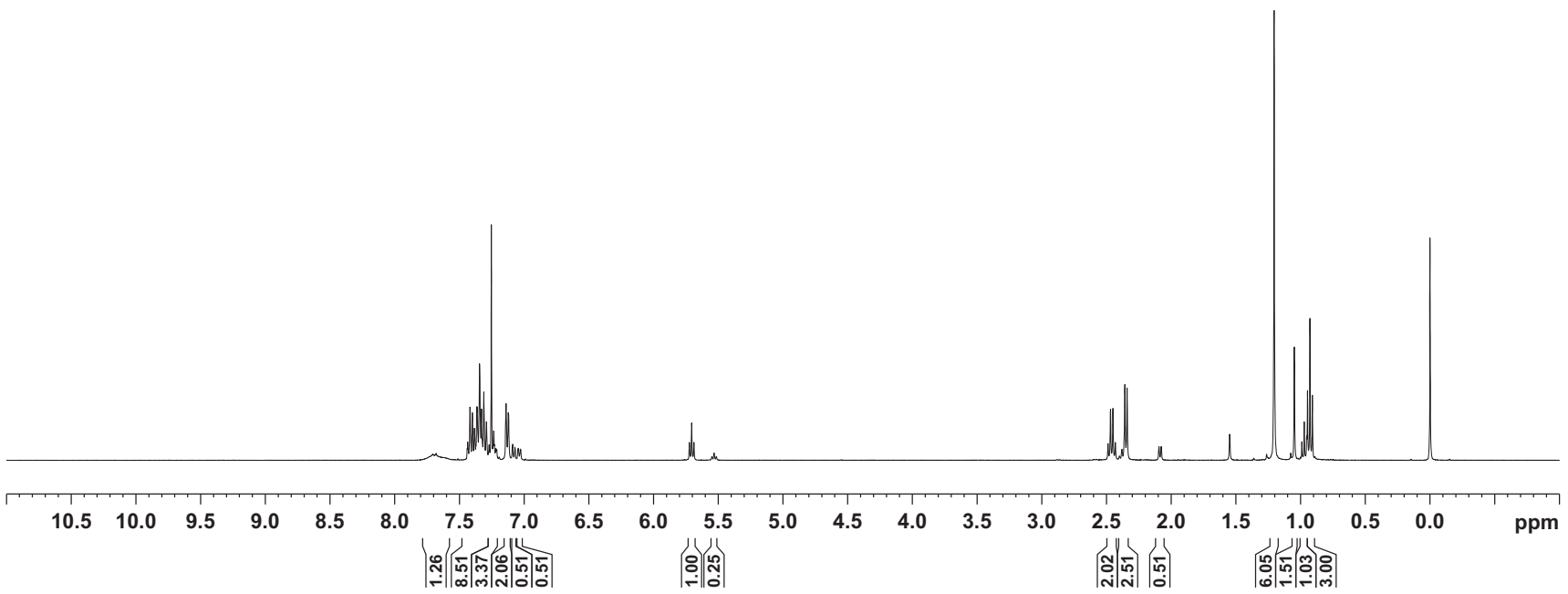

(l)

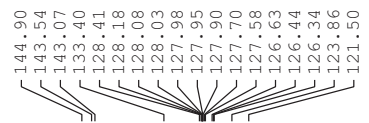<smiles>CC/C(=C\CC(C)(C)/C(=N/O)c1ccccc1)c1ccccc1</smiles> 
compound (1w)

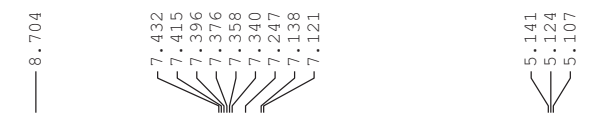

$\left.\right|^{\infty}$<smiles>CC(C)(CC=C1CCCCC1)C(=NO)c1ccccc1</smiles>
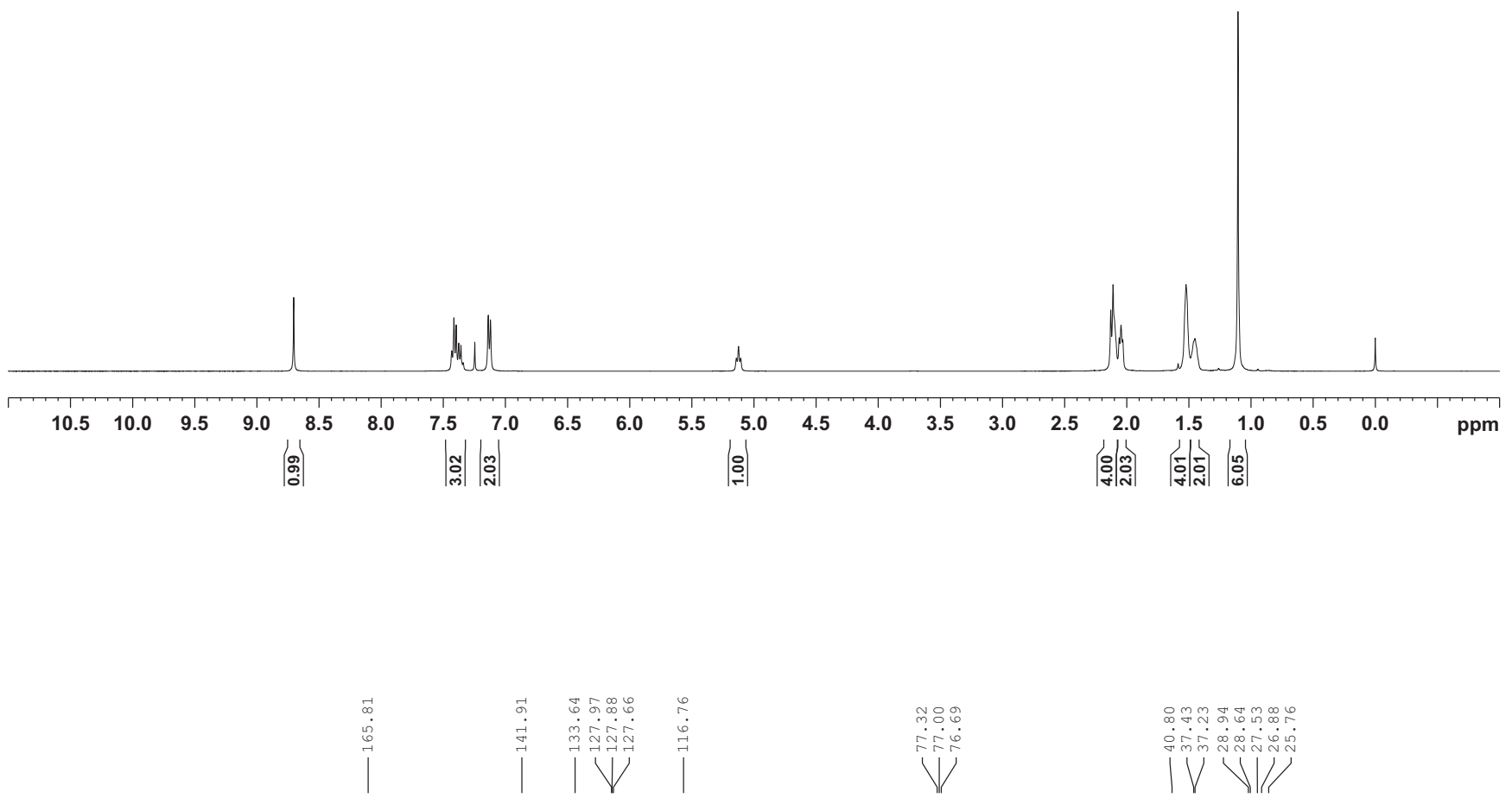

HO-

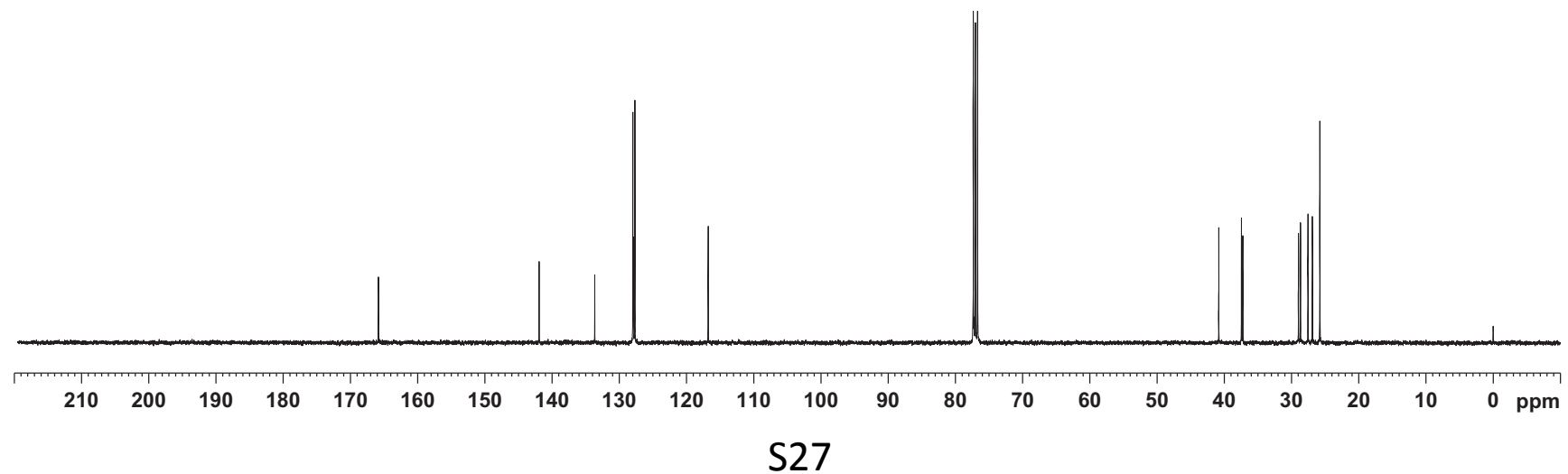


$\mathrm{HO}$<smiles>CC(C)(C/C=C(\c1ccccc1)C1CCCCC1)C(=NO)c1ccccc1</smiles>

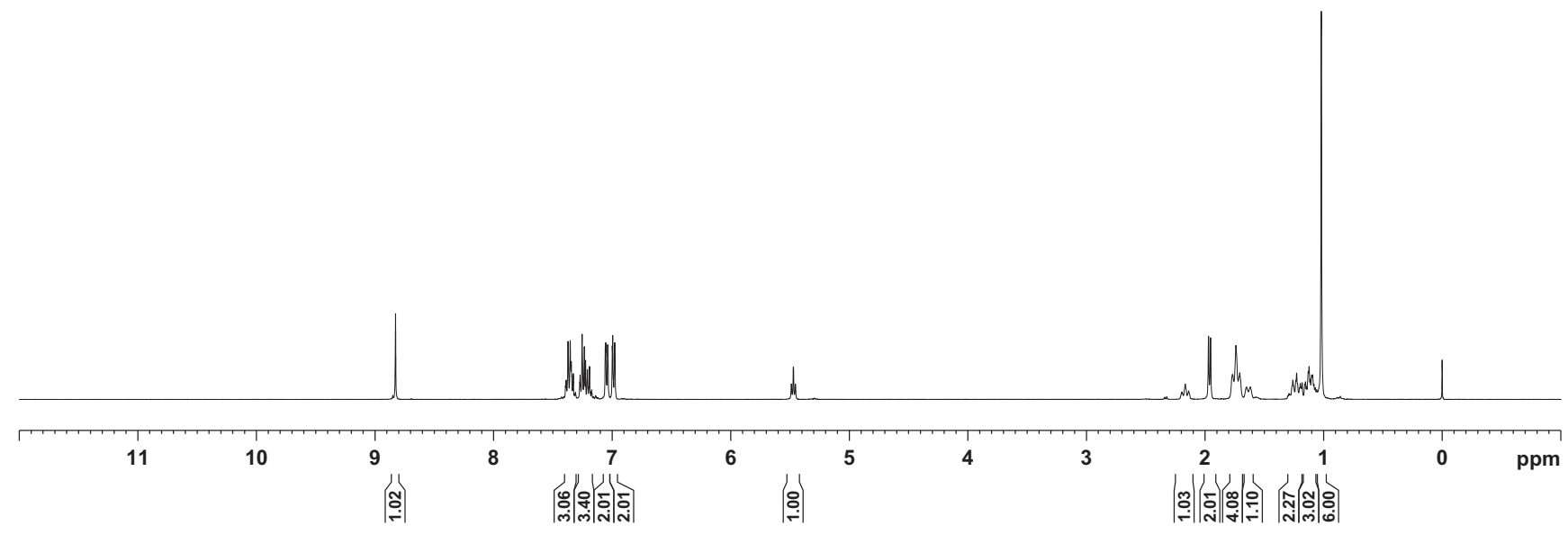

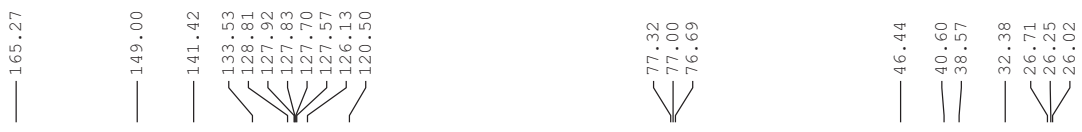<smiles>CC(C)(C/C=C(\c1ccccc1)C1CCCCC1)/C(=N/O)c1ccccc1</smiles>

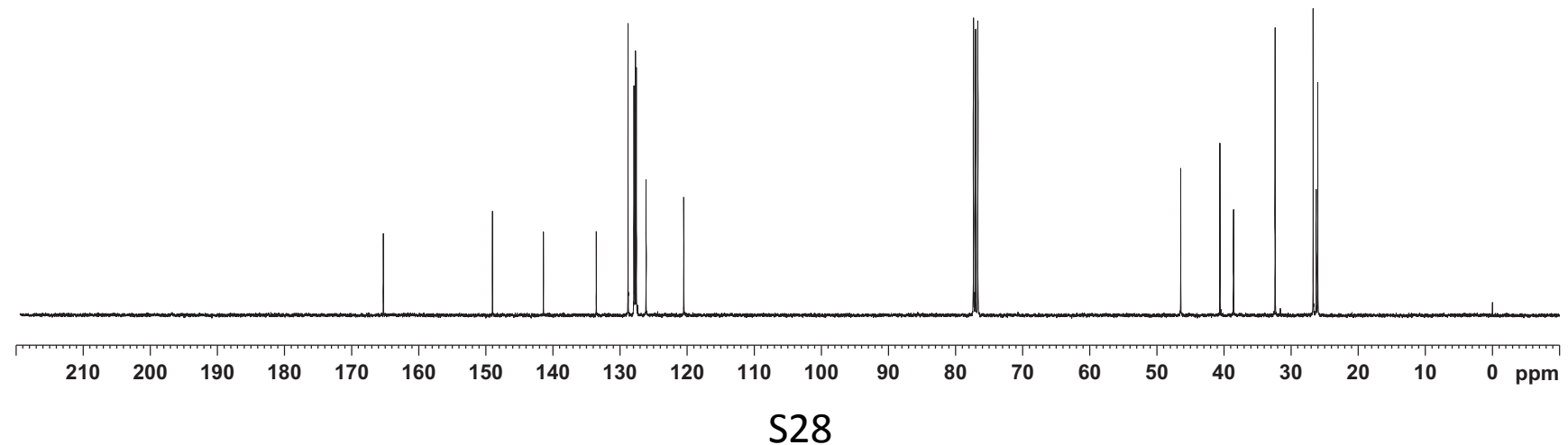


compound (2a)

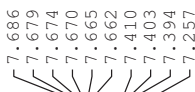

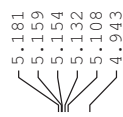

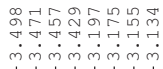

W V<smiles>C=C(C)C1CC(c2ccccc2)=NO1</smiles>

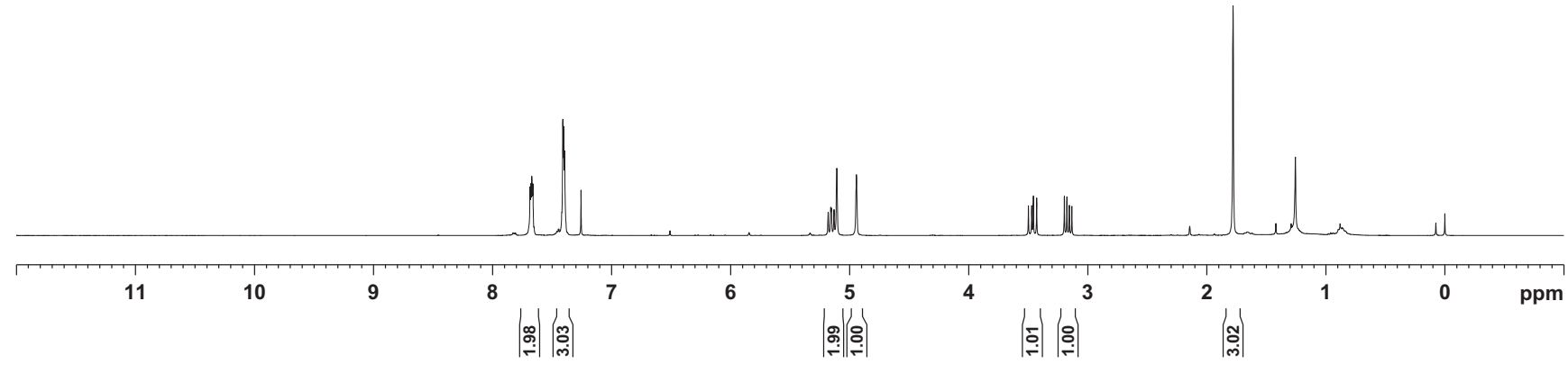<smiles>C=C(C)C1CC(c2ccccc2)=NO1</smiles>

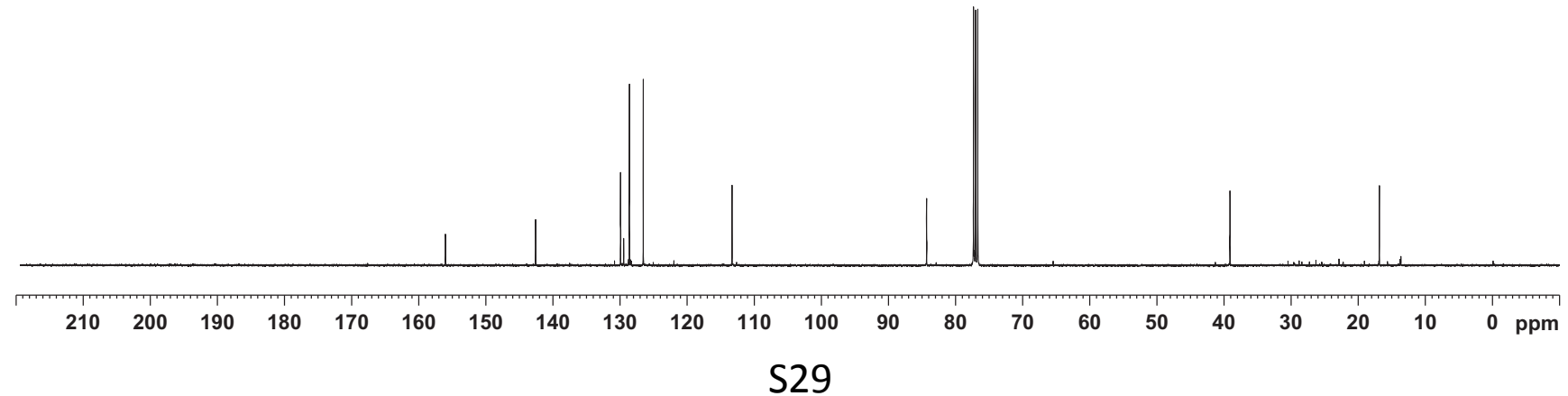


compound (2b)<smiles>C=C(C)C1CC(C2CC([CH2-])C2)=NO1</smiles>

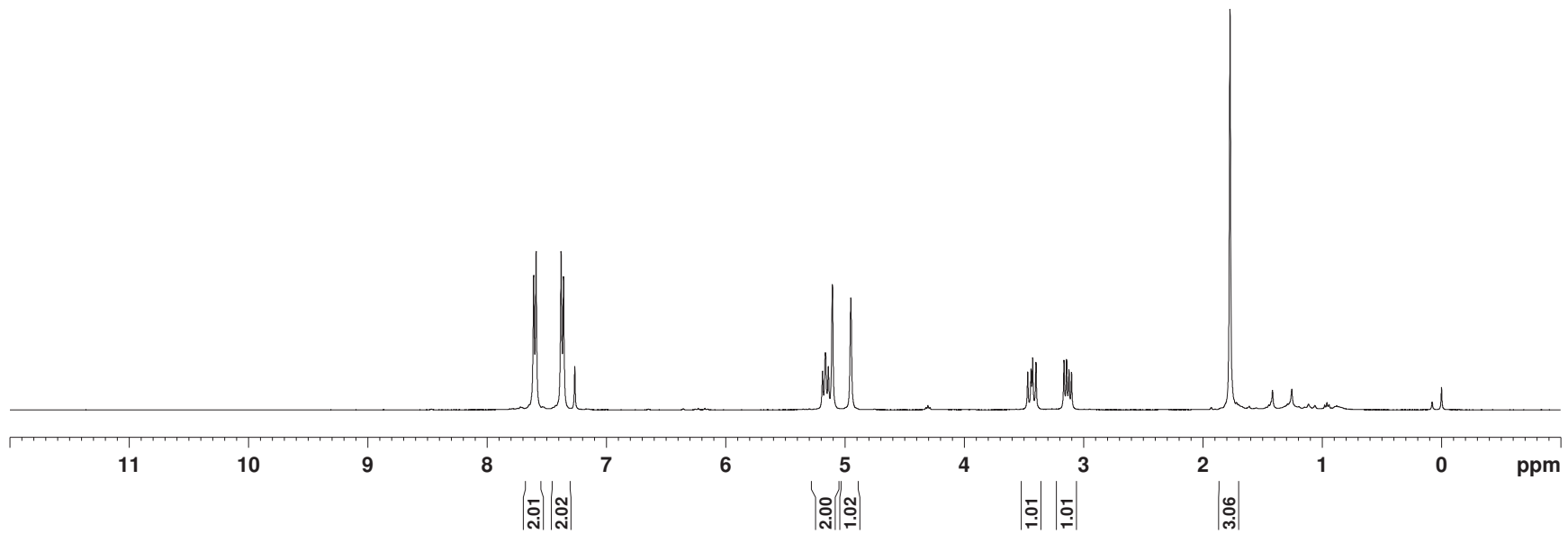<smiles>C=C(C)C1CC(C(C)C)=NO1</smiles>

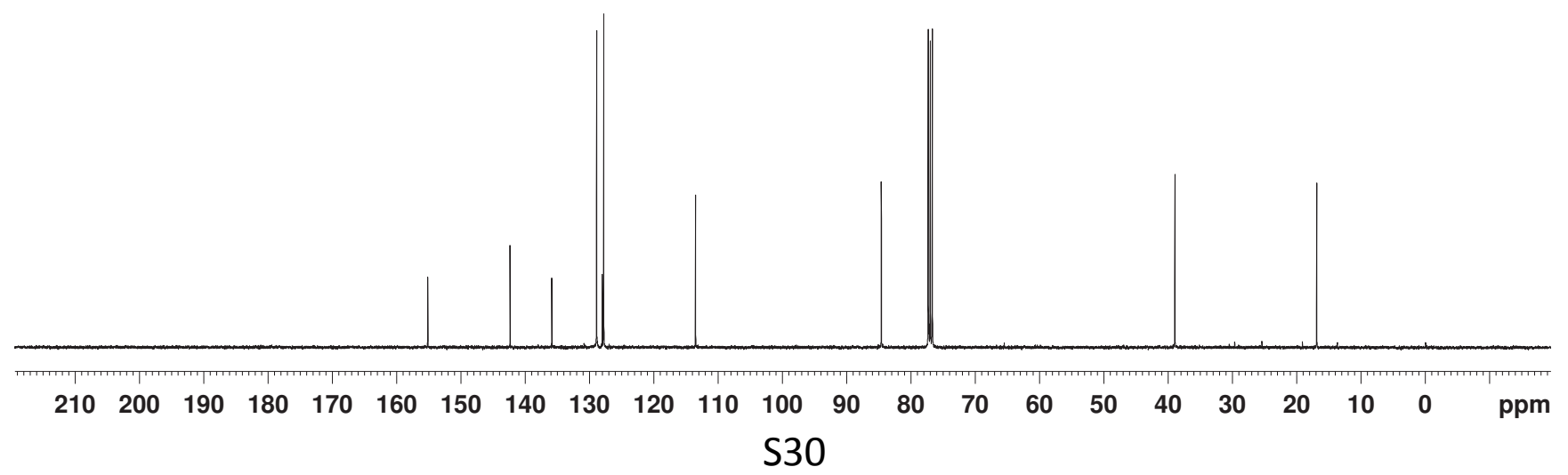


compound (2c)

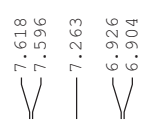

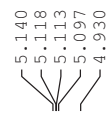

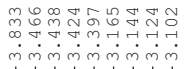

نं

4-OMePh

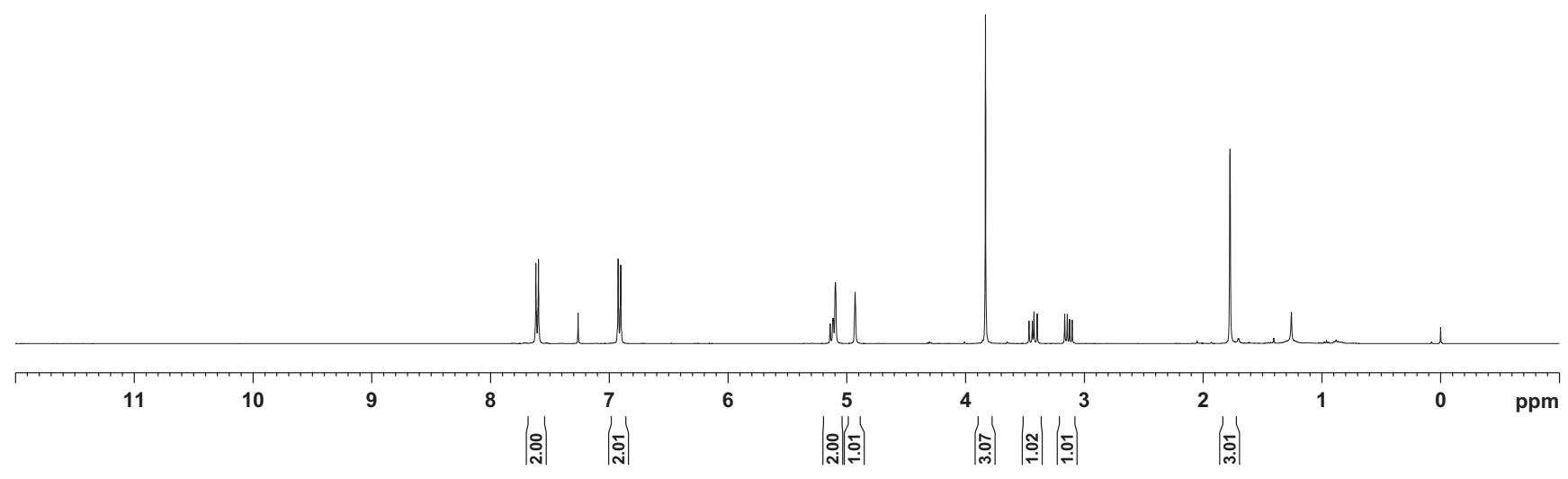

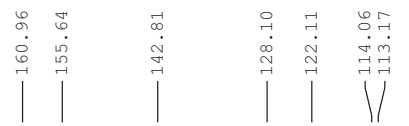
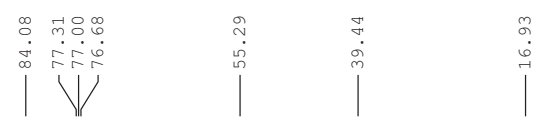

4-OMePh

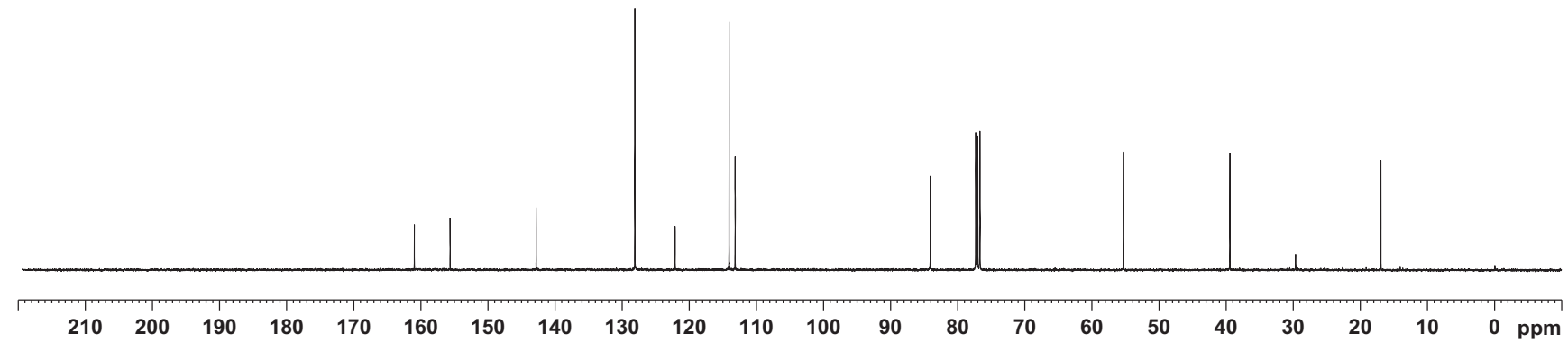


compound $(2 d)$

VV

4-MePh
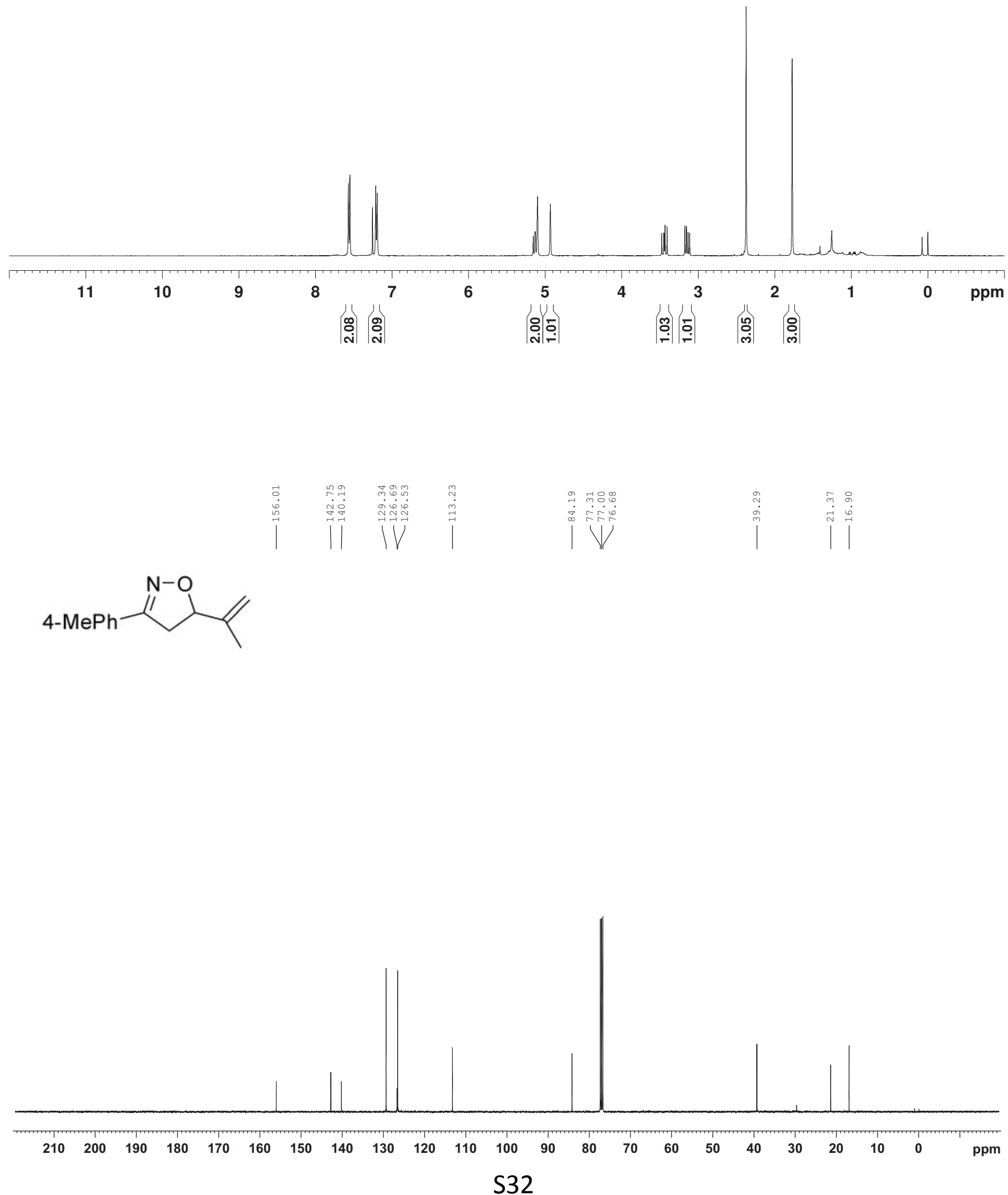
compound (2e)
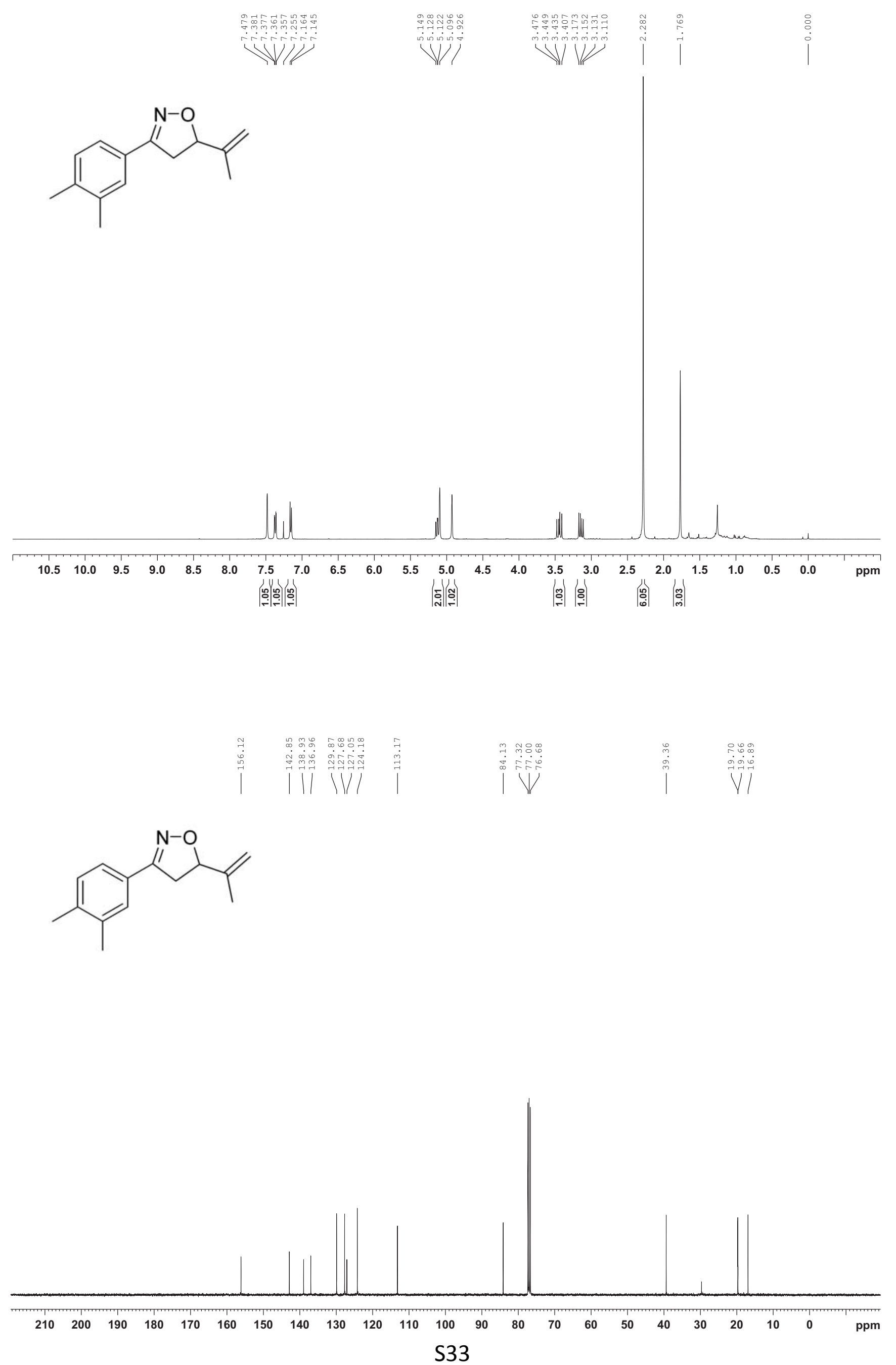
Compound (2f)

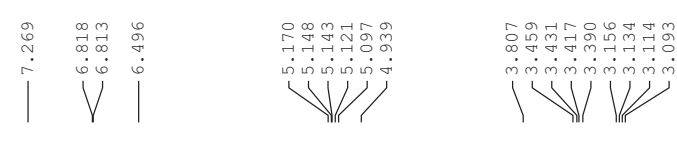

(c)
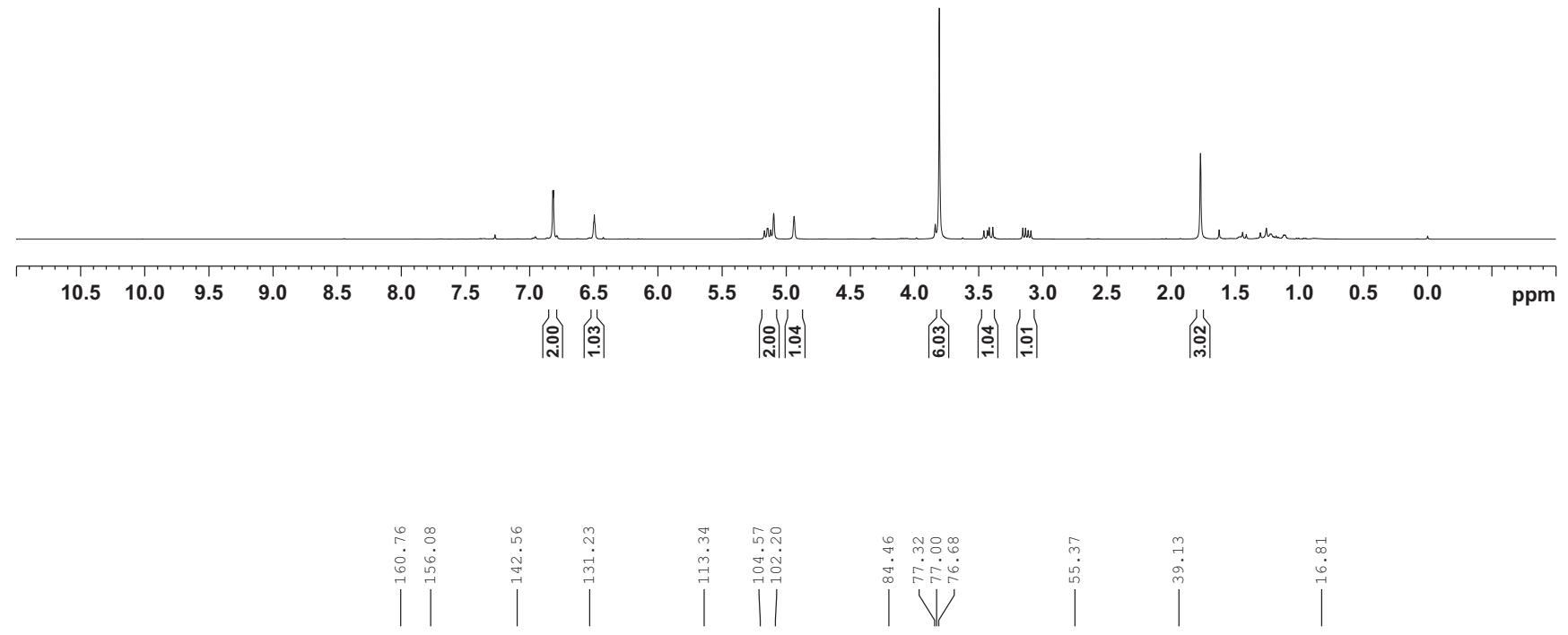<smiles>C=C(C)C1CC(c2cc(OC)cc(OC)c2)=NO1</smiles>

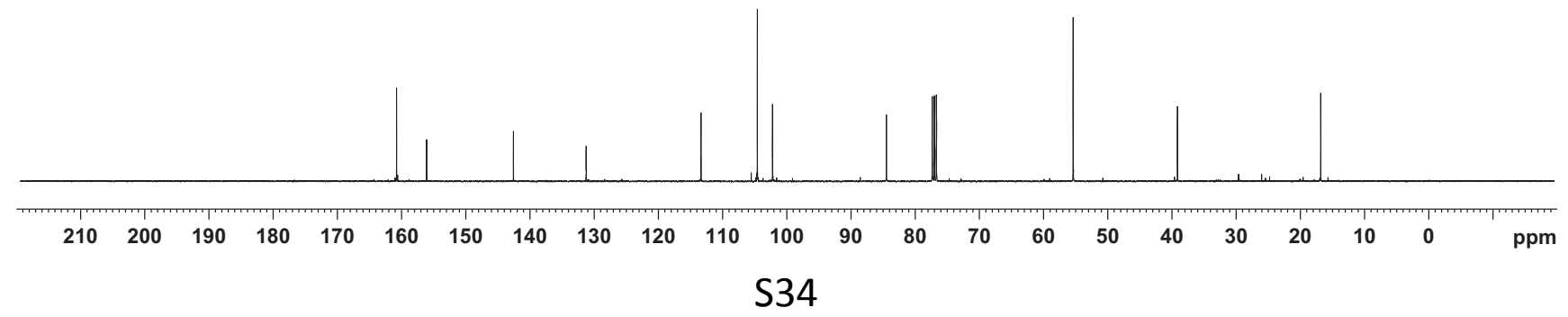


compound (3g)

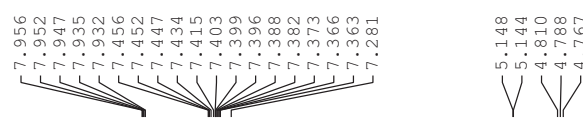<smiles>C=C(C)C1CC(C)(C)C(c2ccccc2)=[N+]1[O-]</smiles>

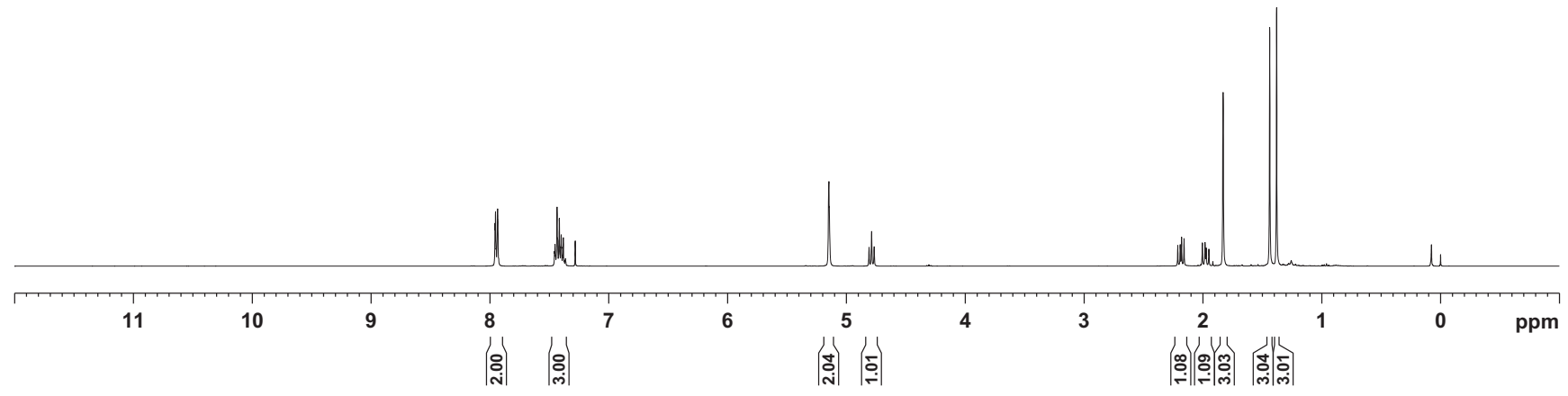<smiles>C=C(C)C1CC(C)(C)C(c2ccccc2)=[N+]1[O-]</smiles>

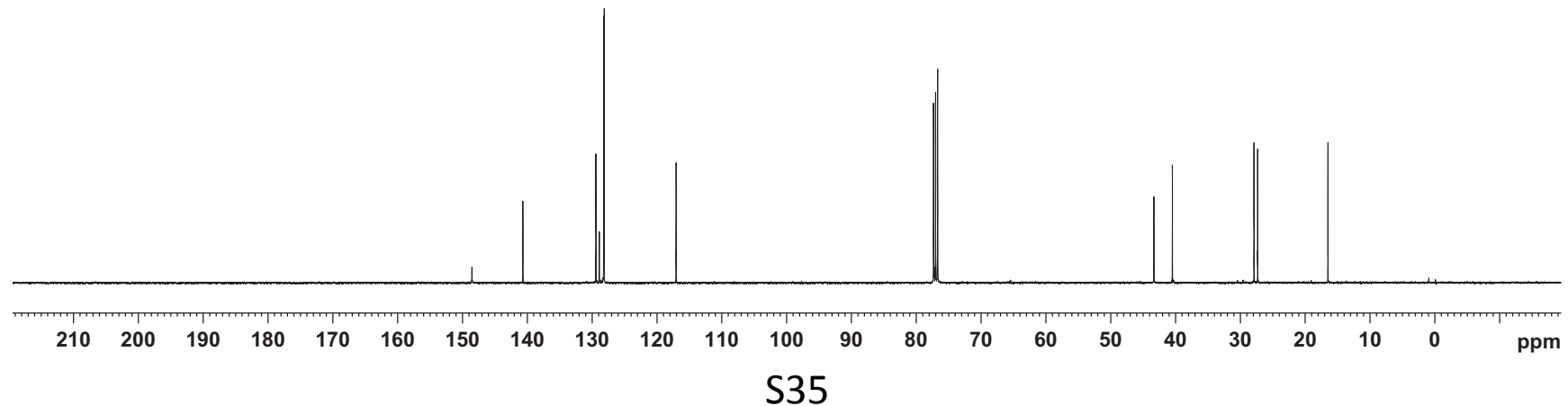


compound (3h)
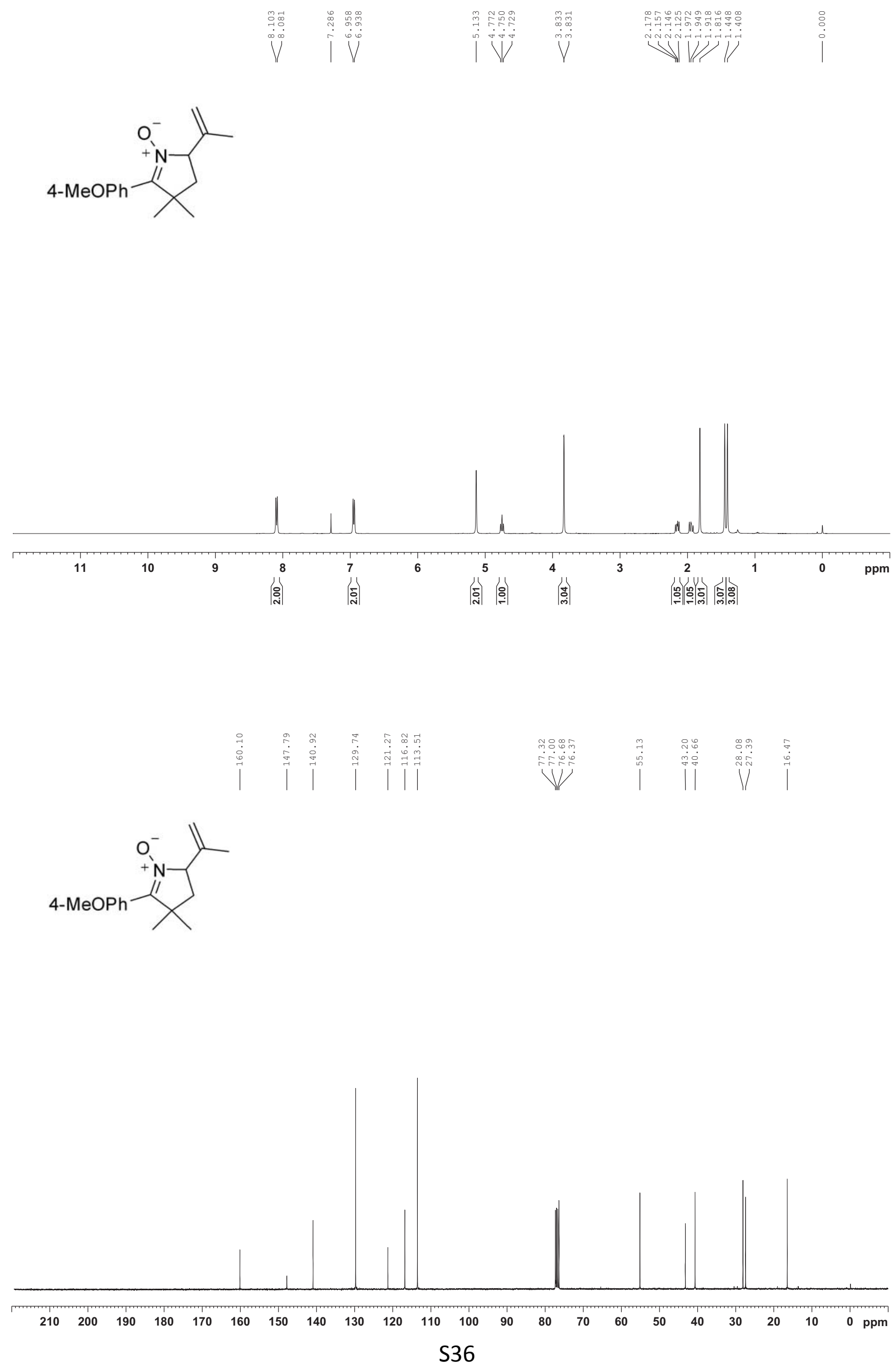
compound (3i)

觜等

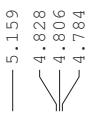

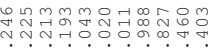
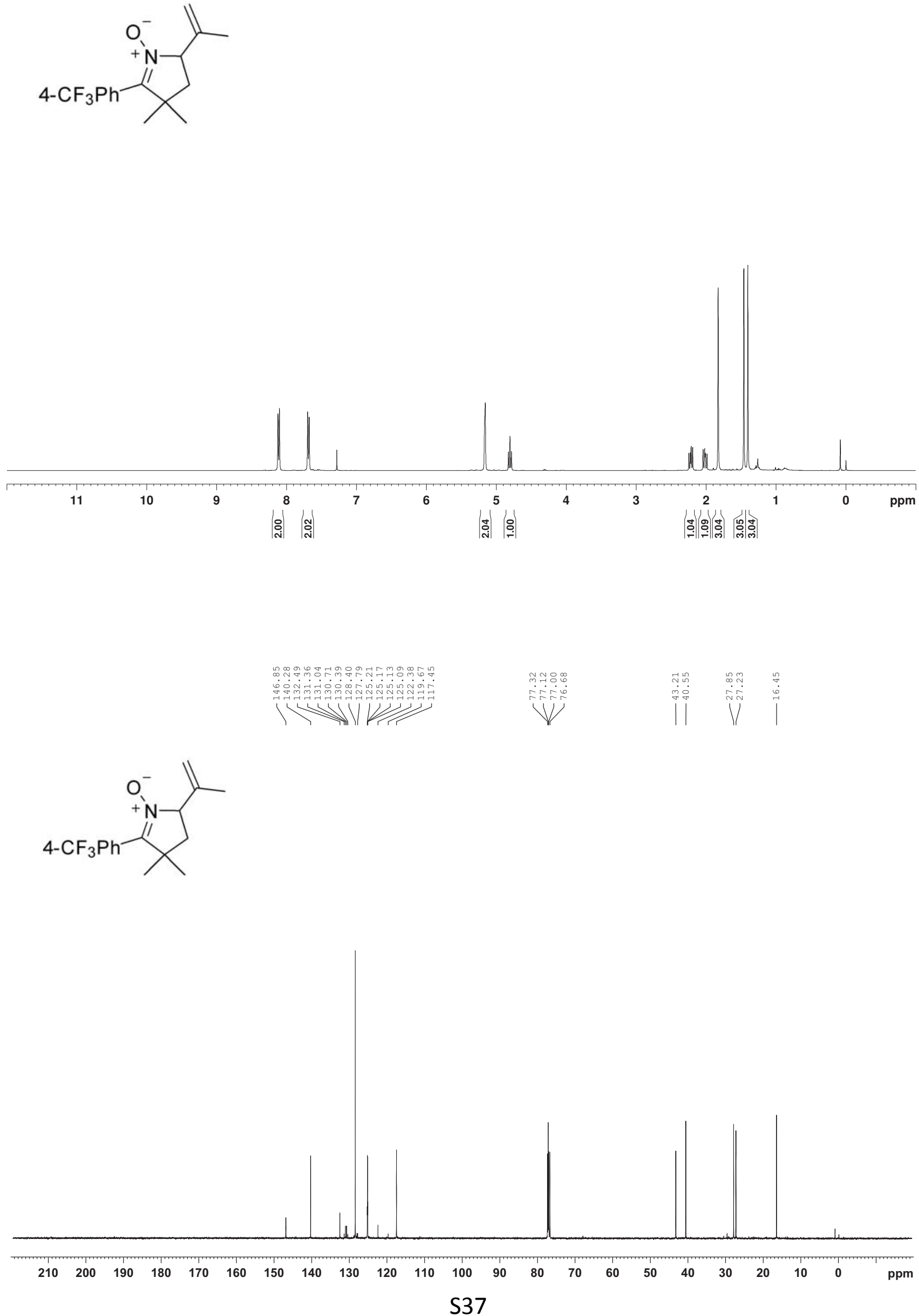
compound (3j)<smiles>C=C(C)C1CC2(CCCC2)C(c2ccccc2)=[N+]1[O-]</smiles>

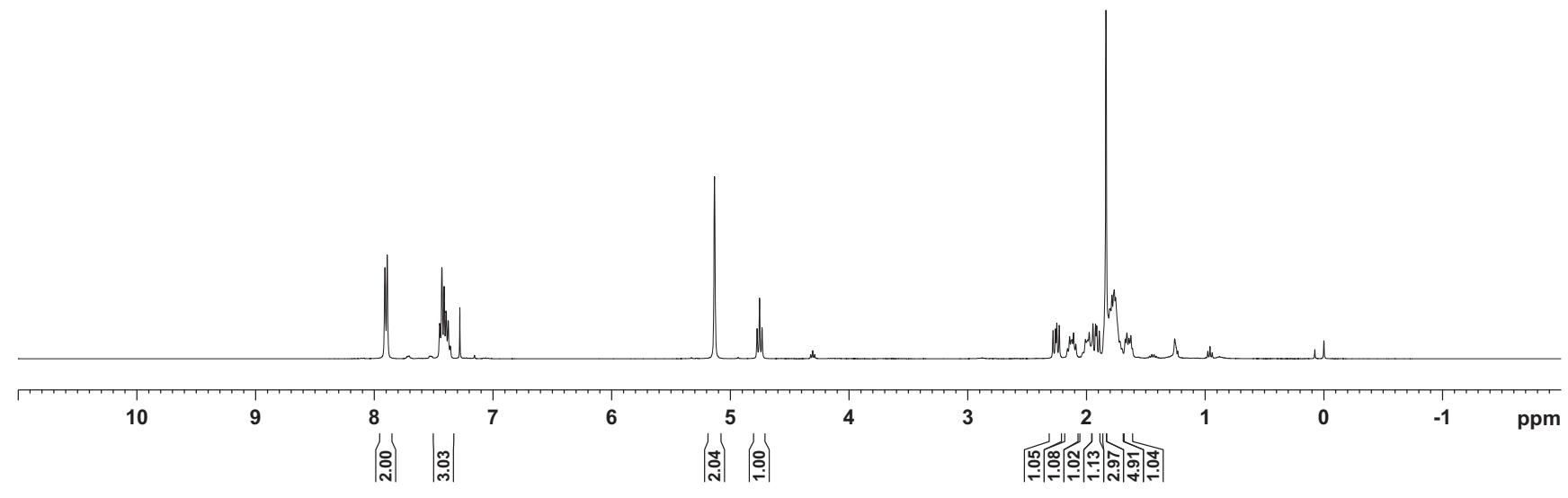<smiles>C=C(C)C1CC2(CCCC2)C(c2ccccc2)=[N+]1[O-]</smiles>

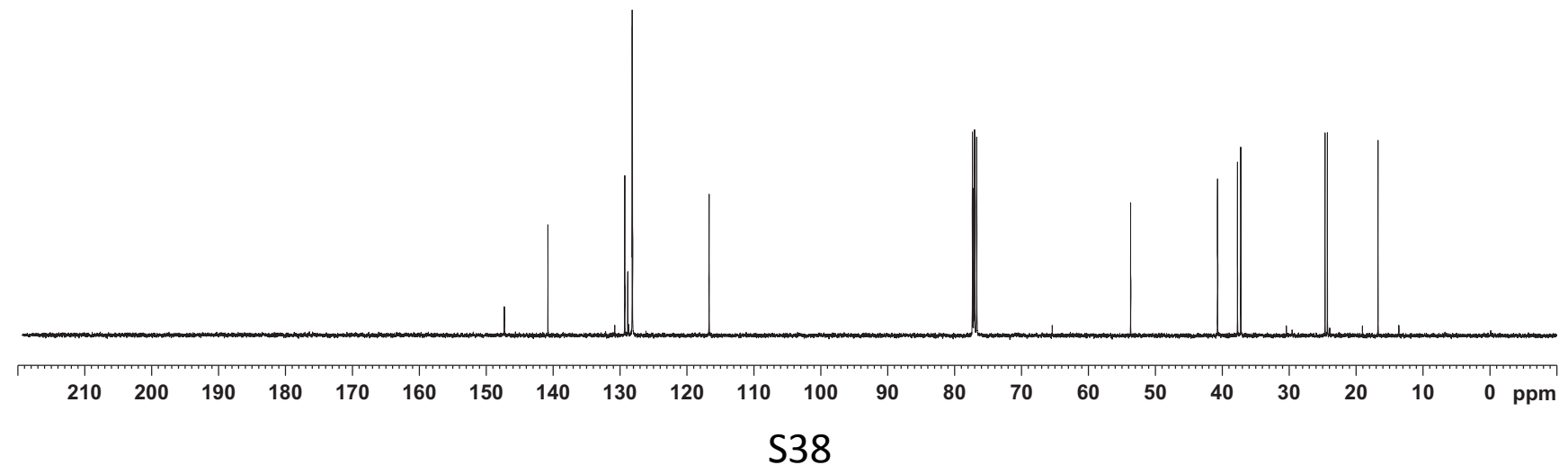


compound (3k)
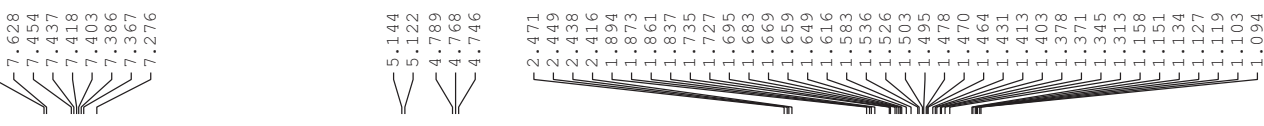<smiles>C=C(C)C1CC2(CCCCC2)C(c2ccccc2)=[N+]1[O-]</smiles>
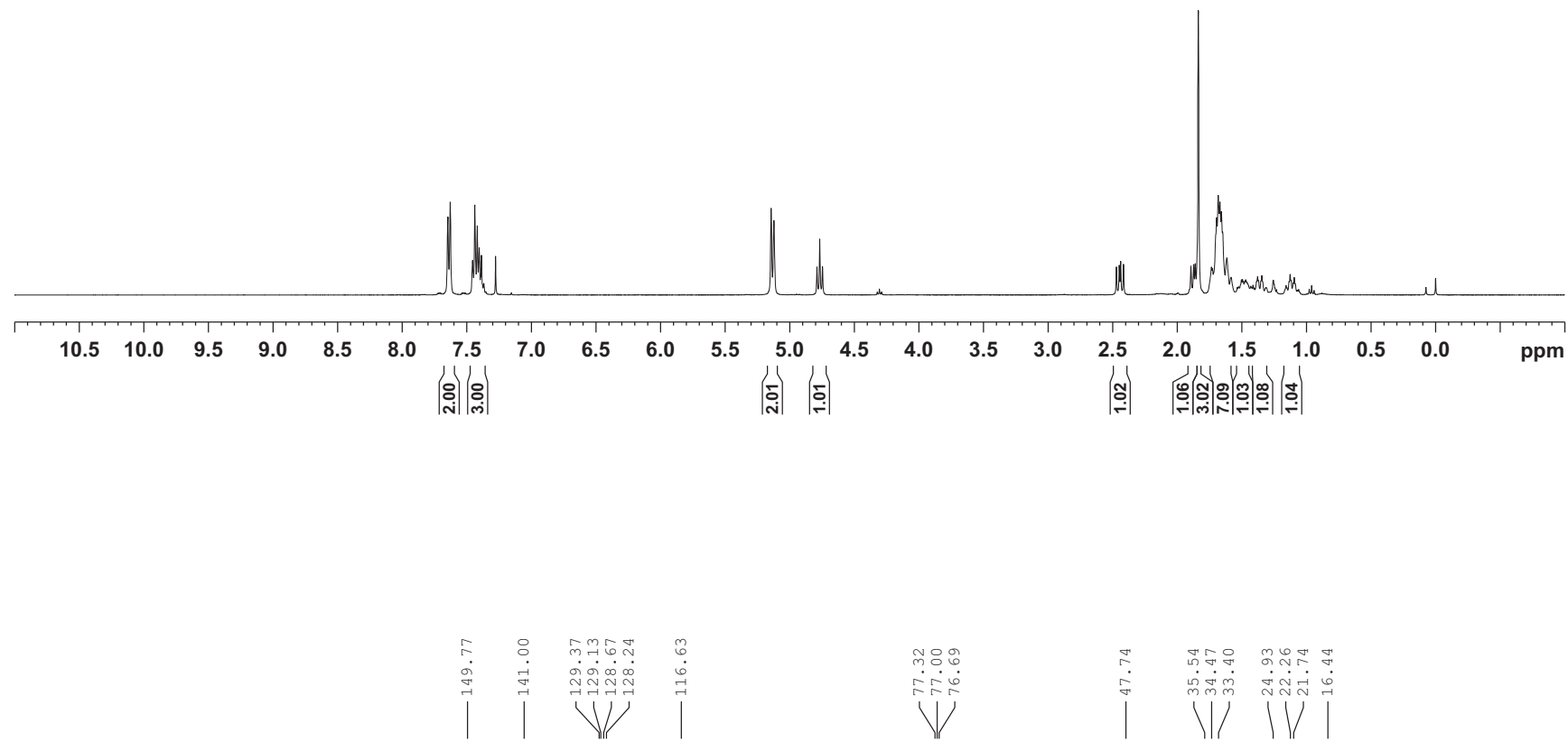<smiles>C=C(C)C1CC2(CCCCC2)C(c2ccccc2)=[N+]1[O-]</smiles>

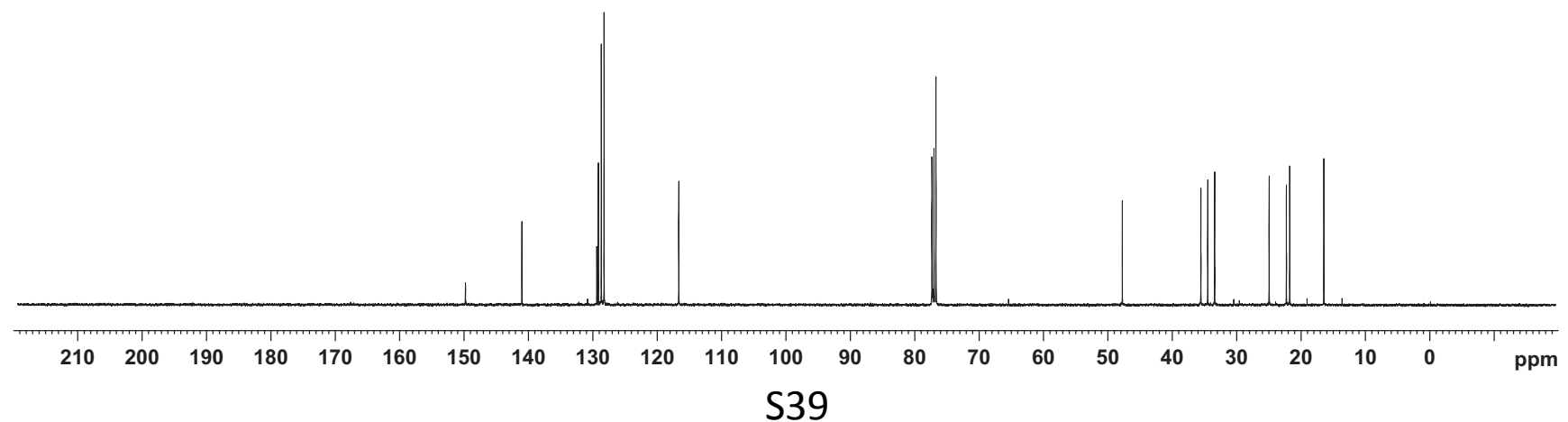


compound (3I)
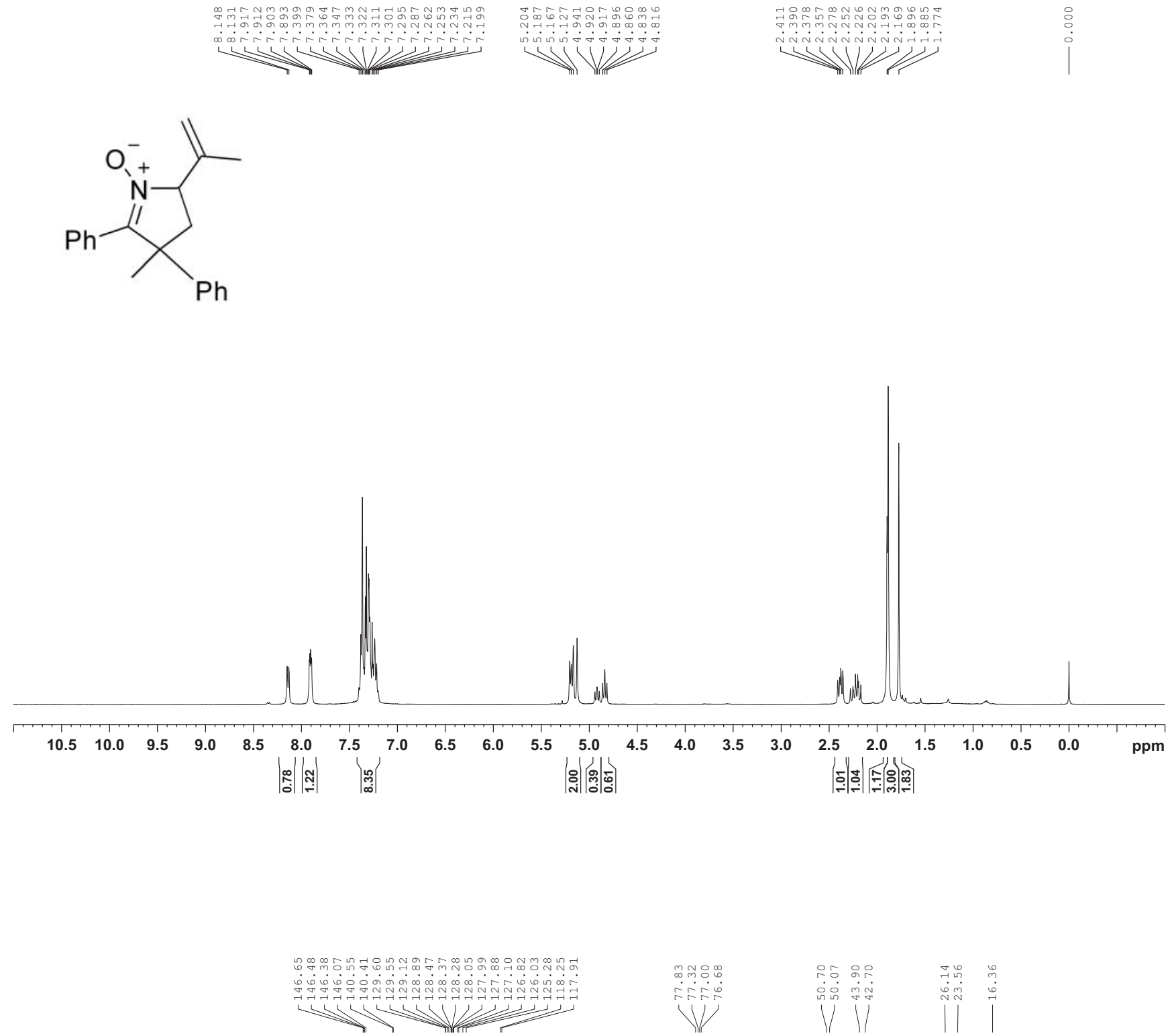<smiles>C=C(C)C1CC(C)(c2ccccc2)C(c2ccccc2)=[N+]1[O-]</smiles>

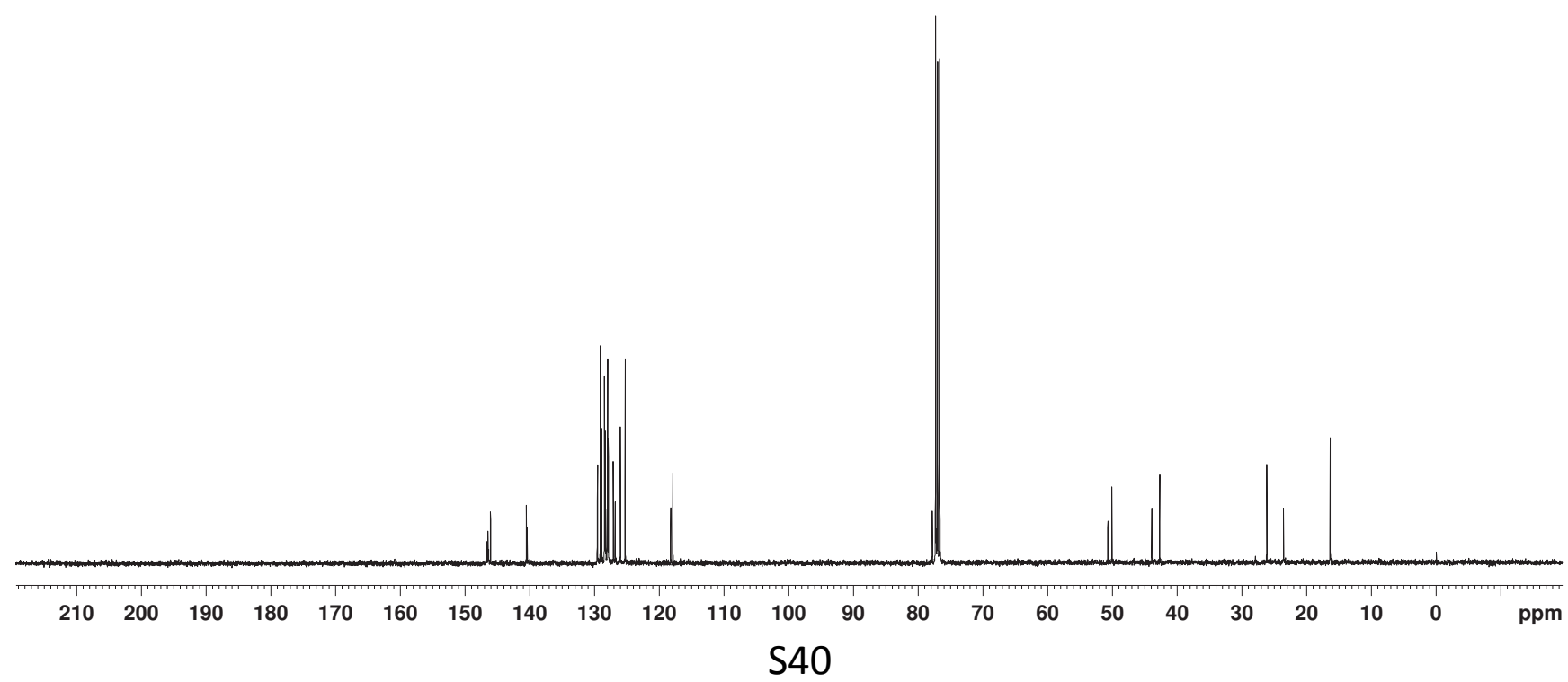


compound (3m)<smiles>C=C(C)C1CCC(c2ccccc2)=[N+]1[O-]</smiles>

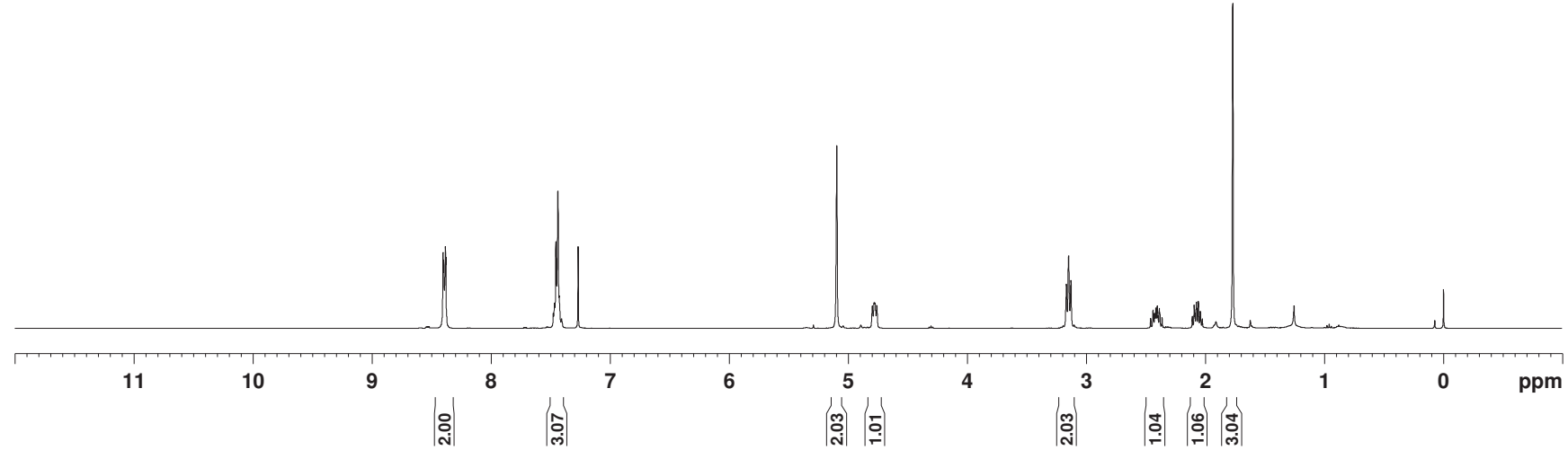<smiles>C=C(C)C1CCC(c2ccccc2)=[N+]1[O-]</smiles>

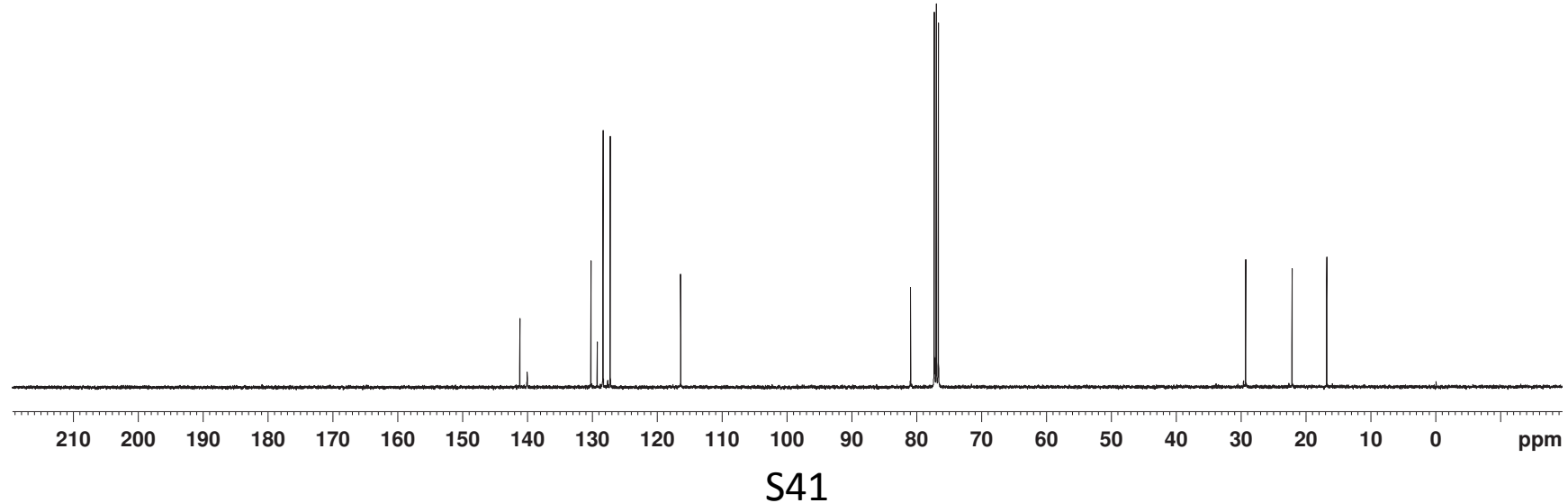


compound (3n)

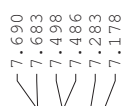

Vy

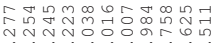

YUN<smiles>C=C(C)C1CC(C)(C)C(c2cccs2)=[N+]1[O-]</smiles>

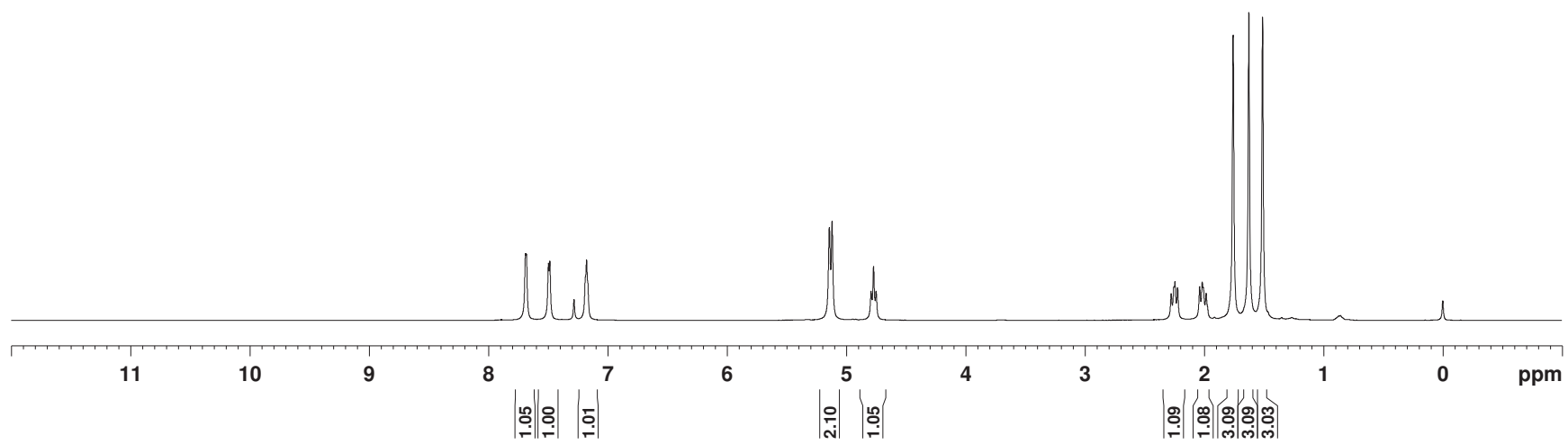<smiles>C=C(C)C1CC(C)(C)C(c2cccs2)=[N+]1[O-]</smiles>

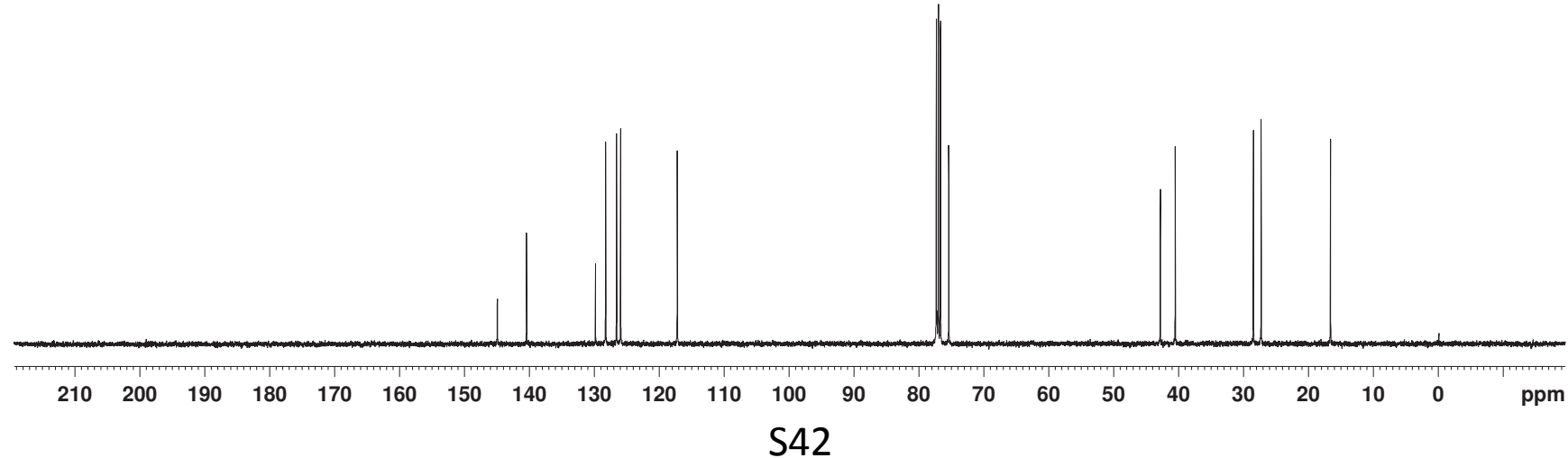




\section{compound (3o)}

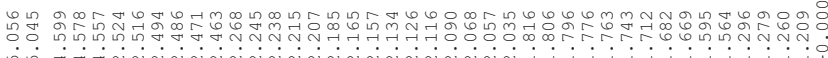

$\ln _{1}$<smiles>C=C(C)C1CC(C)(C)C(C2CCCCC2)=[N+]1[O-]</smiles>

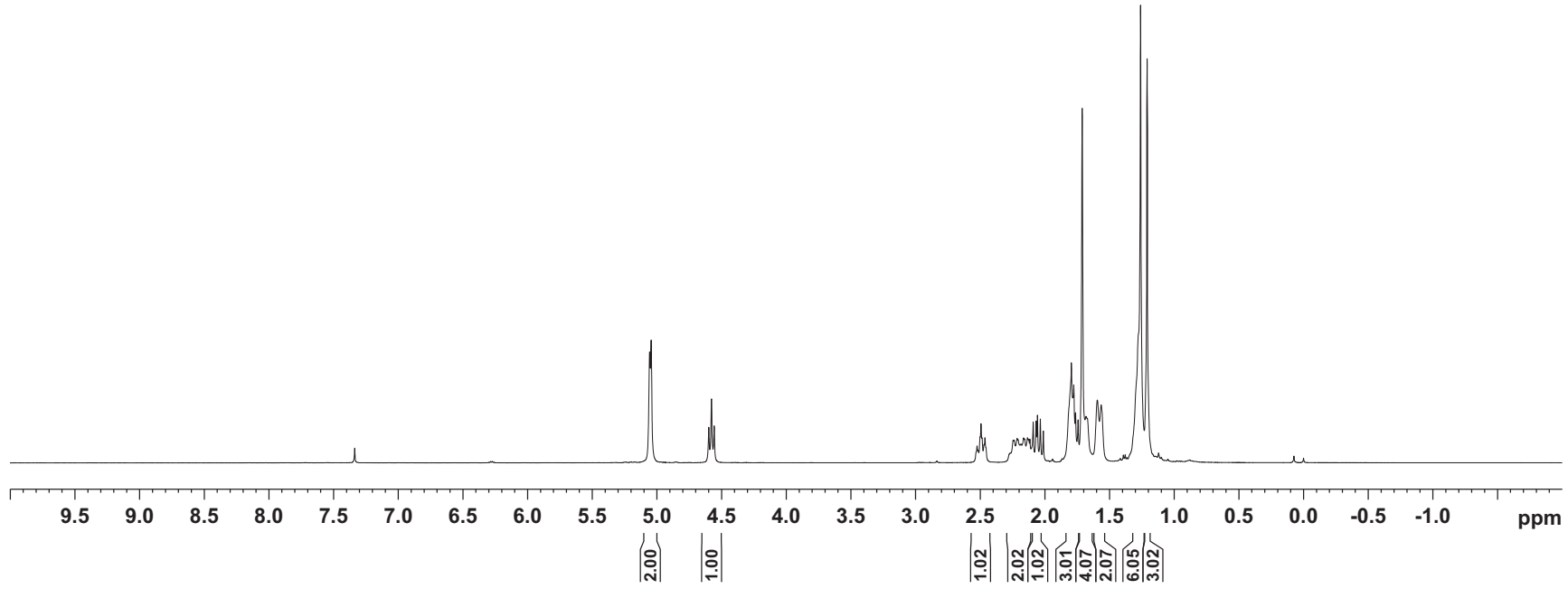<smiles>C=C(C)C1CC(C)(C)C(C2CCCCC2)=[N+]1[O-]</smiles>

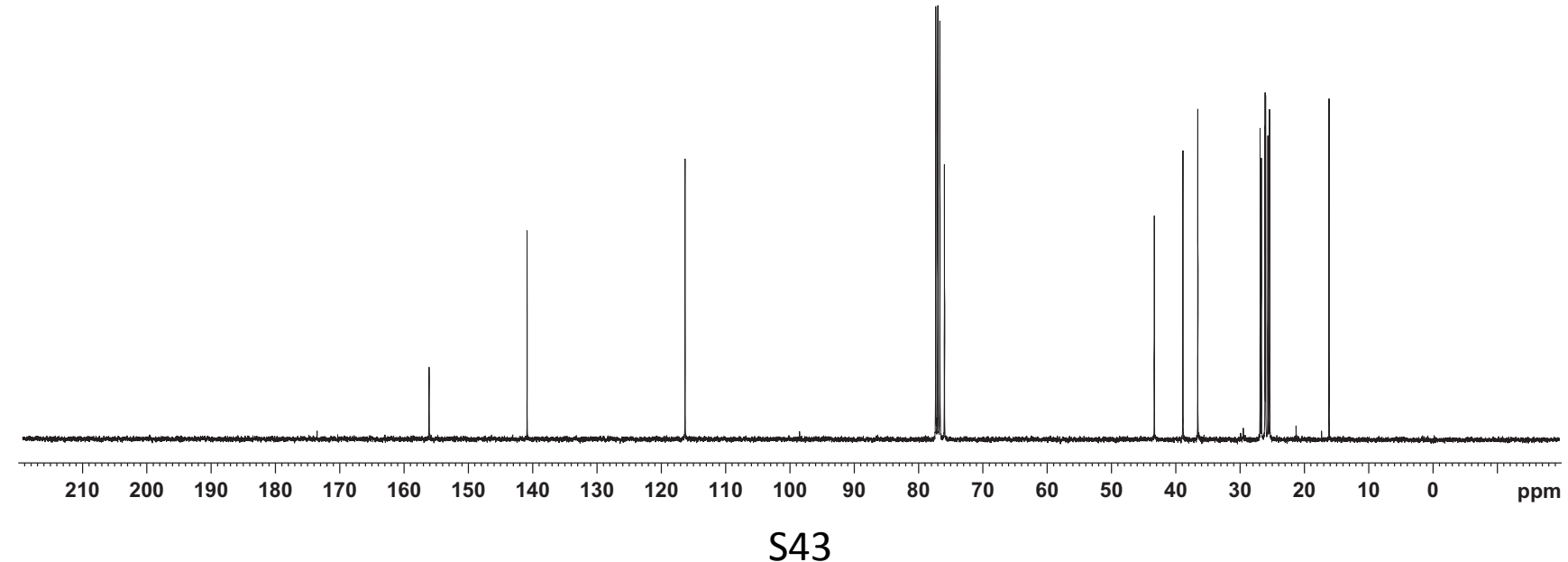


compound (3p)

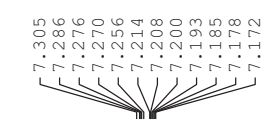

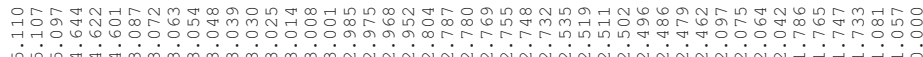<smiles>C=C(C)C1CC(C)(C)C(CCc2ccccc2)=[N+]1[O-]</smiles>
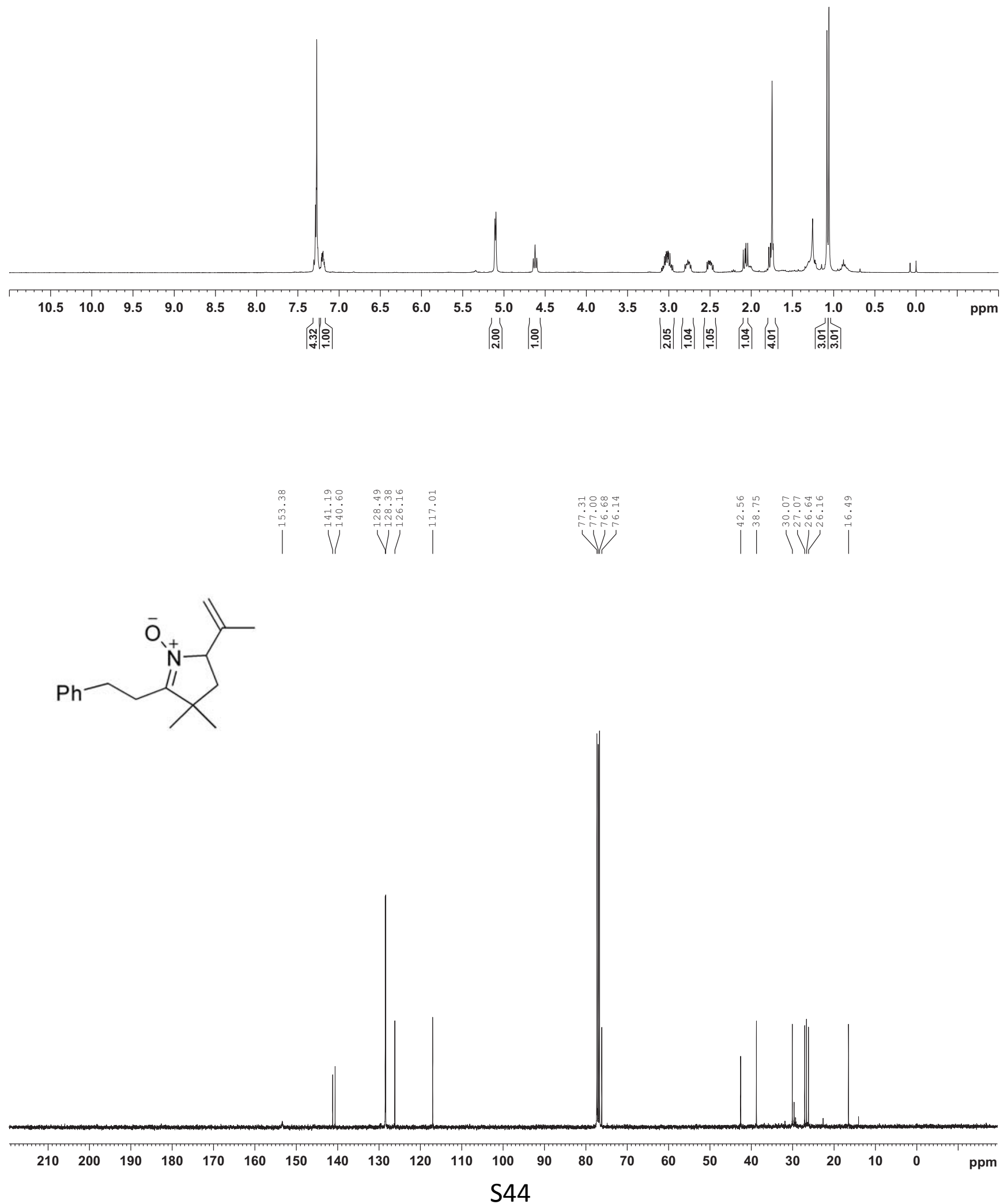
compound (4p)

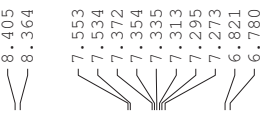<smiles>C=C(C)C1CC(C)(C)C(/C=C/c2ccccc2)=[N+]1[O-]</smiles>

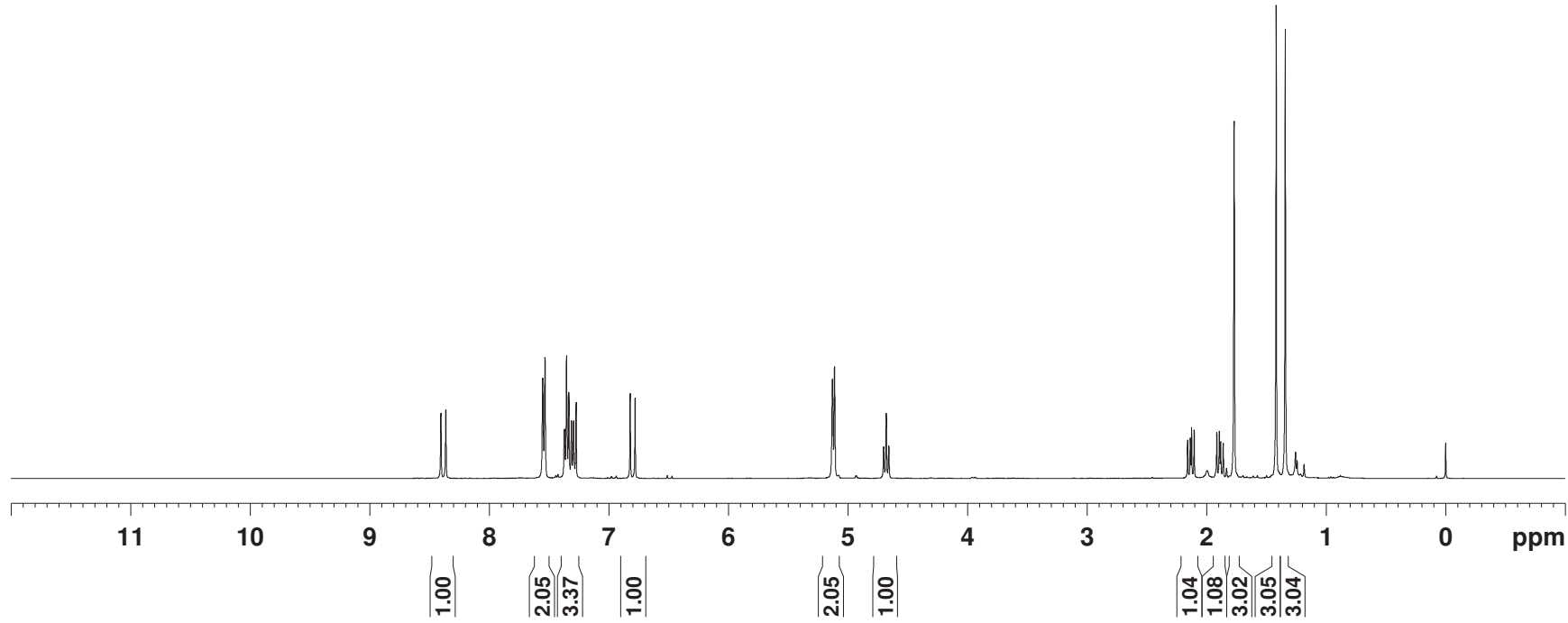<smiles>C=C(C)C1CC(C)(C)C(/C=C/c2ccccc2)=[N+]1[O-]</smiles>

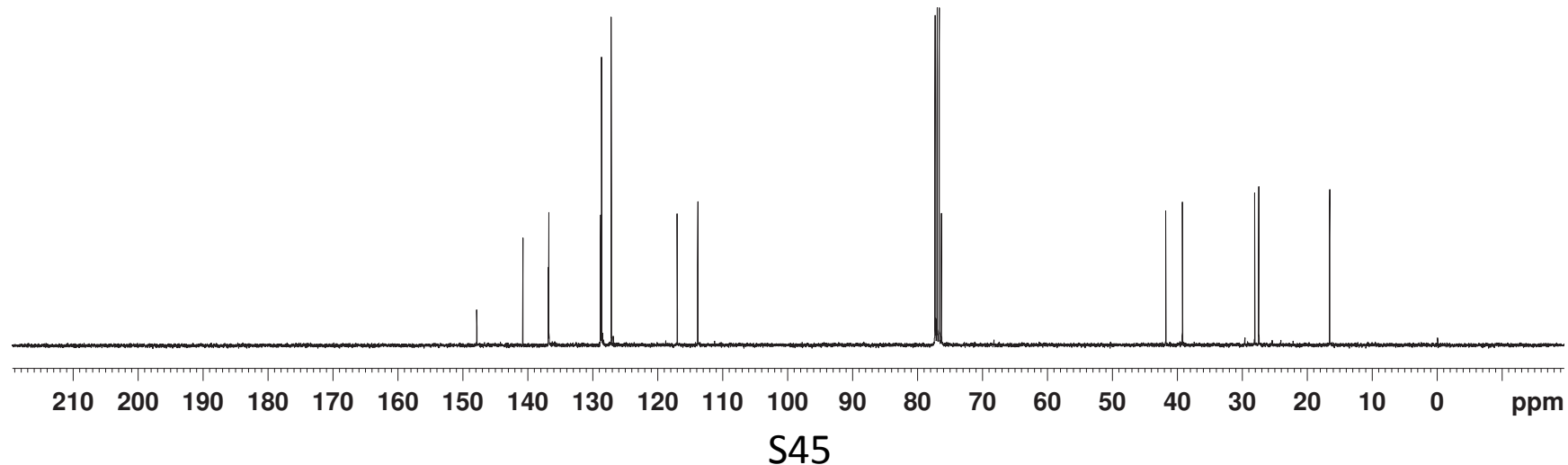


compound (5p)
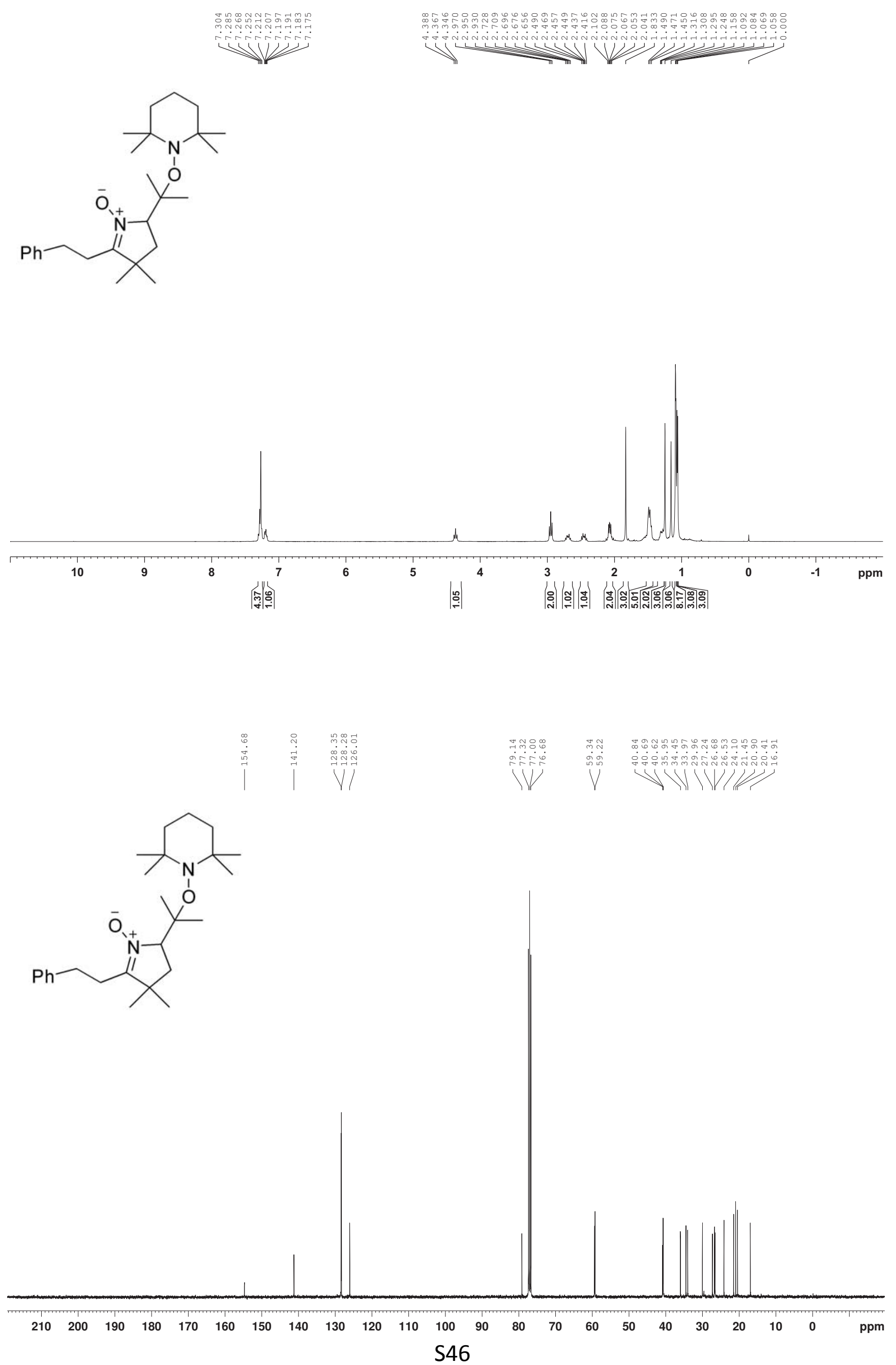
<smiles>C=C(c1ccccc1)C1CC(C)(C)C(c2ccccc2)=[N+]1[O-]</smiles>
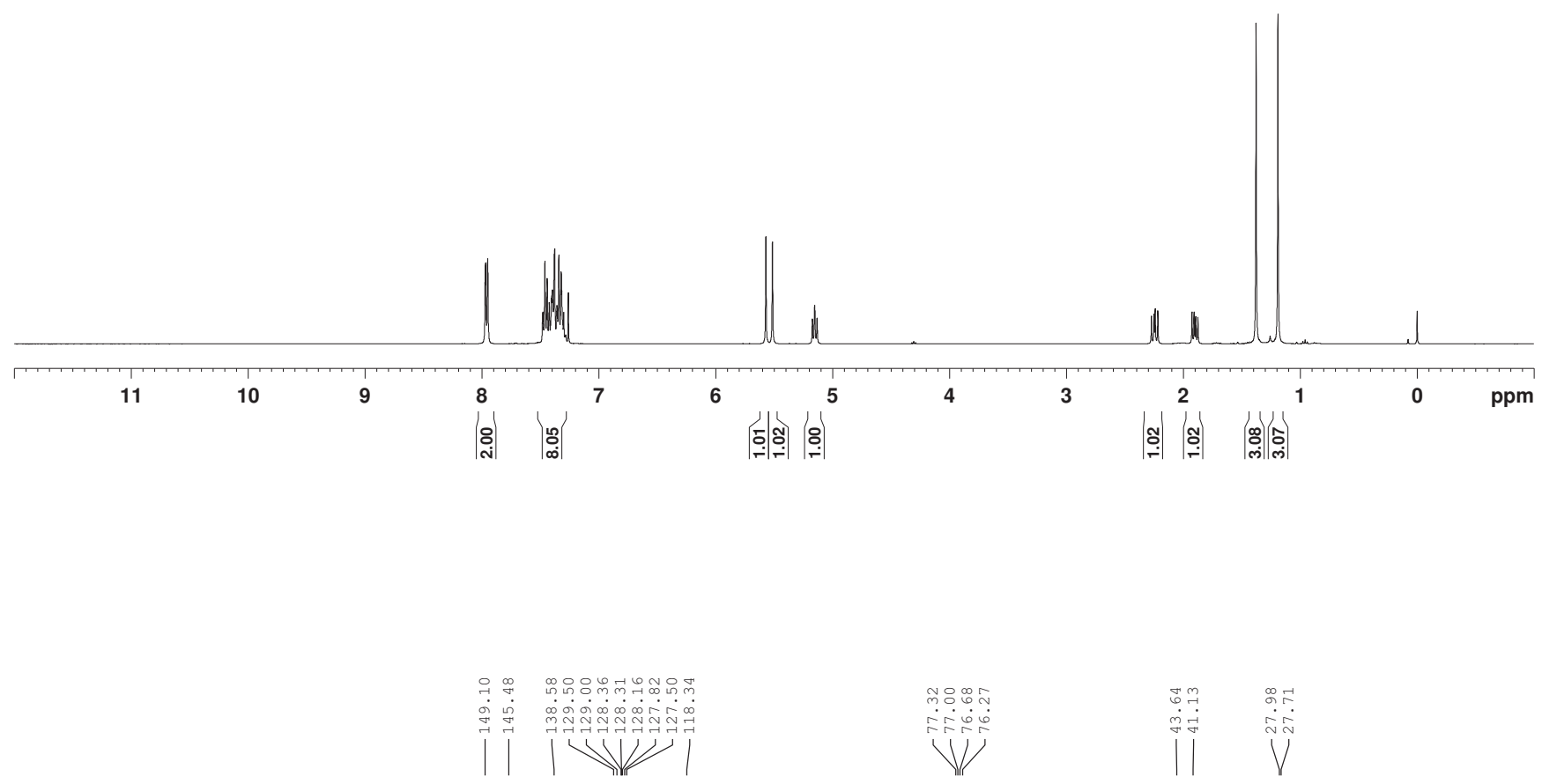<smiles>C=C(c1ccccc1)C1CC(C)(C)C(c2ccccc2)=[N+]1[O-]</smiles>

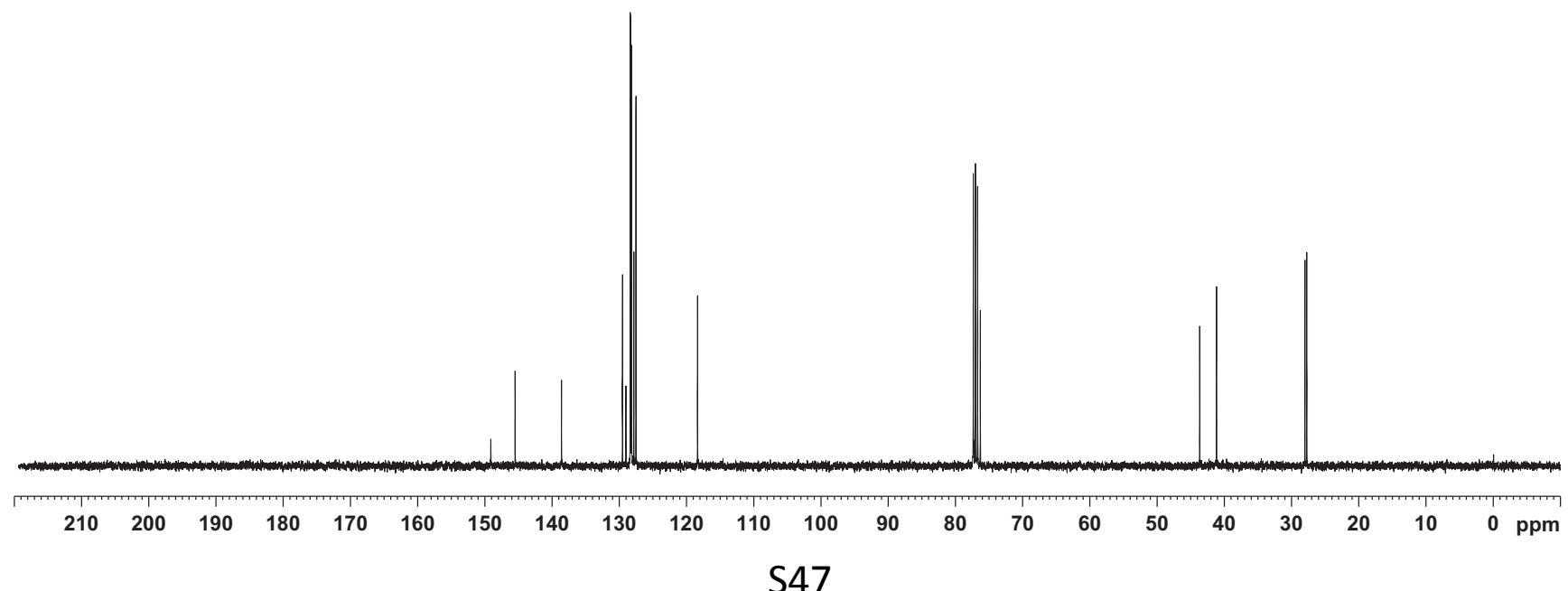


compound (3r)
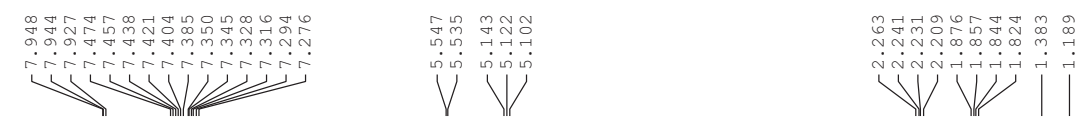<smiles>C=C(c1ccccc1)C1CC(C)(C)C(c2ccccc2)=[N+]1[O-]</smiles>
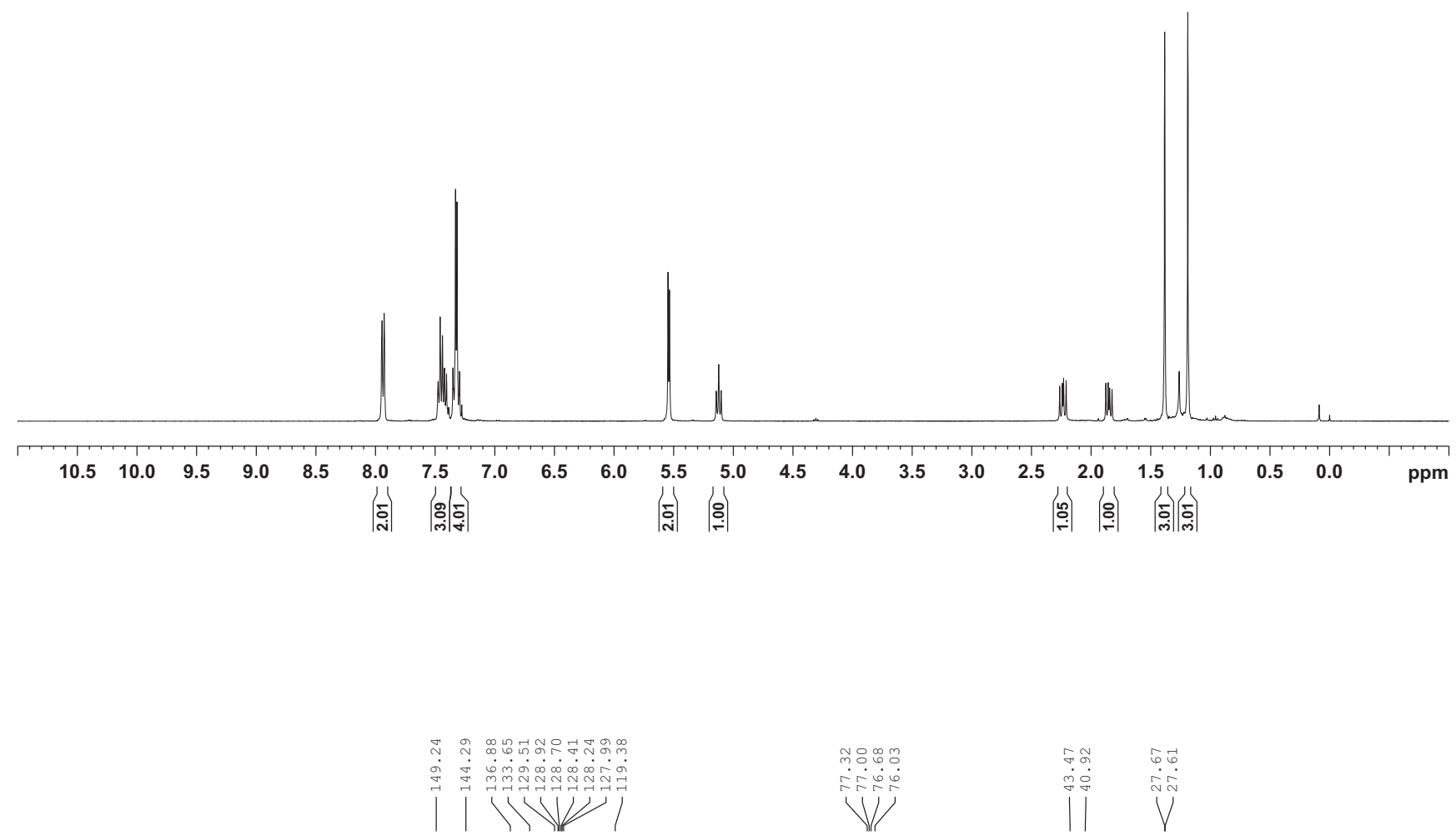<smiles>C=C(c1ccccc1)C1CC(C)(C)C(c2ccccc2)=[N+]1[O-]</smiles>

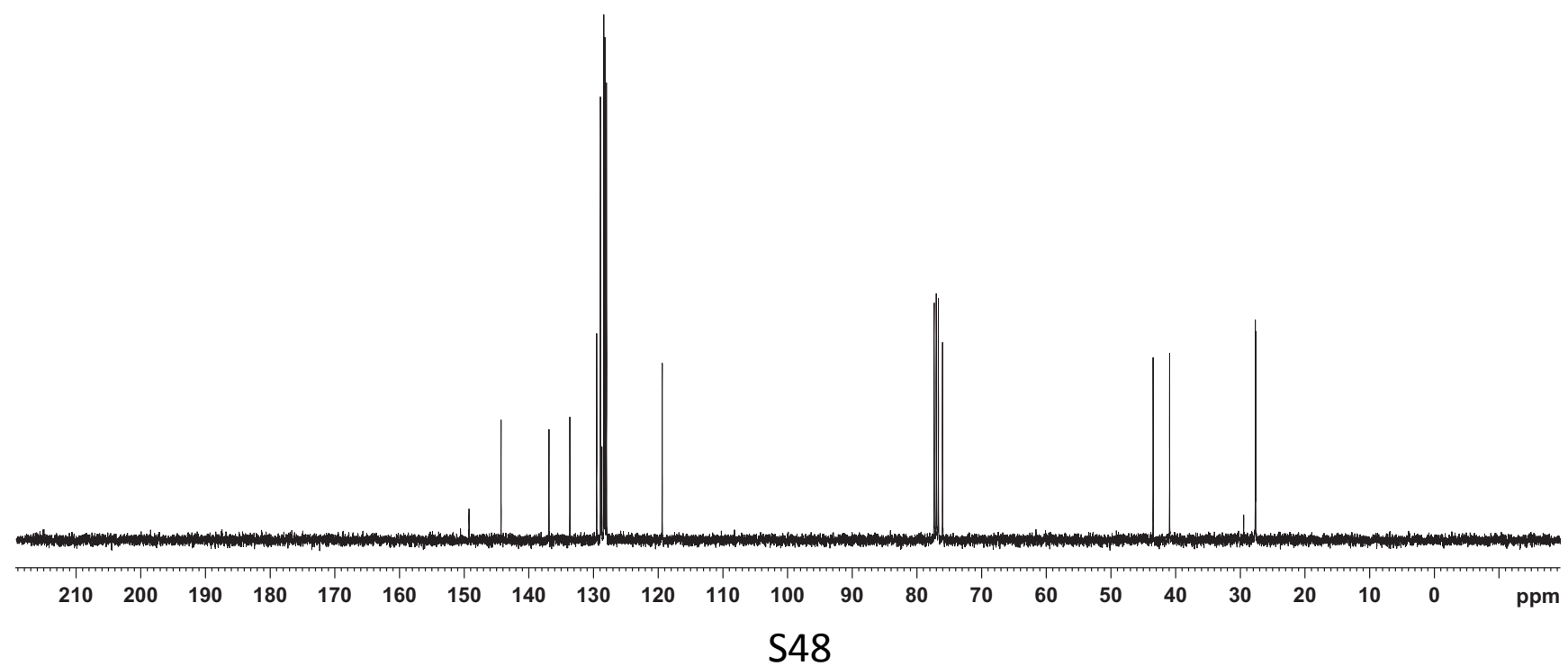


compound (3s)
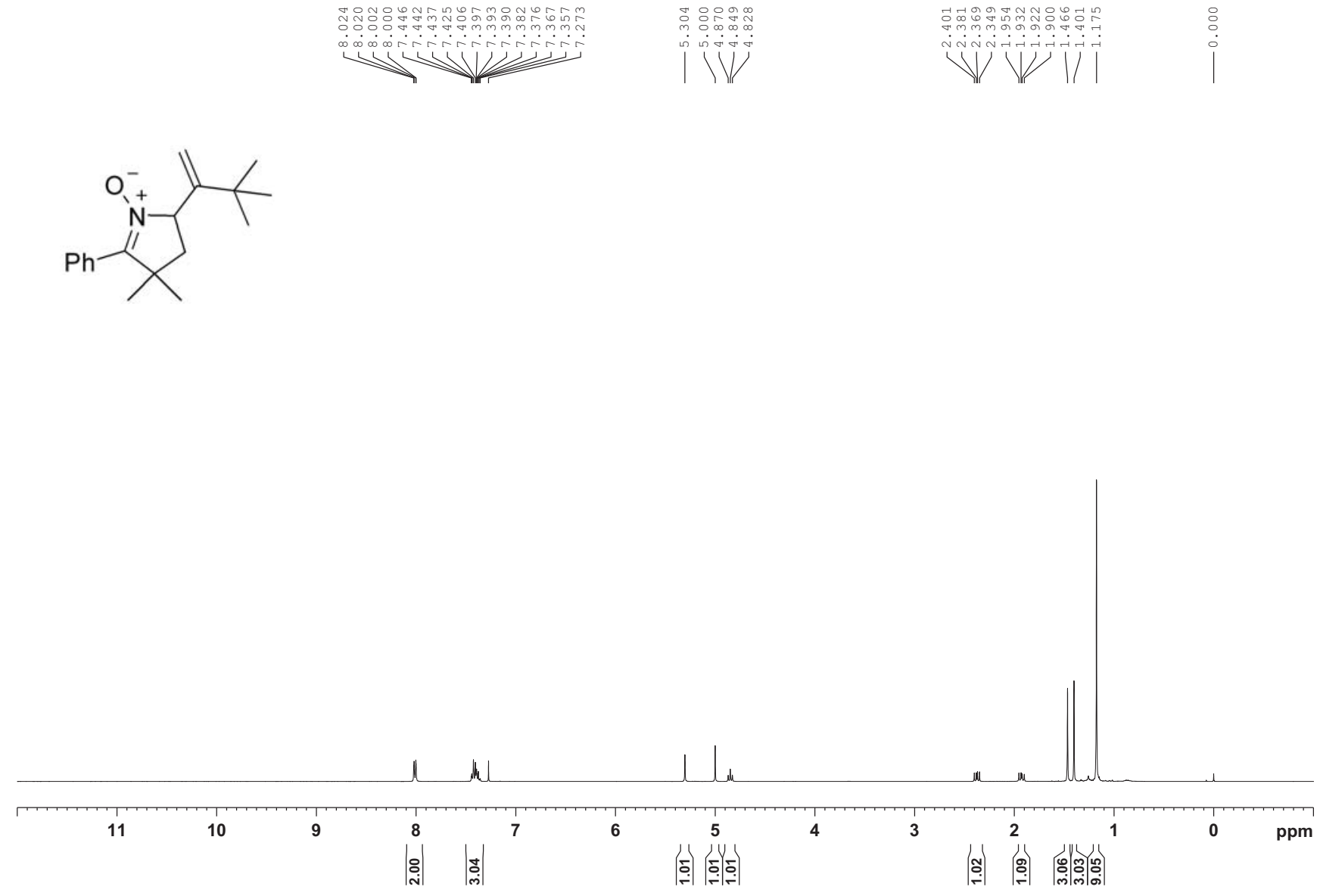

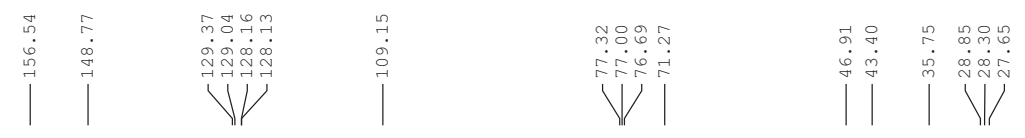<smiles>C=C(C1CC(C)(C)C(c2ccccc2)=[N+]1[O-])C(C)(C)C</smiles>

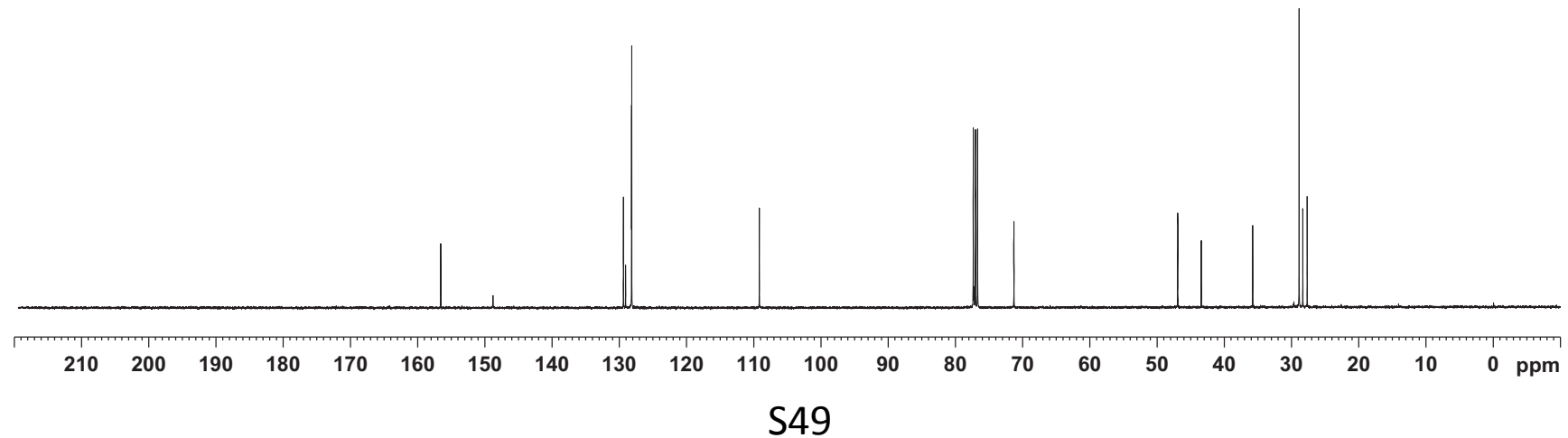


compound (3t)

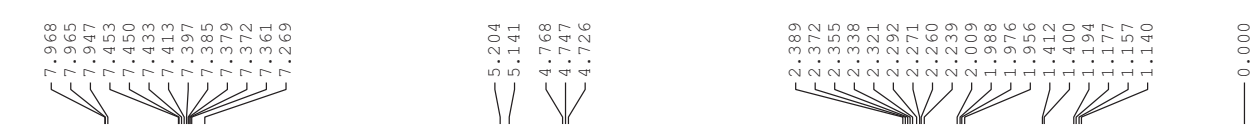<smiles>C=C(C(C)C)C1CC(C)(C)C(c2ccccc2)=[N+]1[O-]</smiles>

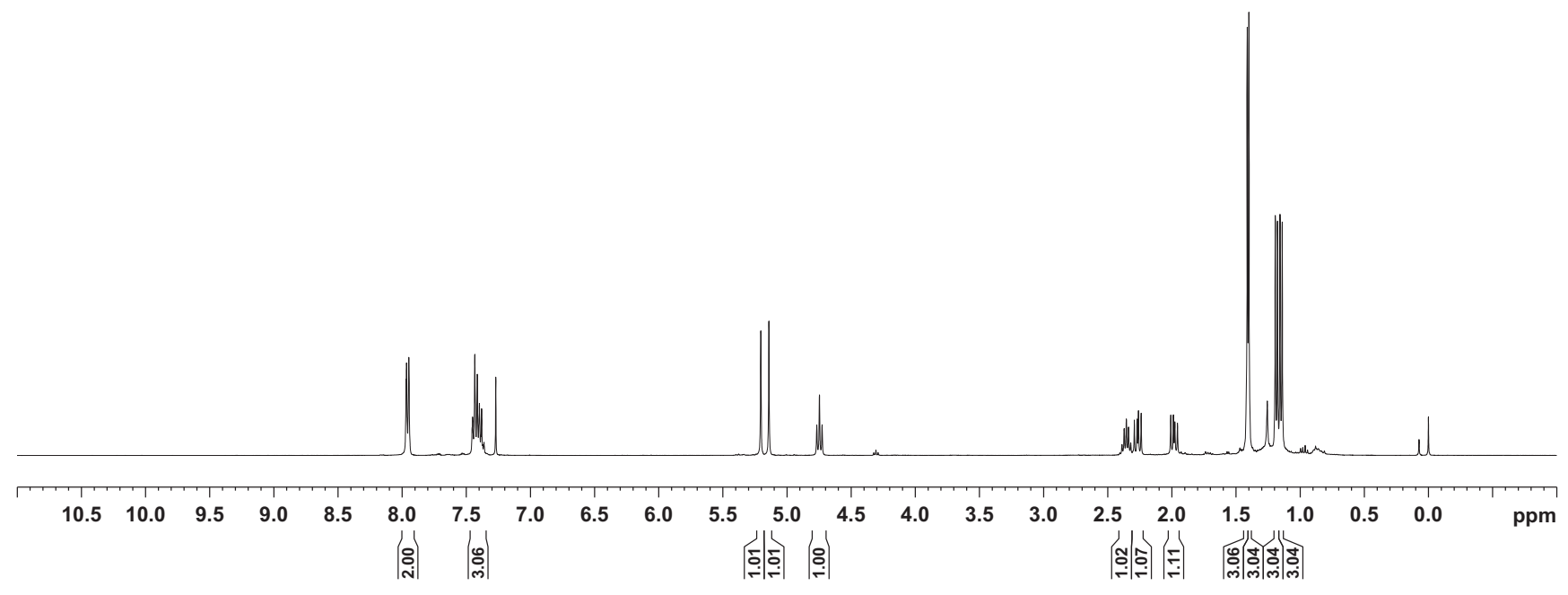

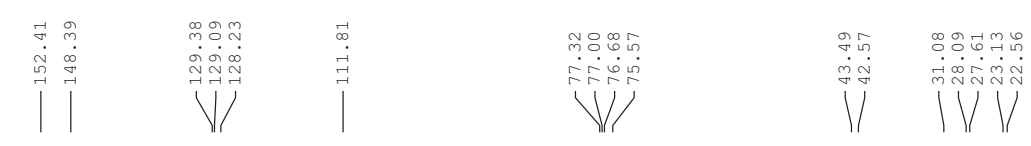<smiles>C=C(C(C)C)C1CC(C)(C)C(c2ccccc2)=[N+]1[O-]</smiles>

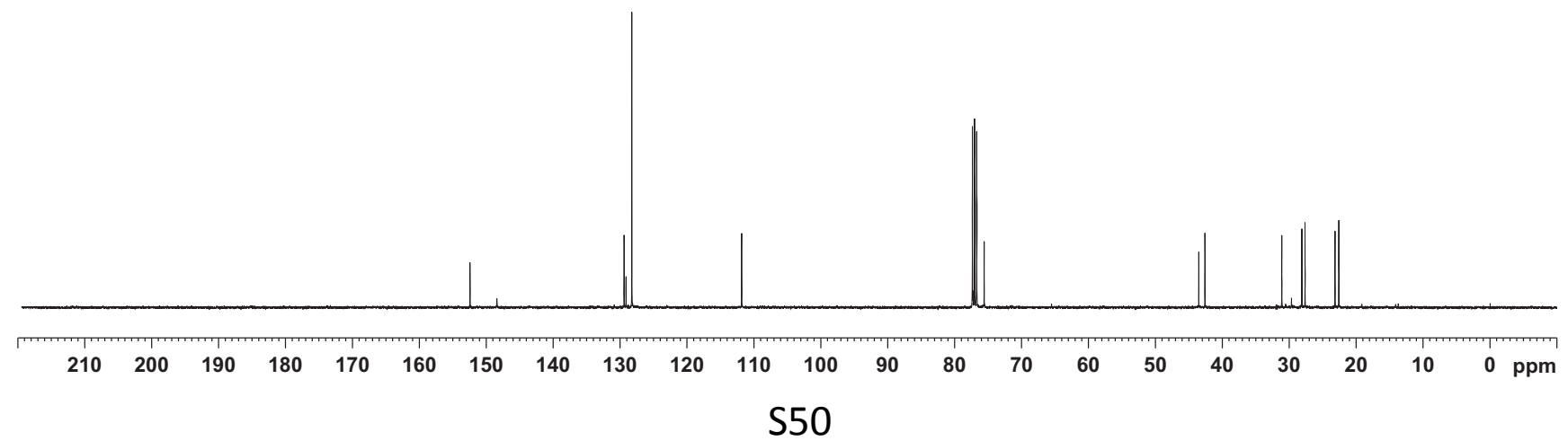


compound (3t')

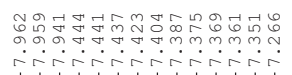

u w W

W

N

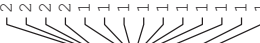<smiles>CC(C)=C(C)C1CC(C)(C)C(c2ccccc2)=[N+]1[O-]</smiles>
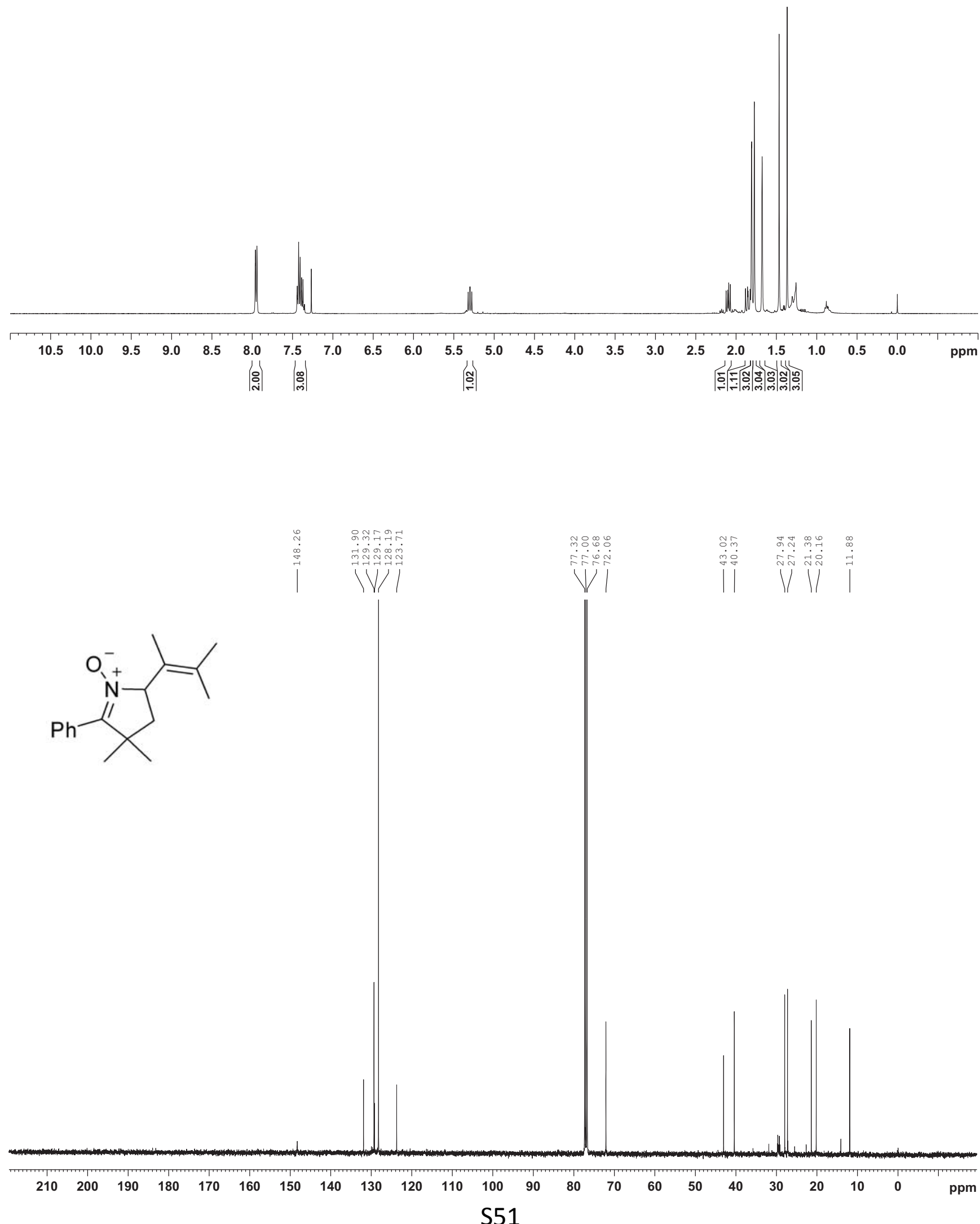


\section{compound (3u)}

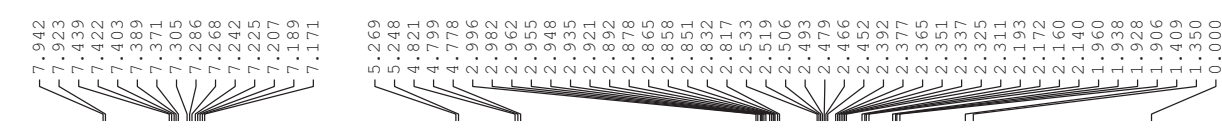<smiles>C=C(CCc1ccccc1)C1CC(C)(C)C(c2ccccc2)=[N+]1[O-]</smiles>
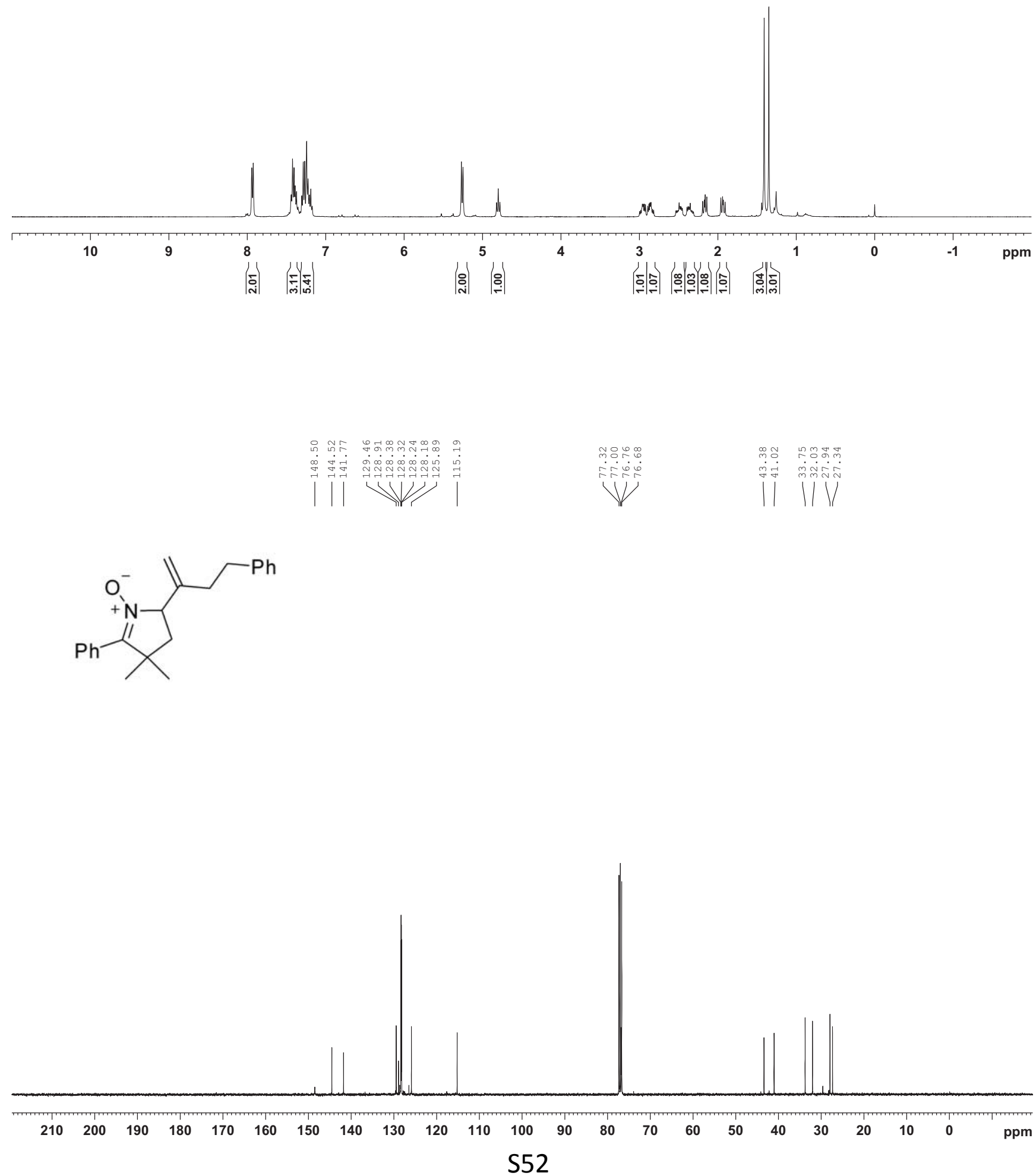
compound (3u')

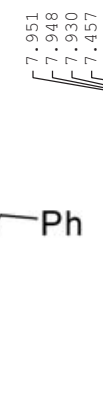<smiles>C/C(=C\Cc1ccccc1)C1CC(C)(C)C(c2ccccc2)=[N+]1[O-]</smiles>
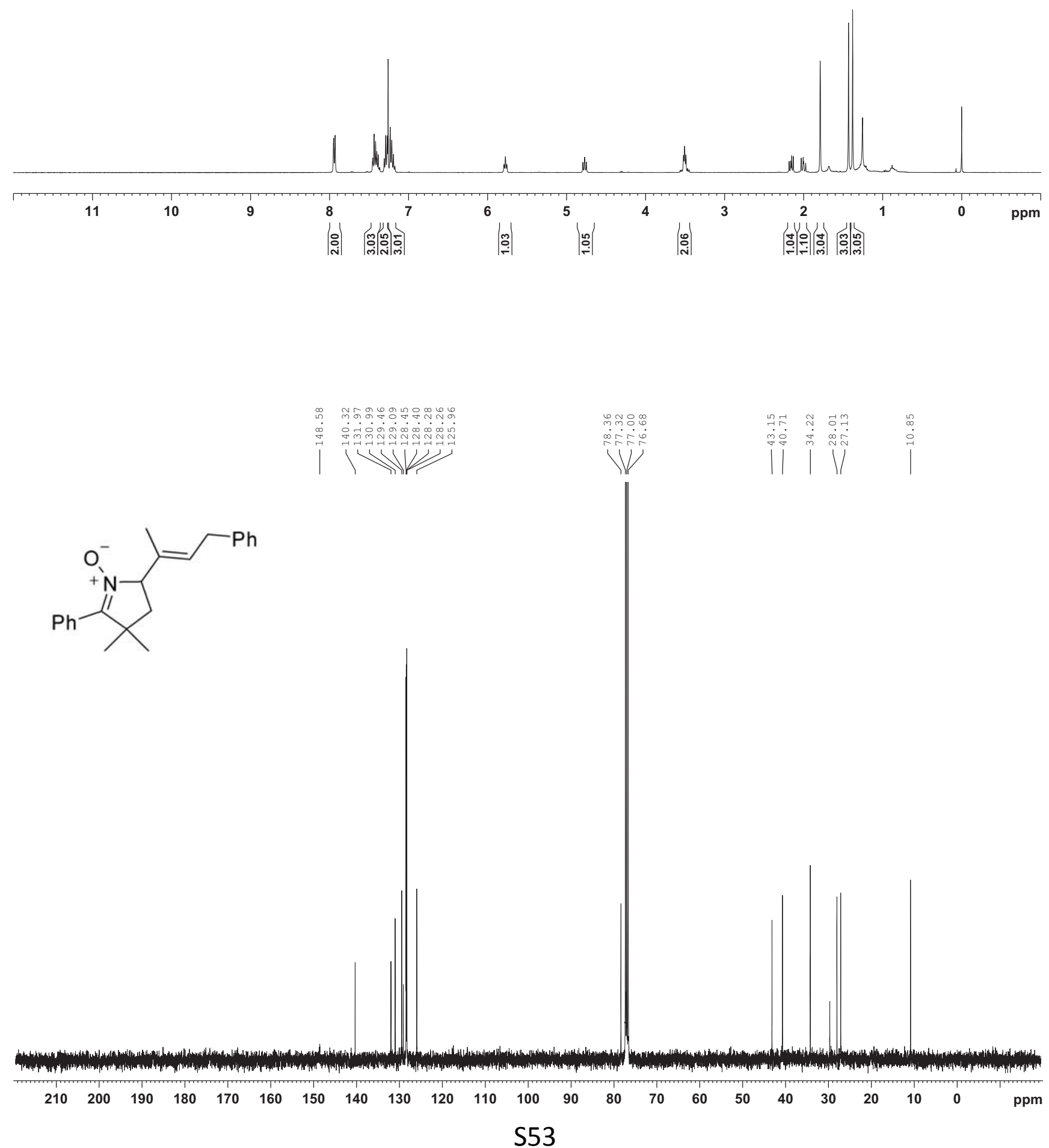
compound (3v)

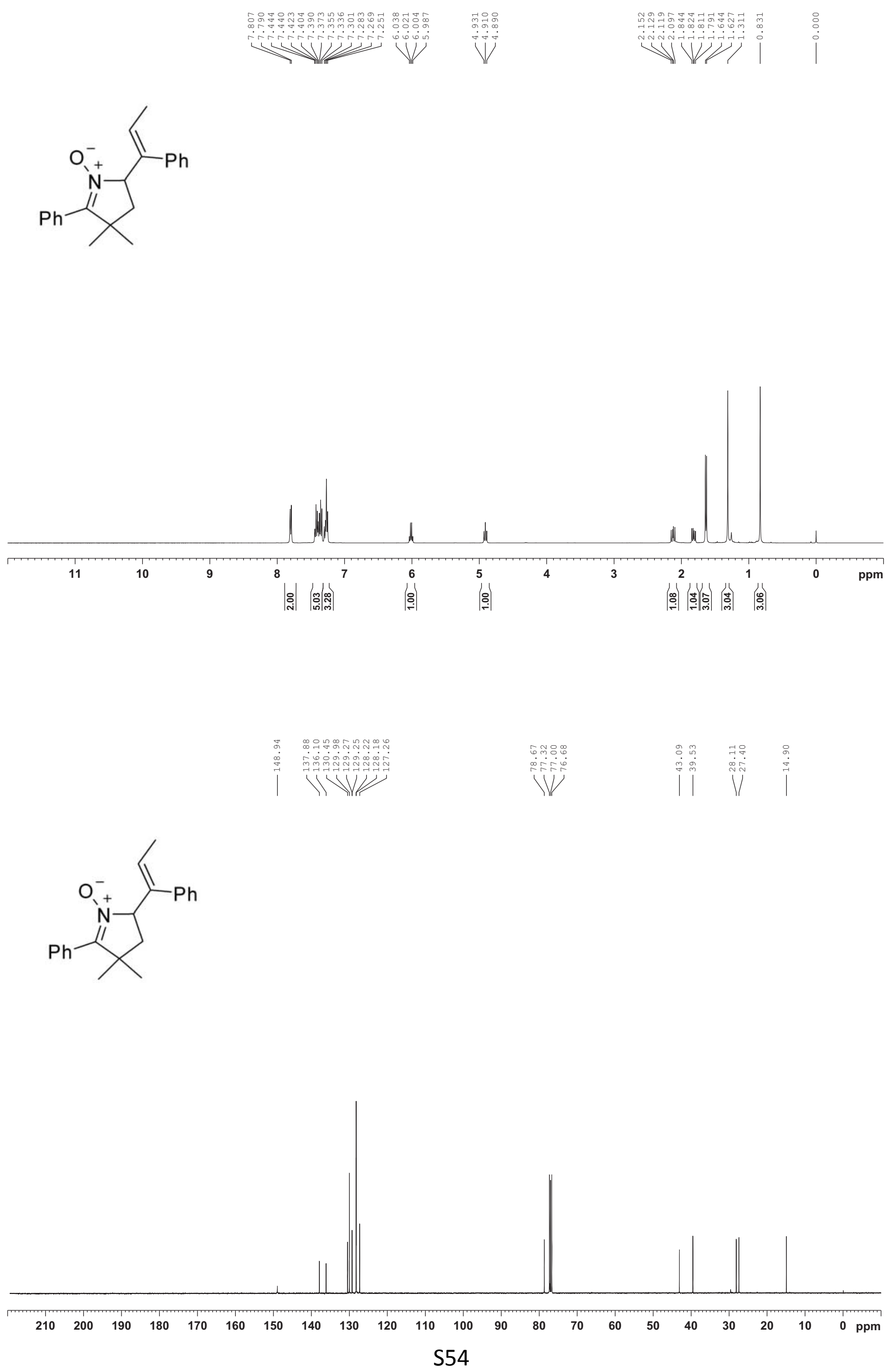




\section{compound (3v')}

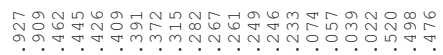

in

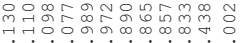

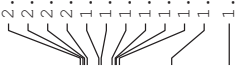<smiles>C/C=C(/c1ccccc1)C1CC(C)(C)C(c2ccccc2)=[N+]1[O-]</smiles>
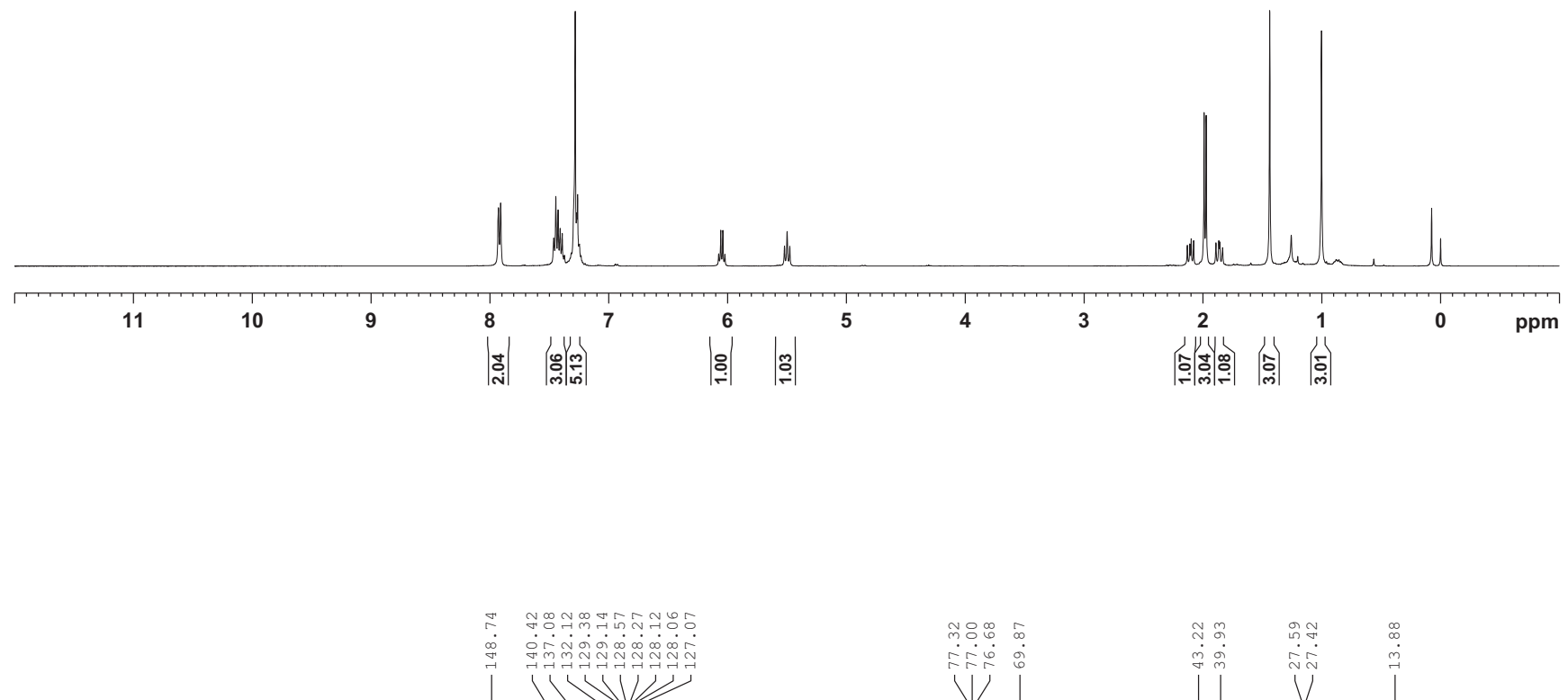

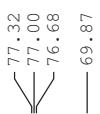

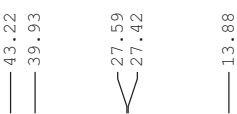<smiles>C/C=C(\c1ccccc1)C1CC(C)(C)C(c2ccccc2)=[N+]1[O-]</smiles>

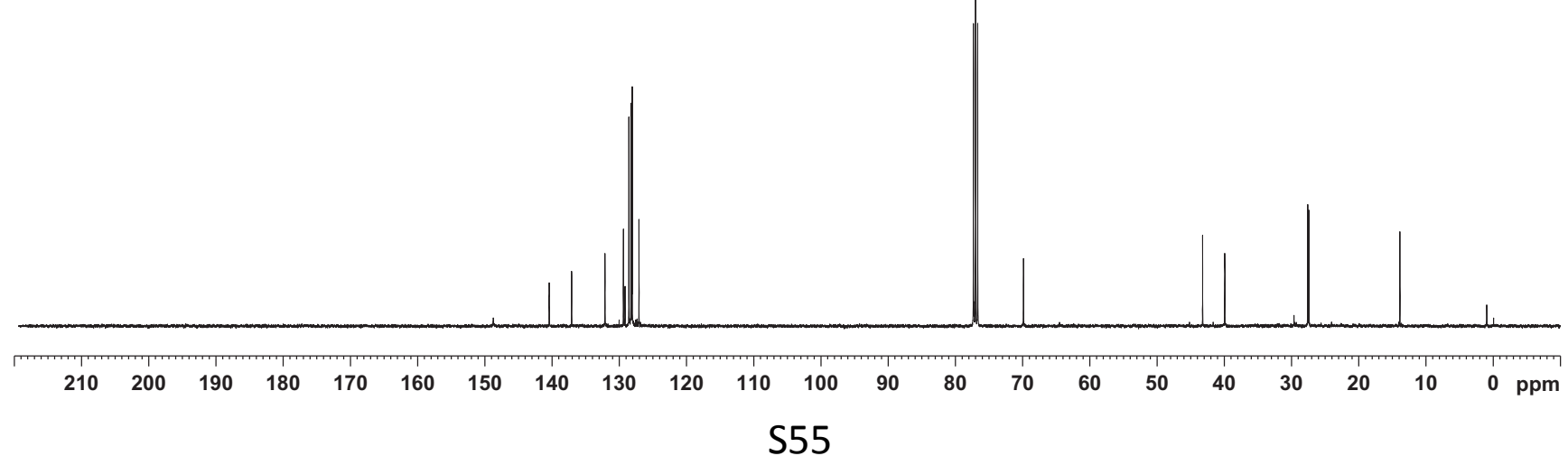


<smiles>CC1(C)CC(C2=CCCCC2)[N+]([O-])=C1c1ccccc1</smiles>
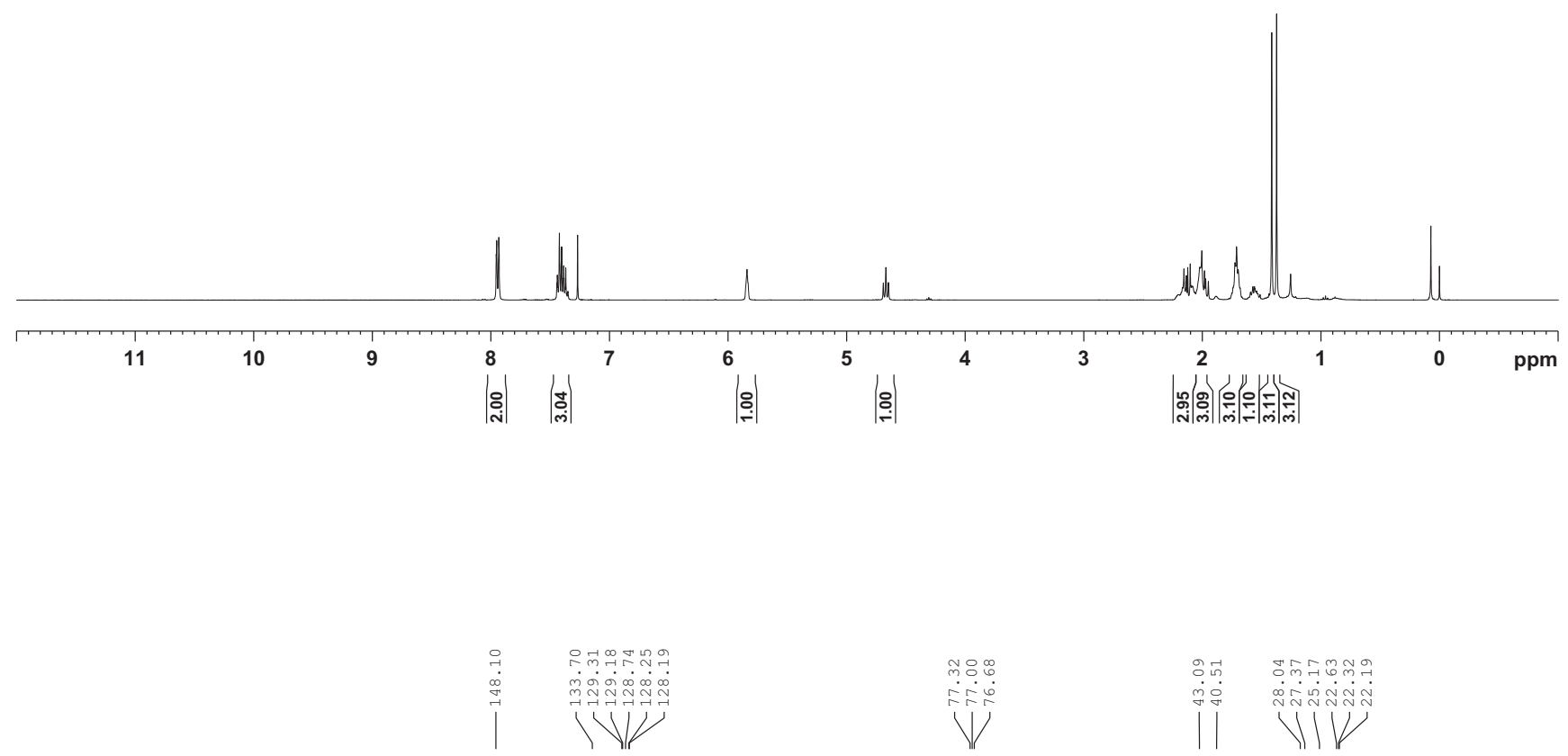<smiles>CC1(C)CC(C2=CCCCC2)[N+]([O-])=C1c1ccccc1</smiles>

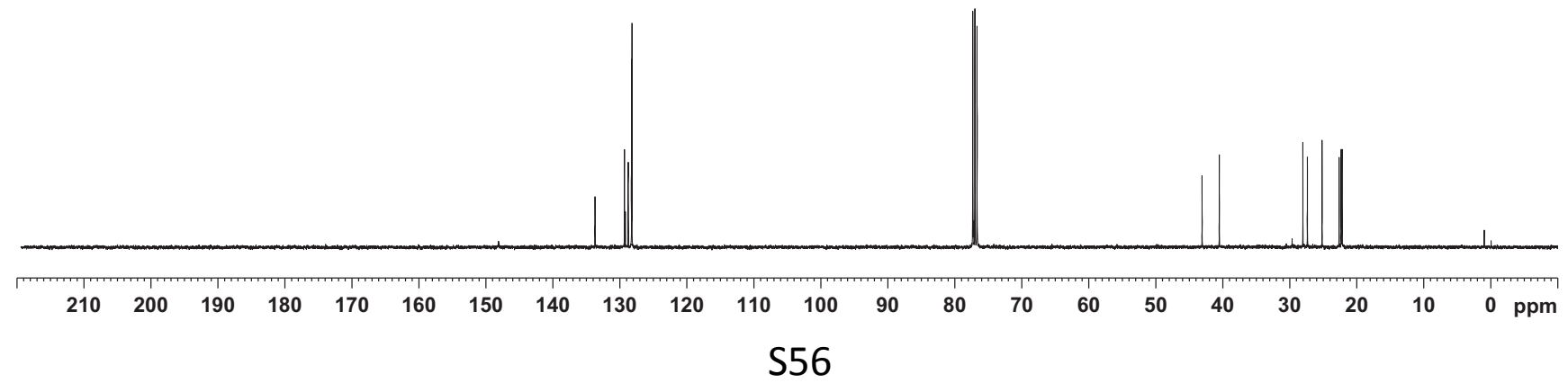


compound (6)

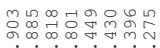

VIV VII

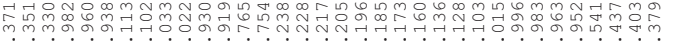

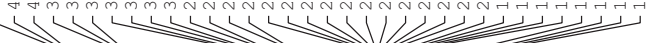<smiles>CC1(C)CC(C2(C)CO2)[N+]([O-])=C1c1ccccc1</smiles>

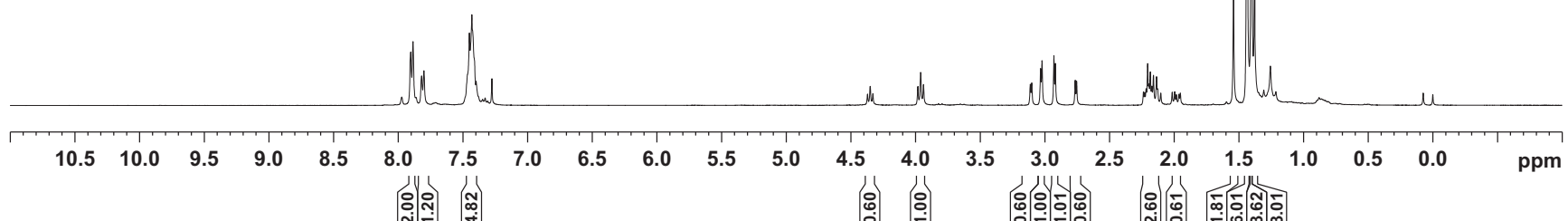

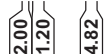<smiles>CC1(C)CC(C2(C)CO2)[N+]([O-])=C1c1ccccc1</smiles>

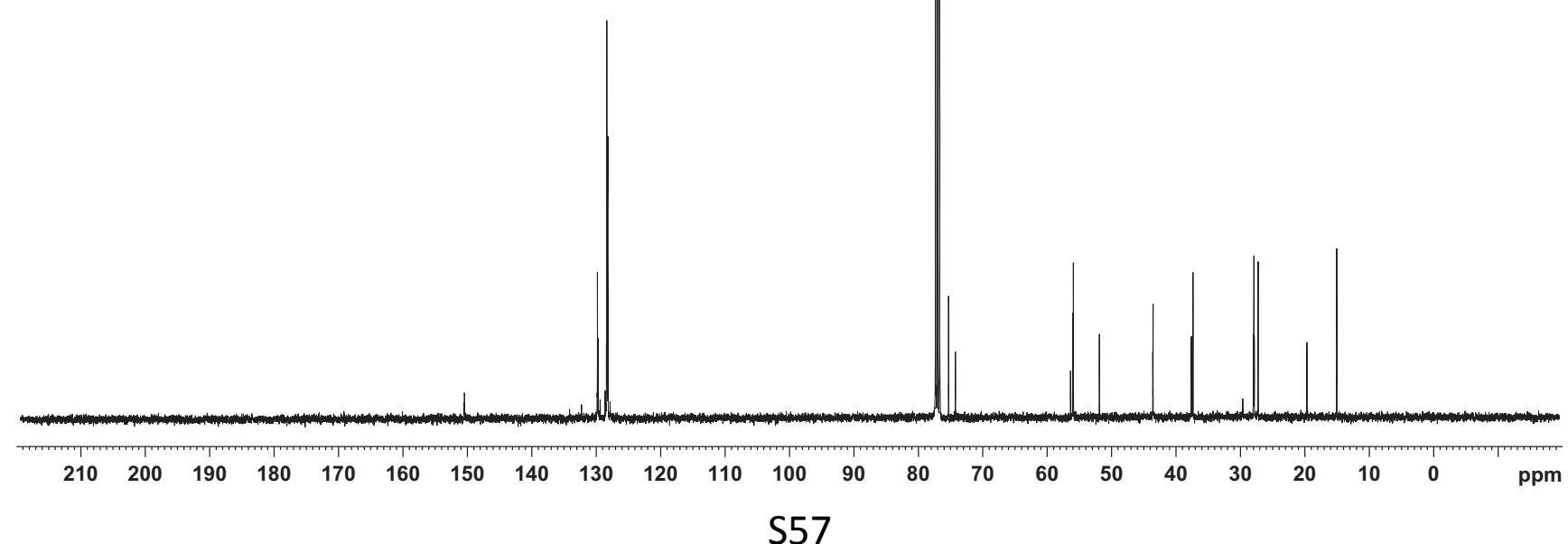


compound (7)<smiles>C=C(C)C1CC(C)(C)C2(P(C(=O)OC)c3ccccc3)C(C(=O)OC)=CON12</smiles>

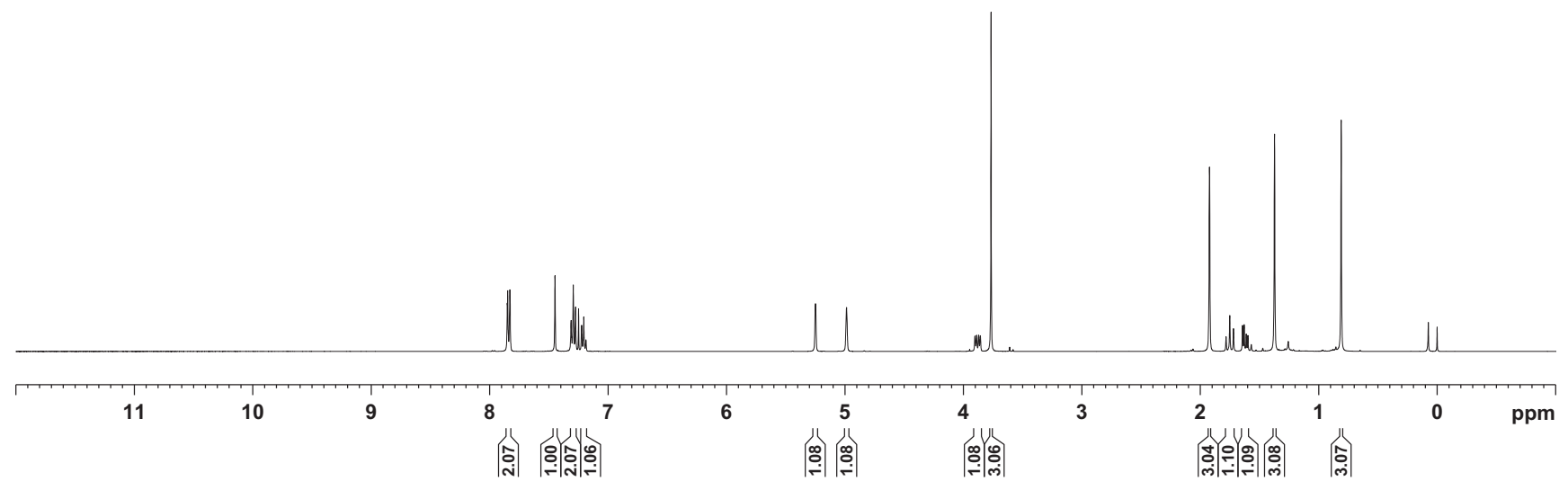

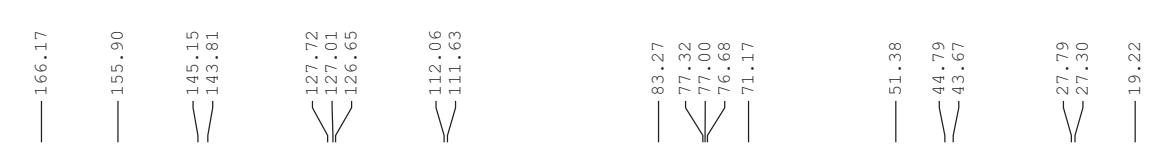<smiles>C=C(C)C1CC(C)(C)C2(c3ccccc3)C(C(=O)OC)=CON12</smiles>

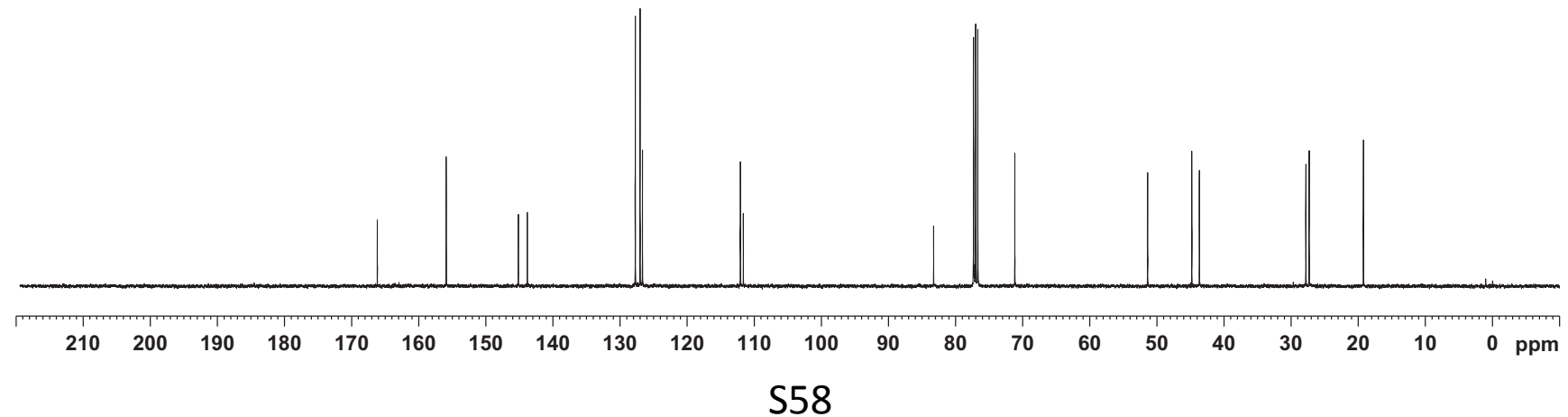


compound (8)
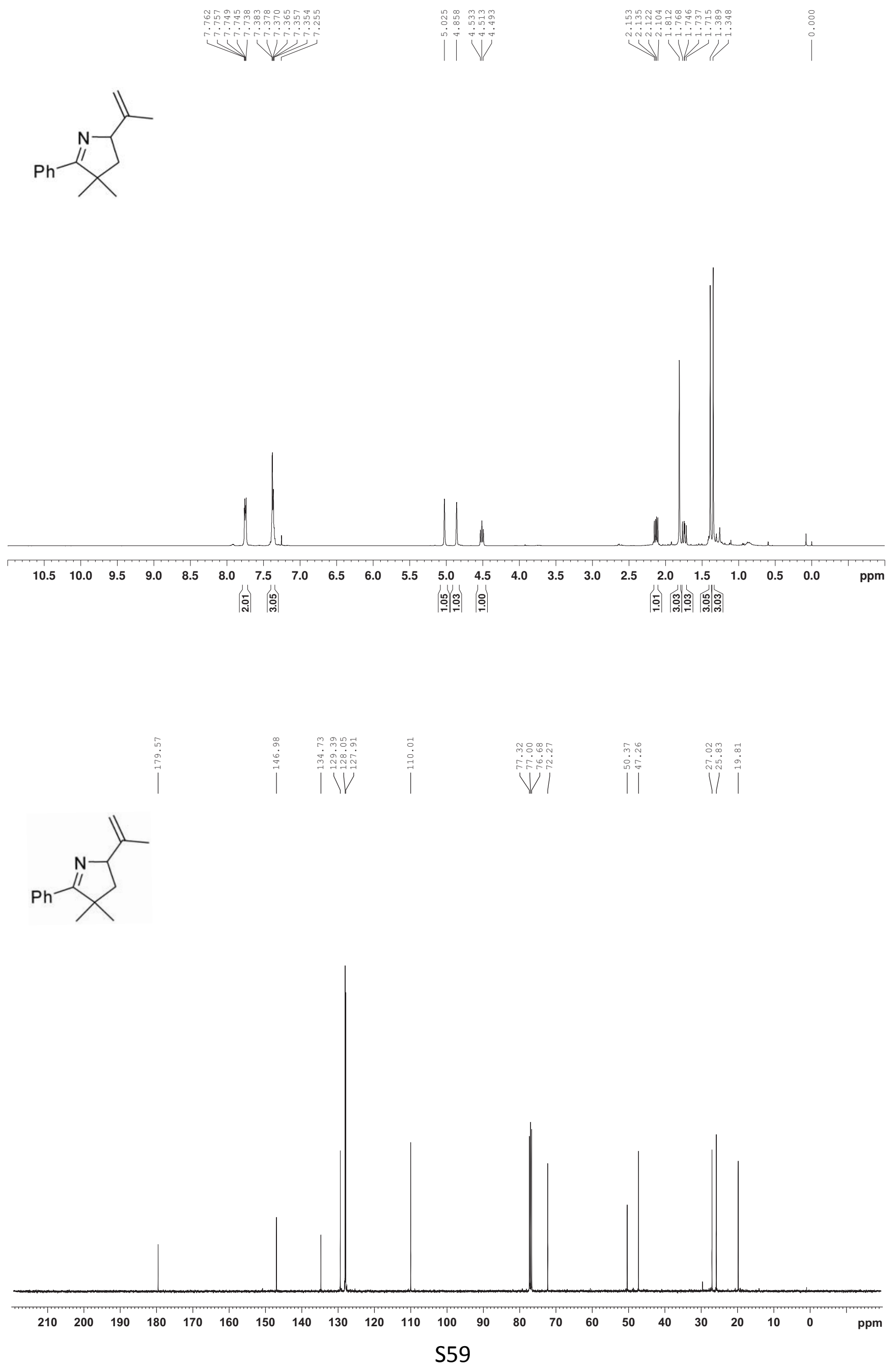